\title{
1 Insights into the late stages of the Acheulean technocomplex of Western \\ 2 Iberia from the Arbo site (Galicia, Spain)
}

\author{
E. Méndez-Quintas ${ }^{1,2^{*}}$, M. Demuro³, L. J. Arnold ${ }^{3}$, M. Duval $^{4,5}$, A. Pérez-González², M. Santonja ${ }^{2,5}$
}

${ }^{1}$ Grupo de Estudos de Arqueoloxía, Antigüidade e Territorio (GEAAT), University of Vigo, Campus As Lagoas, 32004 Ourense, Spain.

${ }^{2}$ IDEA (Instituto de Evolución en África), University of Alcalá de Henares, Covarrubias 36, 28010 Madrid, Spain.

${ }^{3}$ School of Physical Sciences, Environment Institute, and Institute for Photonics and Advanced Sensing (IPAS), University of Adelaide, North Terrace Campus, Adelaide SA 5005, Australia.

${ }^{4}$ Australian Research Centre for Human Evolution. Environmental Futures Research Institute, Griffith University, 170 Kessels Road Nathan, QLD 4111, Australia.

$13{ }^{5}$ Centro Nacional de Investigación sobre la Evolución Humana (CENIEH). Paseo de Atapuerca, 3. 09002 Burgos, Spain.

14 *Corresponding author. E-mail: eduardo.mendez.quintas@uvigo.es

\section{Abstract}

The arrival and disappearance of the Acheulean technocomplex in Europe, and specifically in the Iberian Peninsula, is a longstanding topic of discussion with relevance for unravelling the Middle Pleistocene human occupation dynamics of the continent. Despite containing one of the first Acheulean sites excavated in Europe (As Gándaras de Budiño site), the Miño River basin (north-western Iberian Peninsula) remains understudied and has yielded relatively limited information on the temporal and spatial dynamics of the regional Acheulean technocomplex over the last fifty years. Here we present a systematic archaeological and numerical dating study of a previously undocumented Acheulean site located in the lower Miño River basin (Arbo site, Pontevedra, Spain). This newly discovered site preserves a late Middle Pleistocene Acheulean assemblage that has been dated to pre-Marine Isotope Stage 5 by a combination of post-infrared infrared stimulated luminescence ( $\mathrm{pIR}-\mathrm{IR}$ ) and electron spin resonance (ESR) dating of sedimentary silicates. The new excavations reveal that the site preserves a dense concentration of artefacts made from allochthonous raw materials. Detailed lithic analyses show that the industry has some elementary flake production systems devoid of Levallois cores, but with supplementary non-standardized flake tool types and some large cutting tools (LCTs) - mainly handaxes that are usually finalized with soft-hammer. The results obtained at Arbo complement those obtained recently at the nearby Porto Maior site, as well as the seminal study of As Gándaras de Budiño, and demonstrate an important Acheulean and hominin presence in the Miño River basin during the second half of the Middle Pleistocene.

\section{Key words}

Acheulean, Iberian Peninsula, Middle Pleistocene, electron spin resonance (ESR) dating, luminescence dating, post-infrared infrared stimulated luminescence (pIR-IR). 


\section{Introduction}

Recent studies of the European Acheulean technocomplex have enabled improved reconstructions of complex human occupation patterns during the Middle Pleistocene (Santonja and Villa, 2006; Moncel et al., 2015; Gallotti, 2016; Rocca et al., 2016; Santonja et al., 2016; Sharon and Barsky, 2016). However, significant debate surrounds the spatial and temporal dynamics of the Acheulean technological tradition (Moncel et al., 2015; Voinchet et al., 2015; Santonja et al., 2016; Villa et al., 2016a), particularly at individual regional scales (Santonja and Villa, 2006), owing to non-trivial gaps in the Middle Pleistocene archaeological and chronological record. From a pan-European perspective, the Acheulean technocomplex is a phenomenon restricted to the occidental and southern regions; the manifestation of which appears to become increasingly weak northwards along the Rhine River, and is, as-yet, unknown across Central Europe and the Russian Plain (Santonja and Villa, 2006; Richter, 2015; Rocca et al., 2016). The arrival of the Acheulean technology in Europe appears to have taken place before Marine Isotope Stage (MIS) 13 (Moncel et al., 2013; Vallverdu et al., 2014; Moncel et al., 2015; Pereira et al., 2015; Voinchet et al., 2015) and, according to the "Out of Africa" scenario, it is possibly related to a South route of dispersal, potentially one invoking a migration event through the Strait of Gibraltar (Bar-Yosef and Belfer-Cohen, 2001; Santonja and Villa, 2006; Santonja et al., 2016; Sharon and Barsky, 2016). Another possible route, in relation to more meridional areas (e.g., Italy), could be through the Aegean, but the current data are inconclusive (Dinçer, 2016; Taşkıran, 2018). An alternative explanation proposes local re-invention of the Acheulean, without a direct connection to the African technocomplex (Nicoud, 2013; Carbonell et al., 2016). Existing chronological data indicate that the European Acheulean covers a time period spanning MIS 16, and possibly even earlier (see an overview in Moncel et al, 2018), to MIS 6 (676-130 ka) (Santonja and Villa, 2006; Moncel et al., 2015; Ollé et al., 2016; Rubio-Jara et al., 2016; Santonja et al., 2016; Duval et al., Submitted), which is significantly shorter than the documented age range of the African Acheulean technocomplex ( 1.7-0.3 million years ago or Ma) (Asfaw et al., 1992; Clark, 1994; Lepre et al., 2011; Diez-Martín et al., 2015; Gallotti, 2016; Sharon and Barsky, 2016; Deino et al., 2018).

In the south-western part of the European continent, including the Iberian Peninsula, the first widespread and unequivocal evidence for Large Flake Acheulean technology (LFA sensu Sharon, 2010) emerges after MIS 16. The technological characteristics at these sites include the use of large flakes as blanks (LFA industries) for the large cutting tools (LCTs), and the presence of flake cleavers (Santonja and Villa, 2006; Sharon, 2011; Sharon and Barsky, 2016; Baena Preysler et al., 2018). The end of the Acheulean technology in SW Europe has been placed within MIS 6 (Santonja and Villa, 2006; Santonja and Pérez-González, 2010; Cologne et al., 2013; Jaubert et al., 2013; Sánchez-Cervera et al., 2015; Hérisson et al., 2016; Rubio-Jara et al., 2016; Santonja et al., 2016; Villa et al., 2016a; Soriano and Villa, 2017). This terminal age range for the Acheulean industry implies significant technological complexity across the region towards the end of the Middle Pleistocene as a number of Iberian sites characterised by Early Middle Palaeolithic (EMP) lithic industries have also been dated from MIS 9 onwards (Scott and Ashton, 2011; White et al., 2011; Jaubert et al., 2013; Santonja et al., 2014; Hérisson et al., 2016; Santonja et al., 2016; Villa et al., 2016a; Soriano and Villa, 2017; Lauer and Weiss, 2018). The emerging chronological patterns thus suggest the coexistence of two distinctly 
different technological traditions in Europe during the Middle Pleistocene, with potential consequences for our understanding of human evolution and occupation dynamics across the continent. A non-linear evolutionary scenario has recently been proposed to explain the temporal overlap of the two technocomplexes, which focuses on the superimposition of established European populations utilising coreflake industries by human groups of African origin associated with an Acheulean technology (Santonja et al., 2014; Santonja et al., 2016; Méndez-Quintas et al., 2018b). While this hypothesis is subject to ongoing testing as new chronological datasets emerge, it is further supported by the observation that lithic industries from the end of the Middle Pleistocene (MIS 9 to MIS 6) show different technological solutions, which may be partly derived from the mutual influences of both Acheulean and Middle Palaeolithic technocomplexes. The proposed non-linear evolutionary scenario is also consistent with recent anthropological models that recognise a variety of hominin lineages in the European Middle Pleistocene (Rightmire, 2008; Mounier et al., 2009; Stringer, 2012; Bermúdez de Castro and Martinón-Torres, 2013; Arsuaga et al., 2014; Mounier and Caparros, 2015; Bermúdez de Castro et al., 2018; Vialet et al., 2018).

Improved archaeological and geochronological studies are needed to address existing uncertainties about the nature and timing of the Acheulean across southwest Europe, as well as to test hypotheses about the evolution and replacement of the Acheulean technocomplex, and to enable refined meta-scale reconstructions of spatial technological patterns during the Middle Pleistocene. This is particularly true for geographic areas that contain rich but poorly studied Acheulean records. The present study forms part of a broader project aimed at addressing such knowledge gaps for an important, yet understudied, region of the Iberian Peninsula - the Miño River basin.

The Atlantic River basins of the Iberian Peninsula have produced numerous Acheulean assemblages with LCTs of extensive shaping and high symmetrical feature (Raposo et al., 1985; Santonja and Pérez González, 2004; Santonja and Villa, 2006; Arroyo and de la Torre, 2013; Sánchez-Cervera et al., 2015; Rubio-Jara et al., 2016), but few of these assemblages are found in clear stratigraphic contexts or have been reliably dated using modern radiometric techniques. The Miño River basin preserves a range of Acheulean sites in primary stratigraphic context, and has traditionally been considered a key focus for research into the Lower Palaeolithic of the Iberian Peninsula during the twentieth century (Viana, 1930; Álvarez Blázquez and Bouza Brey, 1949; Bouza Brey and Álvarez Blázquez, 1954), particularly after the discovery of the As Gándaras de Budiño site (Aguirre, 1964). However, further research into these early human occupation discoveries has been limited, and the problematic chronology of the As Gándaras de Budiño site, which was initially radiocarbon dated to MIS 2 using disseminated charcoal (Aguirre and Butzer, 1967; Butzer, 1967), has proved to be a significant limitation for the development of research on the Palaeolithic records of the region. The identification of several new Acheulean sites in the basin over the last decade has resulted in a resurgence of interest in the Lower Palaeolithic record of the Miño River. Most recently, Méndez-Quintas et al. (2018b) presented the newly discovered Acheulean site of Porto Maior, which contains an extensive LCT accumulation that is comparable in size and density to the traditional Acheulean assemblages of Africa and the Near East. In the current study, we report the discovery of an additional Acheulean site in the vicinity of Porto Maior site, which offers further insights into the nature and timing of the later stages of the Acheulean 
technocomplex in the region. This new site, known as Arbo, is one of the first systematically excavated and well-dated Iberian sites to display a well-finished Acheulean LCT assemblage. This study aims to present the geomorphological, stratigraphic and chronological context of the new site. Additionally, we provide a systematic assessment and characterisation of the lithic industry preserved at the site, with a special focus on the chaînes opératoires analysis. Finally, we discuss the regional significance of the site, assess the implications of our findings within a regional chronological framework, and examine the strength of evidence for the coexistence of Acheulean and Middle Palaeolithic technocomplexes in southwest Europe during the later Middle Pleistocene.

\section{Materials and methods}

The Arbo Acheulean site is located in the O Cabrón vineyard (Pontevedra, Spain) on the northern bank of the Miño river, $60 \mathrm{~km}$ from the town of Vigo (Fig. 1). The site was discovered by M. Ledo Bernárdez and J. C. Amil Baltasar during the vineyard improvement works in 2001. Subsequent geoarchaeological assessments have been undertaken in three related fields between 2010 and 2012. In total, a $38 \mathrm{~m}^{2}$ surface has been excavated across the terrain (Fig. 2 and 8) and a large number of lithic artefacts have been recovered from within two stratigraphic units (Fig. 3-4). Unfortunately, the acidity of the host sediment has prevented the conservation of any faunal remains, as is common for open-air archaeological sites across the basin (e.g., Méndez-Quintas et al., (2018b)).

As part of the present study, we have undertaken a comprehensive assessment of the geomorphology, stratigraphy, geoarchaeology and geochronology of the Arbo site. Additionally, we have carried out a broader geomorphological characterisation of lower Miño River basin, with special attention given to the identification of preserved fluvial deposits (fluvial terraces and alluvial fans). This aspect of the study included fieldwork, geographic information system (GIS) analysis and the synthesis of geological information available for the study area. We have used LIDAR digital elevation model -DEM- (IGN, Spanish National Geographic Institute) to create contour line maps, topographic profiles and hillshading models in order to detect and map the terrain features, as well as recognize and map landforms. DEM altimetric data were also used to estimate the relative position of landforms. Geological mapping was assisted by 1:50,000 geological maps (IGME, Geological Survey of Spain). Urban and road infrastructures were extracted from 1:25,000 BTN25 maps (IGN). Stratigraphic characterisation of sedimentary deposits in the basin has been done in accordance with the identification of fluvial model facies (Miall, 1996).

\subsection{Luminescence dating experimental details}

\subsubsection{Sample collection and dose rate determination}

Three luminescence dating samples were collected at the site of Arbo (Fig. 2). Samples OC16-1 and OC16-2 were collected from level OC3 in the North sector of the excavation, and immediately overlie the associated archaeological horizon (OC1). A third sample, OC16-3, was collected from level OC2 in the South sector of 
the excavation (Fig. 3). It was not possible to collect luminescence dating samples from level OC1 in either sector owing to the absence of suitable sampling exposures at the time of visit. The luminescence samples were collected by inserting opaque PVC tubes (20 cm-long) into cleaned vertical exposures. The extracted tubes were immediately sealed with duct tape and wrapped in black plastic bags for transportation. Owing to the high environmental dose rates of the Miño River basin and expected antiquity of the site, we have utilised the K-feldspar pIR-IR signal (Thomsen et al., 2008) for luminescence dating purposes. The 90-125 $\mu \mathrm{m}$ Kfeldspar fraction was extracted under subdued red light conditions following standard procedures (Aitken, 1998). The fine sand fraction $(90-300 \mu \mathrm{m})$ was sieved and treated with $\mathrm{H}_{2} \mathrm{O}_{2}$ and $\mathrm{HCl}$ to eliminate organics and carbonates, respectively. K-feldspar grains were isolated using heavy liquid separation in the 2.53 to $2.58 \mathrm{~g} / \mathrm{cm}^{3}$ density range. The $90-125 \mu \mathrm{m}$ fraction was then sieved and etched with $10 \%$ hydrofluoric acid for 10 minutes to remove the outer $10 \mu \mathrm{m}$ rind of each grain (Duval et al., 2018). Finally, the etched K-feldspar grains were washed in $30 \%$ hydrochloric acid to remove any precipitated fluorides and re-sieved using a 63 $\mu \mathrm{m}$ sieve to eliminate any disaggregated grains.

Environmental dose rate assessments were made using a combination of in situ gamma spectrometry measurements and low-level beta counting (Table 1). Field gamma spectrometry measurements were performed at each sample position immediately after sample removal. The 'energy windows' method described in Arnold et al. (2012) was used to determine elemental concentrations of $\mathrm{K}, \mathrm{U}$ and Th from field gamma spectra. Additional sediment was collected from the immediate area around each sample position for beta dose rate assessments (beta counting), water content evaluations, and high-resolution gamma-ray spectrometry (HRGS) measurements. Low-level beta counting was performed on dry and homogenised sediment using a Risø GM-25-2 beta counter (Bøtter-Jensen and Mejdahl, 1988). HRGS measurements were used to investigate the state of secular equilibrium in the ${ }^{238} \mathrm{U}$ and ${ }^{232} \mathrm{Th}$ decay series. Daughter-parent isotopic ratios for ${ }^{238} \mathrm{U},{ }^{226} \mathrm{Ra},{ }^{210} \mathrm{~Pb},{ }^{228} \mathrm{Ra}$ and ${ }^{228} \mathrm{Th}$ are consistent with unity at either $1 \sigma$ or $2 \sigma$, indicating that the ${ }^{238} \mathrm{U}$ and ${ }^{232} \mathrm{Th}$ chains exhibit present-day secular equilibrium (Table 2). Cosmic-ray dose rates were calculated using the approach described in Prescott and Hutton (1994). Internal dose rate contributions for K-feldspar grains have been estimated using an assumed internal ${ }^{40} \mathrm{~K}$ content of $12.5 \pm 0.5 \%$ (Huntley and Baril, 1997) and ${ }^{87} \mathrm{Rb}$ content of $400 \pm 100$ ppm (Huntley and Hancock, 2001).

The beta, gamma and cosmic-ray dose rates have been corrected for estimated long-term water contents of each sample (Aitken, 1985; Readhead, 1987). The present-day sediment water contents ranged between 9 and $16 \%$ but they are not considered to be representative of long-term moisture conditions at the site because the sediment profiles had been exposed for 3 years prior to sampling and had partially dried out. To determine more suitable long-term sediment moisture contents, we have adopted conservative estimates based on $60 \%$ present-day saturated water contents for each luminescence sample. A relative uncertainty of $20 \%$ has been assigned to the long-term moisture estimates to accommodate any potential variations in hydrologic conditions during burial. This approach yielded long-term sediment moisture contents of $25-28 \%$ for samples OC16-1 to OC16-3 (Table 1). These long-term moisture estimates, which are expressed as percentages of dry sediment weight, are consistent with the adopted long-term water contents in the pIR-IR dating study of 
the nearby Porto Maior site (Méndez-Quintas et al., 2018b), and the long-term water contents of the ESR dating samples from Arbo ( $20 \pm 5 \%$ ), which are expressed as percentages of wet sediment weight.

\subsubsection{Equivalent dose $\left(D_{e}\right)$ determination}

Measurements of K-feldspar pIR-IR signals were made using a Risø TL/OSL-DA-20 reader equipped with a calibrated ${ }^{90} \mathrm{Sr} /{ }^{90} \mathrm{Y} \beta$ radiation source that delivered a dose rate of $\sim 0.106 \mathrm{~Gy} / \mathrm{s}$. The pIR-IR signals were stimulated using IR diodes (875 $\mathrm{nm}$, maximum power of $\left.166 \mathrm{~mW} / \mathrm{cm}^{2}\right)$ at $90 \%$ power and measurements were performed on 90-125 $\mu \mathrm{m}$ K-feldspar grains mounted on $9.7 \mathrm{~mm}$-diameter stainless steel discs; approximately 160 grains were placed on each disc. Blue emissions were detected using an EMI 9235QB photomultiplier fitted with a 4 mm-thick Schott BG39, 3 mm-thick Corning 7-59, and 4 mm-thick Schott GG400 filter pack.

Equivalent dose $\left(D_{e}\right)$ measurements were made using modified versions of the pIR-IR single-aliquot regenerative dose (SAR) protocols detailed by Buylaert et al. (2009) and Thiel et al. (2011) (Table 3), which involve performing pIR-IR stimulation at either $225^{\circ} \mathrm{C}$ following a preheat of $250^{\circ} \mathrm{C}$ for $60 \mathrm{~s}$ (pIR-IR 225 signals) or at $290^{\circ} \mathrm{C}$ following a preheat of $320^{\circ} \mathrm{C}$ for $60 \mathrm{~s}$ (pIR-IR 290 signals). pIR-IR signals were measured for the naturally accumulated dose $\left(L_{n}\right)$ of each aliquot, as well as for a series of different sized laboratory doses $\left(L_{x}\right)$. Each of the natural and regenerative dose pIR-IR measurements were subsequently normalised for sensitivity change using a fixed test dose pIR-IR measurement $\left(T_{x}\right)$, and the sensitivity-corrected natural $\left(L_{n} / T_{n}\right)$ was then interpolated onto the sensitivity-corrected $L_{x} / T_{x}$ dose-response curve to obtain a $D_{e}$ value. To minimise unwanted isothermal TL contributions to the pIR-IR signal (Wang and Wintle, 2013), measurements were made for $200 \mathrm{~s}$ and the IR diodes were switched on $10 \mathrm{~s}$ after reaching the desired measurement temperature. A high temperature IR wash was also added at the end of each SAR measurement cycle to minimise the effect of charge transfer on the sensitivity-corrected pIR-IR signal responses.

Multi-grain K-feldspar $D_{e}$ values were calculated from the first $10 \mathrm{~s}$ of stimulation after subtracting a mean background count from the last $20 \mathrm{~s}$ of stimulation. Individual $D_{e}$ values were included in the final age calculation if they satisfied the following SAR quality assurance criteria: (i) the recycling ratio (i.e., sensitivitycorrected luminescence responses $\left(L_{x} / T_{x}\right)$ for two identical regenerative doses) was consistent with unity at $2 \sigma$; (ii) the recuperation ratio, calculated as the ratio of the sensitivity-corrected 0 Gy dose point $\left(L_{0} / T_{x}\right)$ to the sensitivity-corrected natural $\left(L_{n} / T_{n}\right)$, was $<5 \%$; (iii) the sensitivity-corrected natural signal intercepted the sensitivity-corrected dose-response curve and it intercepted the non-saturated part of the dose-response curve (i.e., the $L_{n} / T_{n}$ value did not exceed the $I_{\max }$ saturation limit of the dose-response curve at $2 \sigma$ ); (iv) the dose-response curve did not display anomalous properties (e.g., zero or negative responses with increasing dose) and resulted in suitable Monte Carlo fits.

Individual $D_{e}$ estimates are presented with their 1 standard error ranges, which have been derived from three sources of uncertainty: (i) a random uncertainty term arising from photon-counting statistics for each pIR-IR measurement, calculated using equation 3 of Galbraith (2002); (ii) an empirically determined instrumentreproducibility uncertainty of $0.5 \%$ for each multi-grain aliquot measurement, calculated specifically for the 
reader used in this study; and (iii) a dose-response curve fitting uncertainty determined using 1,000 iterations of the Monte Carlo method implemented in Analyst (Duller, 2007).

\subsection{Electron spin resonance (ESR) experimental details}

\subsubsection{Sampling}

Two sediment samples (VI1201 \& VI1202) were collected in 2012 for ESR dating purpose (Fig. 2). They were both taken in the North sector of the excavation from unit OC3 (Fig. 3), and are laterally distant by $\sim 1 \mathrm{~m}$. In situ measurements of the gamma dose rate were performed at the exact location of the ESR samples, using a Nal probe connected to an Inspector-1000 multichannel analyser. Additional sediment samples were collected for the evaluation of the water content and radioelement concentrations.

\subsubsection{Methods}

The two sediment samples were dated in accordance with the multiple centre (MC) approach (Toyoda et al., 2000). Sediment samples were processed at CENIEH (Burgos, Spain) following the same analytical procedure used in Mendez-Quintas et al (2018b).

\subsubsection{ESR dose evaluation}

The ESR dose evaluation was performed using the standard Multiple Aliquots Additive (MAA) dose method. Each natural sample was divided into 14 multiple grain aliquots. Twelve aliquots for each sample were irradiated using a ${ }^{137} \mathrm{Cs}$ Gammacell-1000 source (dose rate $6.90 \mathrm{~Gy} / \mathrm{min}$ ) to the following doses: $50.0,100.1$, 200.1, 400.3, 800.5, 1601.2, 3202.1, 6003.9, 10006.4, 17010.9, 27017.3 and 40025.7 Gy. One aliquot was kept unirradiated (natural aliquot), while the last aliquot was exposed to a SOL2 (Dr Hönle) solar light simulator for about $1440 \mathrm{~h}$, in order to evaluate the non-bleachable residual ESR signals of the Aluminium centre.

ESR measurements were carried out as in Mendez-Quintas et al (2018b), i.e. at low temperature ( 90 K) with an EMXmicro 6/1Bruker X-band ESR spectrometer coupled to a standard rectangular ER 4102ST cavity. Full details about the experimental setup and its stability over time can be found in Duval and Guilarte Moreno (2012). The acquisitions parameters employed for the measurement of the ESR signals of both the Al and Ti centres may be found in Mendez-Quintas et al (2018b). For the Al signal, each of the 14 aliquots (one natural, one optically bleached and eleven gamma irradiated aliquots) of a given sample were measured 3 times after a $\sim 120^{\circ}$ rotation in the cavity in order to consider angular dependence of the signal due to sample heterogeneity. In contrast, such a measurement procedure was not possible for the Ti signal: the very weak ESR intensities required a higher number of scans (up to 25), which resulted in very long measurement times ( $>5 \mathrm{hrs}$ ). However, although no rotation was considered for the two samples, the angular dependence of the signal was indirectly taken into account through repeated measurements. All measurements for the Al and $\mathrm{Ti}$ centres were repeated three times over distinct days in order to evaluate the reproducibility of the ESR intensities and of the resulting equivalent dose $\left(D_{E}\right)$ values. 
The ESR intensity of the Al signal was extracted from peak-to-peak amplitude measurements between the top of the first peak $(g=2.0185)$ and the bottom of the 16th peak $(g=1.9928)$ (Toyoda and Falgueres, 2003). Following the conclusions from Duval and Guilarte Moreno, (2015), the ESR intensity of the Ti-Li centre was preferentially evaluated by measuring the peak-to-baseline amplitude around $g=1.913-1.915$ (option D), although option A was also measured for comparison. The intensity of the $\mathrm{Ti}-\mathrm{H}$ (option $\mathrm{C}$ ) centre was taken from the peak-to-baseline amplitude measurement at $\mathrm{g}=1.915$.

For each aliquot, ESR intensities of $\mathrm{Al}$ and $\mathrm{Ti}$ centres were corrected by the corresponding receiver gain value, number of scans, mass and a temperature correction factor (Duval and Guilarte Moreno, 2012). The fitting procedures were carried out with the Microcal OriginPro 9.5 software using a Levenberg-Marquardt algorithm by chi-square minimization. For the Al centre, an exponential+linear function (EXP+LIN) was preferentially fitted through the experimental points (see equation in Duval et al., 2017), with data weighted by the inverse of the squared ESR intensity $\left(1 / \mathrm{I}^{2}\right)$. A comparison fitting was also performed with a Single Saturating Exponential (SSE) function. $D_{E}$ values were obtained by extrapolating the EXP+LIN function to the residual intensity (Total bleach method, Forman et al., 2000). For the Ti centre, we used the function labelled Ti-2 in Duval and Guilarte Moreno (2015), in order to describe the non-monotonic dose dependence of the ESR signal at high doses. Data were weighted by the inverse of the squared experimental error $\left(1 / \mathrm{s}^{2}\right)$ and $D_{E}$ values were obtained by back extrapolation to the $X$ axis $(Y=0)$. Note that we also employed the SSE function with data weighting by $1 / \mathbb{l}^{2}$ for fitting comparison. For each sample, final dose response curves (DRCs) were obtained by using the average ESR intensities and their associated standard deviations derived from the repeated measurements.

\subsubsection{Dose rate evaluation}

The total dose rate value was derived from a combination of in situ and laboratory measurements. External gamma dose rates were derived from in situ measurements by using the "threshold technique" (Duval and Arnold, 2013). For each sample, the corresponding radioelement (U, Th, K) concentrations in the sediment were determined by ICP-MS analysis of $\sim 5 \mathrm{~g}$ of dry raw sediment. In addition, $\sim 150 \mathrm{~g}$ of this same raw sediment, previously dried and powdered, were analysed by HRGS using a Canberra Extended Range (XTra) $\mathrm{HpGe}$ detector in order to identify possible disequilibrium in the U-238 decay chain. Concentration values were used to derive external alpha and beta dose rate components using the dose rate conversion factors from Guérin et al. (2011). Dose rate values were calculated assuming a mean grain size of $150 \mu \mathrm{m}$, and an assumed thickness removed by HF etching of $20 \mu \mathrm{m}$. Values were corrected with beta and alpha attenuations for spherical grains (Brennan et al., 1991; Brennan, 2003) and water attenuation formulae from Grün (1994). Current water contents were evaluated in the laboratory by drying the sediment at $50{ }^{\circ} \mathrm{C}$ in an oven during three weeks. Results vary within a relatively narrow range from 7.7 to $9.2 \%$ (wet weight) for the two samples. These values however most likely underestimate the long term water content, because the sediment profile had been exposed for several years in the excavation area and the ESR samples were collected at shallow depths from the section surface $(<30 \mathrm{~cm}$ ). Consequently, a value of $20 \pm 5 \%$ (wet weight) was considered for age calculations, which is equivalent to the $25 \%$ (dry wet) used for the luminescence dating method (section 2.1.1.). Internal dose rate was assumed to be $50 \pm 30 \mu \mathrm{Gy} / \mathrm{a}$ as in Mendez-Quintas et al (2018). The cosmic 
dose rate was calculated using formulae from Prescott and Hutton (1994), with depth, altitude and latitude corrections (Prescott and Hutton, 1988).

ESR age calculations were performed using a non-commercial SCILAB based software, which provide results within error with those derived from DRAC (Kreutzer et al., 2018). ESR ages are reported with their $1 \sigma$ uncertainties.

\subsection{Lithic analysis}

The lithic industry has been analysed with several criteria of technological and typology terminology commonly used in this discipline (Tixier, 1956; Bordes, 1961; Boëda, 1993; Bourguignon, 1997; Inizan et al., 1999; Tixier and Turq, 1999). A more specific definition of the nomenclature applied in the core classification is in the Figure S1. Our analysis also uses the Large Flake Acheulean (LFA) and Large Cuttings Tools (LCT) technological concepts (Sharon, 2007) to describe the relationship between the African and south-western European Acheulean industries. The statistical analyses and tests utilised as part of the lithic study were undertaken using the SPSS and PAST software applied to data collected. We applied nonparametric statistical tests (Mann-Whitney (U) tests or Kolmogorov-Smirnov test (D)) to quantify any difference among the size variables.

\section{Results}

\subsection{Geomorphology}

The site of Arbo is located in a small hanging valley on the northern side of the Miño river, and is incised into a fluvial surface (erosive or dismantled terrace) lying $+62 \mathrm{~m}$ above the current river level. This river sector shows a strongly incised course in the granitic substratum and exhibits a slight amount of sinuosity (sinuosity index IS = 1.3; (Schumm, 1977). However, straight stretches of river can also be recognised in this sector, and these stretches are orientated according to pre-existing tectonic features (faults). We have been able to identify 9 levels of fluvial terrace in the lower Miño basin, with the following relative elevations above river level estimated during the summer: T1 (+4-7 m), T2 (+13-17 m), T3 (+21-29 m), T4 (+30-39 m), T5 (+45-51 m), T6 (+53-61 m), T7 (+65-77 m), T8 (+78-89 m) and T9 (+91-108 m). In the neighbouring region of the site, we distinguish the remains of fluvial surfaces at $+62 \mathrm{~m}$ and $+53 \mathrm{~m}$, as well as additional terraces outcrops with high altitudes, especially the T7 (+65-77 m), T8 (+78-89 m) and T9 (91-108 m) terraces. Downstream, at the point of confluence between the Miño and Deva rivers, there are outcrops belonging to lower terraces at T1 (+4-7 m), T2 (+13-17 m), T3 (+21-29 m), T4 (+30-39 m) and T5 (+45-51 m) (Fig. 1). Though there are relatively few exposed stratigraphic sections available in the lower Miño basin, it is possible to determine that the main sedimentary deposits of these terraces are characterised by thick sequences of clast-supported, crudely-bedded gravels. The gravel beds mainly comprise quartzite and quartzes with minor components of granites (Gh facies), and exhibit internal planar cross-bedded facies (Gp) or cross-bedding (Gt), which alternate with fine to very coarse sands or pebbles with planar $(S p)$ or cross-bedded $(S p)$ structures. It is also 
possible to identify fine to coarse Sm facies with massive structure or faint laminations, similar to Fsm facies of silts and muds with massive structure, occasionally displaying mud cracks (Fm facies). The facies architecture indicates that the fluvial style is of a braided river system, with deposits dominated by gravels (Schumm, 1977; Miall, 1996).

The chronological information available for the formation of the regional staircase is limited, although some useful numerical age constraint has been obtained on the bracketing T2 and T4 terraces recently (Viveen et al., 2012; Méndez-Quintas et al., 2018b). The second lower terrace T2 (+13-17 m) has been dated to at least 103-134 ka (minimum ages) using quartz optically stimulated luminescence (OSL) and feldspar post IR-IR dating (Viveen et al., 2012), while the same fluvial levels were also dated to $150 \mathrm{ka}$ by ${ }^{10} \mathrm{Be}$ exposure dating (Viveen et al., 2012). These ages suggest that the development of this terrace occurred during MIS 6 . The overlying T4 terrace in the lower Miño basin (+30-39 m) has been dated at Porto Maior using ESR of optically bleached quartz and pIR-IR luminescence of K-feldspar grains (Méndez-Quintas et al., 2018b). This study yielded ages ranging between $259 \pm 29$ ka and $279 \pm 26$ ka for the T4 overbank facies, and $264 \pm 27 \mathrm{ka}$ for the underlying gravel facies of the T4 terrace. All available ages for T4 $(+30-39 \mathrm{~m})$ therefore indicate that this terrace was deposited sometime during MIS 8-7 (Méndez-Quintas et al., 2018b). Viveen et al. (2012) have additionally published ${ }^{10} \mathrm{Be}$ exposure ages of $458 \pm 40 \mathrm{ka}, 563 \pm 30 \mathrm{ka}$ and $530 \pm 120 \mathrm{ka}$ for three consecutive fluvial terraces found at $+31 \mathrm{~m},+40 \mathrm{~m}$ and $+53 \mathrm{~m}$ in the Vila Meã area, respectively. However, the statistically indistinguishable ages obtained in that study for three terraces spanning an elevation range of $>20 \mathrm{~m}$ is unexpected; particularly as these landscape features are purportedly controlled by $\sim 100$ ka glacial-interglacial cyclicity (Viveen et al., 2012). An additional, unrealistically old age of $>5 \mathrm{Ma}$ was obtained for the $+53 \mathrm{~m}$ terrace, and required recalculation using the muon contributions, while several replicate ${ }^{10} \mathrm{Be}$ exposure ages were reported with unrealistically large maximum age range uncertainties or meaningless best fit age estimates (Viveen et al., 2012). Collectively, these complications appear to reflect the high inheritance of ${ }^{10} \mathrm{Be}$ concentrations encountered in the Vila Meã area, which in turn raises doubts about the veracity and replicability of the ${ }^{10} \mathrm{Be}$ ages since the final age calculations will be sensitive to the assumed (or inferred) inheritance estimates.

\subsection{Stratigraphy}

The sedimentary sequence preserved at the Arbo site, which is situated on top of the altered feldspar alkaline granite, exhibits lateral variations between the North and South excavation sections (Fig. 2-3). It is difficult to fully correlate the layers preserved between the two areas because the sedimentary profiles have become disconnected by recent anthropic excavation activity. For this reason, luminescence and ESR dating samples were collected from both the North and South sections to independently assess the lateral continuity of the sedimentary sequence. The South sequence is composed of a lower thin level of matrix-supported gravels and cobbles (level OC1) that has been eroded (cut and filled) by another layer of matrix-supported cobbles and boulders (level OC2). In the North sector, level OC1 is represented by a very thin layer of matrix- 
supported gravels and cobbles, that disappears towards the northern excavated area, and is overlain by a massive fine sandy level (level OC3) and a capping Holocene organic Ap soil (level OC4) (Fig. 2-3).

The lower bed OC1 in the Southern sector is classed as a Gmg facies with angular pebble, cobbles and isolated boulder of quartz and granite (length average $=78.4 \mathrm{~mm}$ and length $\max .=670 \mathrm{~mm}$ ) in a finemedium sand matrix. Its thickness is not uniform, but does not exceed $25-30 \mathrm{~cm}$ in maximum depth. The lateral continuity of $\mathrm{OC} 1$ is variable and it thins out significantly towards the north, where it sometimes cannot be unambiguously observed in parts of the excavation exposures (Fig. 2-3). The colouration of OC1 changes from 2.5 Y 7/2 (light grey) to 5 YR 5/8 (olive) and it exhibits an erosive contact with the granitic substratum, which has developed significant grooves and potholes. The dip and orientation of the erosive forms and clasts suggest a dominant ENE-E flow, in accordance with the valley's main drainage pattern. In this layer it is also possible to observe manganese concretions as a consequence of the phreatic water variations.

Unit OC2 is a similar Gmg lithofacies displaying the largest accumulation of angular cobbles and boulders in muddy sands (average length $=96.6 \mathrm{~mm}$ and maximum length $=680 \mathrm{~mm}$ ). This layer displays variable thickness, although it does not exceed $40 \mathrm{~cm}$ at its maximum depth. It also has a limited lateral extension and is only observed on the southernmost side of the excavation area. The colouration of OC2 is a homogeneous 2.5 Y 6/4 (light yellowish brown) and it displays manganese concretions. The clasts have a poor metric classification, but are habitually NNW-N imbricated and different to those observed in the underlying level OC1 (Fig. 2-3).

The main stratigraphic level preserved in the northern sequence is OC3, a massive mud-fine sand $\mathrm{Sm} / \mathrm{Fm}$ lithofacies that contains limited angular granite or quartz pebbles, mainly at its base. The predominant coloration is 10 YR 6/4 (light yellowish brown) and its thickness exceeds 1.5 m (Fig. 2-3).

Capping the entire stratigraphic sequence in both sectors is a 50 cm-thick massive level characterised by the development of a soil Ap horizon (level OC4). This level displays colouration changes that ranges between 10 YR 4.5/5 (yellowish brown) and 10 YR 3.4/4 (dark yellowish brown). A variable number of quartz and granite angular pebbles are also observed within this layer (Fig. 2-3).

As noted above, reconstruction of the sedimentary history of the site is made difficult by the disturbance feature (anthropogenic hole) at the centre of the excavated area. This feature limits direct correlation between the northern and southern exposures, as well as reconstruction of the full geometric extent and tempostratigraphic relationships of the various beds preserved at the site. The lithofacies $(\mathrm{Gmg})$ observed in the southern sequence indicate a medium to high energetic sedimentary environment, typical of gravity (debris) flow sediments with poorly sorted clast in a massive silty-sand matrix. These beds are in accordance with the hanging valley context of the site, and reflect a strong erosive event that could have removed the lower beds found locally (OC2 and parts of OC1). Level OC3 shows a prominent change in the hanging valley sedimentary environment towards the top of the sequence. This layer, which is preserved in the north sector, resembles an overbank channel infill, but with a strong aeolian appearance, and is in sedimentary discordance with the levels in the south section, likely superimposing them (therefore it is more recent). During fieldwork, we could not unequivocally verify the stratigraphic relation between OC3 and OC2 in the 
two sectors, due to the cited human disturbance and facies convergence, although the radiometric ages obtained on the two sectors in this study (see below) support the interpretation that OC3 in the North stratigraphically superimposes OC2 in the South.

Levels $\mathrm{OC} 1$ and $\mathrm{OC} 2$ contain the majority of evidence indicating hominin presence at Arbo, although level OC4 level also contains some clearly recycled archaeological material from older horizons (including some post-Palaeolithic age artefacts). The sedimentary features of both $\mathrm{OC} 1$ and $\mathrm{OC} 2$ are indicative of environments that had sufficient energy to modify the technological or spatial pattern of the archaeological record, particularly in the case of level OC2 (Fig. 4). The deposition event responsible for level OC3 also seems to have affected (locally eroded) the lower layers and it could have contributed to an increase in artefact disturbance. Two reasons can therefore be put forward to explain the presence of artefacts in levels OC1 and OC2: the first includes protracted or repeated human presence at the site with some localised postdepositional sedimentary arrangement, but where the artefacts primarily remain in an autochthonous position. The second explanation is that the artefacts are in an allochthonous position and were re-deposited and accumulated from an eroded lower level. In the latter scenario, the ages obtained on the sediments from levels $\mathrm{OC} 1$ and OC2 would date the geological formation processes (depositional event) but not the hominin activity, and so they would provide a minimal age for the timing of human presence at the site.

\subsection{Chronological framework}

\subsection{1. pIR-IR K-feldspar dating results}

\subsubsection{Dose-recovery tests and signal characteristics}

Dose recovery tests were carried out using the pIR-IR 225 and pIR-IR $R_{290}$ SAR protocols (Table 3) to determine the most suitable pIR-IR measurement and preheat conditions for the Arbo samples. Dose recovery experiments were performed on samples OC16-2 and OC16-3. For each sample, ten 160-grain K-feldspar aliquots were prepared and placed under direct sunlight for $8 \mathrm{hrs}$ to bleach their naturally accumulated pIRIR signals. The bleached aliquots from each sample were then split into two batches of 5 aliquots. For each batch of aliquots, two were left un-dosed to determine the (unbleached) $D_{e}$ residual after daylight bleaching, while the remaining three were given a laboratory dose of 300 Gy for sample OC16-2 and 500 Gy for sample OC16-3. The two batches of five aliquots for each sample were then separately measured with the pIR-IR 225 or pIR-IR $R_{290}$ protocol to determine their $D_{e}$ values. Dose recovery (measured to given dose) ratios were calculated after subtracting the residual (unbleached) $D_{e}$ of the un-dosed aliquots from the mean $D_{e}$ obtained from the dosed aliquots (Table 4). For both OC16-2 and OC16-3, the pIR-IR 290 dose recovery ratio (1.04 \pm 0.03 and $1.02 \pm 0.03$, respectively) overlaps with unity at $2 \sigma$ and indicates that this is the most suitable protocol for $D_{e}$ determination. In contrast, the pIR-IR $R_{225}$ signal yielded inaccurate dose-recovery ratios and underestimated the administered dose by $6-11 \%$. On the basis of these dose-recovery assessments, we have chosen to employ the pIR-IR 290 protocol for luminescence dating purposes at Arbo. 
A representative pIR-IR 290 decay curve and sensitivity-corrected dose-response curve is shown in Fig. 5. The pIR-IR 290 decay curve of the sample shown (OC16-3) decreases by $\sim 90 \%$ within the first $30 \mathrm{~s}$ of stimulation and its dose-response curve is optimally fitted with a single saturating exponential plus linear function. All the $D_{e}$ values were obtained from the non-saturated region of the dose-response when using this type of fitting function. None of the measured aliquots were rejected for failing the SAR quality assurance criteria outlined in the previous section.

\subsubsection{Residual dose and fading rate assessments}

In order to assess the bleaching properties of the pIR-IR $\mathbf{R}_{290}$ signal for these samples, and to examine whether appropriate levels of signal resetting could have been experienced prior to burial, we performed a series of prolonged and controlled daylight exposure tests on the three samples dated. For this experiment, three Kfeldspar aliquots of each sample were prepared and placed under direct sunlight for 15 days. The residual $D_{e}$ values of these bleached aliquots were then measured using the pIR-IR $R_{290}$ SAR protocol shown in Table 3. The mean corresponding pIR-IR 290 residual doses for samples OC16-1, OC16-2 and OC16-3 are $6.0 \pm$ $0.3,9.3 \pm 0.3$ Gy and $7.3 \pm 0.4$ Gy (Table 5), which equate to $7.0 \%, 5.4 \%$ and $1.2 \%$ of their natural $D_{e}$ values, respectively. For all three samples, the age offsets pertaining to these residual $D_{e}$ values lie well within the existing $1 \sigma$ uncertainties of the final age estimates. Given the relatively small size of these empirical residual $D_{e}$ values, the insensitivity of the final ages to residual considerations, and the unknown bleaching durations experienced by each of the dating samples prior to deposition (i.e., natural bleaching durations may have significantly exceeded our experimental bleaching durations), we have not considered an additional residual dose subtraction in the final pIRIR 290 age estimates.

Fading tests were performed to investigate the potential for athermal loss of K-feldspar pIR-IR $R_{290}$ signals over burial timescales. Measurements were made on subsets of four aliquots used to derive $D_{e}$ values. The fading tests were performed using the procedures of Auclair et al. (2003), and involved undertaking repeated SAR $\mathrm{L}_{x} / \mathrm{T}_{\mathrm{x}}$ measurements after different storage times of $0.17-30 \mathrm{~h}$. Anomalous fading rates $(g$-value) normalised to 2 days were calculated as described in Huntley and Lamothe (2001), and used to quantify the expected percentage of signal loss per decade of storage time.

The weighted-mean $g$-values for the Arbo samples range between $0.61 \pm 0.30 \% /$ decade and $1.8 \pm 0.54$ $\% /$ decade (Table 6 ), and the combined weighted average g-values for all individual aliquots $(n=12)$ is $1.13 \pm$ $0.10 \% /$ decade. These empirical fading rates are all within $2 \sigma$ of $1 \% /$ decade, and are similar to published $g$ values for the pIR-IR 290 signals (see summary in Arnold et al., 2015), as well as for athermally stable quartz OSL signals (Buylaert et al., 2012). Such low g-values (on the order of $<1-2 \% / d e c a d e)$ have been interpreted to be potential unreliable indicators of long-term fading rates and / or artefacts of laboratory procedures on the basis of comparisons made with independent age control, observations of natural signal saturation, and measurements of similarly sized g-values for quartz (Buylaert et al., 2012; Roberts, 2012; Vasiliniuc et al., 2012). Consequently, we do not consider the low g-values recorded in the present study to be indicative of the need for pIR-IR age corrections.

\subsubsection{3. $\quad D_{e}$ results and pIR-IR ages}


pIR-IR $290 D_{e}$ values, overdispersion values and ages obtained for the Arbo samples are shown in Table 6. The three samples have moderate to low overdispersion values (i.e., the degree of scatter beyond the empirical $D_{e}$ uncertainties) ranging between 7 and $15 \%$, broadly consistent with well-bleached, unmixed dose populations (e.g., Arnold et al., 2014, 2015; Demuro et al., 2014, 2015; Méndez-Quintas et al., 2018) (Table 6, Fig. 6). As such, the central age model (CAM; Galbraith et al., 1999) has been used to derive the final pIRIR $D_{e}$ values for these samples. Samples OC16-1 and OC16-2 collected from levels OC3 in the North sector of the excavation yield pIR-IR 290 ages of $19 \pm 1.4 \mathrm{ka}$ and $33 \pm 2.5 \mathrm{ka}$, respectively. These ages suggest OC3 was deposited during MIS2-3. An older age of $118 \pm 9$ ka was obtained for sample OC16-3 from level OC2 in the South sector, confirming the stratigraphically lower position of this deposit relative to level OC3 in the North sector, and suggesting that OC2 accumulated during either MIS 5 or the terminal stages of MIS 6.

\subsubsection{ESR dating results}

3.3.2.1. $D_{E}$ results

Al centre

ESR dose response curves (DRCs) and associated fitting results derived from the measurement of the $\mathrm{Al}$ centre are provided in Table 7 and Fig. 7, respectively. Bleaching coefficients values are around 35\% on average, suggesting similar bleaching conditions for the two samples. As a comparison, these values are close to the lower range of values obtained from the samples of Porto Maior located nearby (Méndez-Quintas et al. 2018b).

The quality of the ESR data collected is similar to that of the Porto Maior samples: measurement and $D_{E}$ repeatability is $<3 \%$ and within $10-15 \%$, respectively. Goodness-of-fit achieved for the two samples is overall good, with adjusted $\mathrm{r}^{2}$ around 0.99 (Table 7). Méndez-Quintas et al. (2018b) previously noticed the peculiar behaviour of the Porto Maior samples at high doses and considered the $D_{E}$ values from the EXPLIN function more reliable when derived from a maximum irradiation dose $\left(D_{\max }\right)$ value of $27 \mathrm{kGy}$ instead of $40 \mathrm{kGy}$. At Arbo, the samples show a similar behaviour. For sample VI1201, the fitting gets better with $D_{\max }=27 \mathrm{kGy}$ and the $D_{E}$ value decreases by about $100 \mathrm{~Gy}$, suggesting that the $D_{E}$ results previously obtained from $D_{\max }=$ 40 kGy may be overestimated (Table 7). This is confirmed by comparing with a SSE function fitted thought the first part of the DRC ( $\left.D_{\max }=3.2 \mathrm{kGy}\right)$, which also yielded a $D_{E}$ of around $690 \mathrm{~Gy}(689 \pm 120 \mathrm{~Gy}$; Fig. 7). For sample VI1202, the different fitting options make almost no significant difference in terms of Goodness-of-fit or $D_{E}$ value, although the $D_{E}$ value derived from the SSE is closer to that obtained from the EXPLIN $\left(D_{\max }=27\right.$ kGy).

Consequently, we consider the fitting performed with the EXPLIN function and $D_{\max }=27 \mathrm{kGy}$ as providing the most reliable results, as in Méndez-Quintas et al. (2018b). These values were used for the ESR age calculations of both samples. 
ESR DRCs and fitting results are displayed in Fig. 7 and Table 8, respectively. The quality of the ESR data collected for the Ti-Li centre (intensity and $D_{E}$ repeatability) is within the standards compared with previous studies, and goodness-of-fit appears to be excellent for the two samples (adjusted $r^{2}$ value $>0.99$ ), ensuring meaningful fitting results.

The $D_{E}$ values derived from option $D$ were compared with those obtained from option $A$, and results are within error: they differ by $<7 \%$. Similarly, when considering option $D$ only, the $D_{E}$ values derived from the fitting of the Ti-2 $\left(1 / \mathrm{s}^{2}\right)$ and SSE (1//2; with $\left.D_{\max }=10 \mathrm{kGy}\right)$ functions differ by $<9 \%$ : they are within error for both samples (Fig. 7). These observations indicate that the choice of both the fitting function and the ESR signal has a limited influence on the calculated dose estimates. Consequently, $D_{E}$ values obtained from option $D$ with Ti-2 (1/s²) were used for ESR age calculation, as in Méndez-Quintas et al. (2018b).

Finally, the Ti-H centre was evaluated as well for this set of samples. However, measurement reproducibility was quite poor (variation of 6-11\%), resulting in repeated $D_{E}$ values varying between 11 and $20 \%$ (Table 8). The goodness-of-fit achieved is excellent for sample VI1201 (adjusted $r^{2}$ value > 0.99), while it is poor for sample VI1202 (adjusted $r^{2}$ value $~ 0.96$ ). Taken together, this evidence indicates that the ESR results obtained from this centre should be considered with caution. The $D_{E}$ estimate obtained for VI1201 is less than half of that derived from option D. In contrast, the opposite pattern may be observed for VI1202, but this might be simply an artefact of questionable fitting results for the $\mathrm{Ti}-\mathrm{H}$ signal (adjusted $\mathrm{r}^{2}=0.963$ ). For this sample, the SSE function provides a $D_{E}$ value that is about half of that derived from the Ti-2, but displays a significantly bimprovedetter goodness-of-fit (Table 8, Fig. 7). This would suggest more reliable fitting results in first instance. Note that the significant variability in the dose estimates induced by the different fitting options may be interpreted as additional evidence for the poor quality of the ESR data set obtained for the Ti-H signal. This poor quality is the result of very weak ESR intensities measured in the two quartz samples.

\section{Multiple Centre approach}

The comparison of the $D_{E}$ values derived from the Al and Ti-Li centres shows that none of the samples yield consistent results for a given sample: the Al centre systematically provides higher $D_{E}$ values by a factor of about 2. In accordance with the basic principles of the MC approach (Toyoda et al., 2000), this indicates that the signal of the Al centre has been incompletely reset during sediment transportation. Consequently, the Ti$\mathrm{Li}$ centre most likely provides a closer estimate of the true burial dose of the samples. These dose values might, however, still be overestimated, as indicated by the questionable $\mathrm{Ti}-\mathrm{H}$ results.

\subsubsection{Dose rate and ESR age calculations}

Sediment was analysed in situ as well as in the laboratory by a range of different techniques. ICP-MS and HRGS analyses provide overall consistent results (Table 9), with the exception of the U-238 content obtained for VI1202. Some of the differences observed may be due to inherent variability within the sediment, as ICP and HRGS analyses were performed on $\sim 10 \mathrm{~g}$ and $\sim 150 \mathrm{~g}$ of raw sediment, respectively. HRGS analyses indicate the presence of a significant apparent disequilibrium within the U-238 series decay chain, with a 20$25 \% \mathrm{Rn}$ loss for both samples. Table 10 displays a comparison between gamma dose rate values derived from in situ and laboratory (ICP-MS and HRGS) analyses. The following observations can be made: 
- Full series laboratory gamma dose rates differ by $<5 \%$ : ICP-MS and HRGS techniques provide very close results.

- HRGS laboratory gamma dose rate values assuming equilibrium are higher by $7-11 \%$ than those based on $20-25 \%$ Rn loss.

- HRGS laboratory Rn-loss gamma dose rates are consistent with the in situ measurements (within $5 \%$ ), which indicates that: (i) the surrounding sedimentary environment is relatively homogeneous within a 30$\mathrm{cm}$ radius sphere, and (ii) $\mathrm{Rn}$ loss observed in those samples is not a laboratory artefact due to box sealing issues, but is actually present on site.

Since we have no evidence to evaluate whether this disequilibrium has prevailed throughout time or is perhaps a recent geochemical overprint, two sets of ESR ages were calculated, one assuming equilibrium in the U-238 and based on both beta and gamma dose rates derived from the ICP measurements, and the second assuming constant disequilibrium (20-25\% Rn loss) over time, with beta and gamma dose rates derived from HRGS activities and in situ measurements, respectively (Table 11).

Total dose rates calculated for the two samples form Arbo are significantly higher by several hundreds of $\mu$ Gy/a when compared to those obtained at the neighbour site of Porto Maior (Méndez-Quintas et al. 2018b), indicating significantly different dosimetry environments. This higher radioactivity, however, does not seem to affect the luminescence or ESR signals, as they do not show evidence of saturation.

The Al centre systematically provides the oldest ages of the ESR dataset (between $96 \mathrm{ka}$ and $162 \mathrm{ka}$, depending on the scenario and sample considered), while the Ti results are significantly younger by at least $50 \%$ (Table 11). Consequently, following the principles of the MC approach, the Al centre is interpreted as providing a maximum possible chronology for the two samples. In comparison, the chronology derived from the Ti-Li centre represents most likely a much closer estimate of the true sediment deposition age in the range of about 85 to $50 \mathrm{ka}$. However, the finite age estimates derived from the $\mathrm{Ti}-\mathrm{H}$ centre suggest an even younger chronology. $\mathrm{Ti}-\mathrm{H}$ is known to bleach much faster than any other ESR signal (see bleaching kinetics curves in Duval et al., 2017). When measurable, Ti-H has shown to be very useful to date late Middle to Late Pleistocene samples (e.g. Duval et al., 2017; Kreutzer et al., 2018). At Arbo, sample VI1201 has an ESR Ti-H age estimate of around 30-35 ka, while VI1202 is twice as old (65-80 ka). However, the fitting results for the latter are questionable (see section 3.3.2.1.), and are possibly estimated: the use of the dose estimate from the SSE function yields an age in the range of 30-40 ka that is consistent with that obtained for VI1201.

Considering either equilibrium in the $\mathrm{U}-238$ series or a constant $20-25 \% \mathrm{Rn}$ loss disequilibrium does significantly impact the dose rate, which result in ESR age estimates younger by $10-20 \%$ for the former. Such disequilibrium does not appear to be widespread in the area. Our previous work at Porto Maior showed equilibrium in the U-238 decay chain of all samples (Méndez-Quintas et al. 2018b). Similarly, at Arbo, the luminescence data do not display apparent disequilibrium beyond the $2 \sigma$ errors. These samples were collected in different sections, perpendicular to that sampled for ESR (see Fig. 2), indicating that the N-S section sampled for ESR may have locally experienced a distinctive geochemical history. This may be linked to the proximity of the anthropic hole, which may have affected the geochemistry of the sediment. If so, the 
current disequilibrium that is observed only in this section may simply be a recent overprint. Consequently, in the first instance, we would consider the ESR Ti-H ages based on equilibrium values as the most reliable estimates ( $30.9 \pm 4.7$ and $33.5 \pm 4.5$ for Vi1201 and VI1202, respectively) of the true depositional age of the sediment within OC3. These ages would be older by 3-6 ka if disequilibrium is considered. The ESR result obtained for sample VI1201 is consistent with the pIR-IR result of sample OC16-2 (33 $\pm 3 \mathrm{ka}$ ), while VI1202 is about 10 ka older than OC16-1. The ESR chronology provides a minimum age constraint for the lithic industry found in OC1 level below.

These results are a good illustration of the potential and limitations of the ESR method to date Late Pleistocene deposits. Despite the overall good quality of the ESR data set collected for Al and Ti-Li centres, these two centres provide overestimated ages for the two samples. A few reasons may explain this, such as a slower bleaching kinetics (Duval et al., 2017), and a smaller radiation sensitivity (Duval and Guilarte, 2015), which make them less suitable to detect relatively small dose estimates (<200 Gy). In comparison, our previous work at Porto Maior has showed the significant potential of the Ti-Li signal when dealing with dose estimates of around 1,000 Gy (Méndez-Quintas et al. 2018b). In contrast, although the weak ESR intensities of the Ti-H centre has a direct impact on the measurement and $D_{E}$ repeatability, it seems that this centre surprisingly provides overall correct results at Arbo.

\subsection{Lithic industry}

Excavations at the site have yielded 4968 artefacts in total, comprising 1826 superficial artefacts retrieved in the farming area (Méndez Quintas et al., 2018c) and the 3142 pieces recovered from in situ stratigraphic positions during the site excavations. Level OC1 has yielded 1292 artefacts, while level OC2 has produced 1850 artefacts (Table 12). The lithic analysis performed in the present study focuses exclusively on the in situ material recovered during the excavation.

\subsubsection{General features}

The lithic assemblages from both layers OC1 and OC2 are dominated by flakes, waste and cores (Table 12). The number of allochthonous cobbles (mainly quartzites) introduced to the site by hominin activities (189 in total) is particularly high. Shaped tools (flake tools and LCTs) also have a significant representation (9-11\% of preserved artefacts in each layer), whereas pebble tools are more limited in occurrence $(0.5-1.1 \%$ of preserved artefacts in each layer). The hominin activities developed at the site include the introduction and/or management of $238.4 \mathrm{~kg}$ of raw material in level OC1 and $204.5 \mathrm{~kg}$ in level OC2, despite the rather small excavated surface area (38 $\left.\mathrm{m}^{2}\right)$. The OC1 assemblage was recovered from a $30 \mathrm{~m}^{2}$ area, and the artefact density is 43.1 pieces per $\mathrm{m}^{2}$, while in level OC2 the excavated surface is just $8.7 \mathrm{~m}^{2}$ and the artefact density is substantially higher (212.6 pieces per $\mathrm{m}^{2}$ ) (Fig. 4 and 8 ).

The vast majority of artefacts in both levels OC1 and OC2 do not exhibit any significant fluvial alteration (OC1 $=86.7 \%$ and OC2 $=82.9 \%)$ and only a small percentage of pieces $(13-17 \%)$ are classified as abraded. The sedimentary environment of both levels (gravity flows with poorly sorted clast in massive silty-sand matrices) 
is compatible with some spatial reorganisation of artefacts and other localised post-depositional disturbance (abrasion or size selection, for example). However, these potential reworking processes do not appear to have been sufficiently intense or extensive (in distance and time) to abrade a large percentage of the preserved artefacts. This suggests that the archaeological materials found in OC1 and OC2 did not suffer extensive displacement within the sedimentary system, and that the degree of assemblage integrity is comparable to that of the original accumulation, mainly in OC1 level. Some artefacts from the North excavation area may have experienced a more significant degree of alteration and reworking due to the erosive processes associated with the formation of level OC3. However, this possibility requires further investigation and a taphonomic comparison of artefacts from different excavation areas will be the subject of a separate, dedicated paper.

The available lithic resources in the region are mainly quartzite and quartz pebbles. For the Arbo assemblage, quartzite represents $60.8 \%$ and quartz $36.6 \%$ of the artefacts recovered in level OC1, while in level OC2 there are fewer quartzite artefacts (53.5\%) and slightly more quartz artefacts (44.2\%). The presence of other raw materials (lydites, sandstones or granites) is relatively minor in both levels $(\mathrm{OC} 1=2.6 \%$ and $\mathrm{OC} 2=$ 2.3\%). The quartzite used as a raw material at Arbo comes exclusively from the Miño bedload (pebbles and cobbles), having been introduced to the site either unprocessed or partially transformed. It is likely that this type of raw material would have been abundant in the vicinity of the site as the river bed would have been located within a radius of $<1 \mathrm{~km}$. Unlike the quartzite artefacts, the quartz neocortex allows the identification of raw material selection from more varied catchment areas. A large percentage of quartz supports seem to have been selected from fluvial environments and their appearance indicates a source related to the Miño bedload or one of its main tributaries. Additionally, we have identified a subset of quartz artefacts with prismatic, sub-rounded or patinated neocortex $(\mathrm{OC} 1=31.3 \%$ and $\mathrm{OC} 2=36.1 \%)$. These pebbles and cobbles have a local origin, and are identical to the clasts observed in the sediments formed from the natural erosion of the granitic basement. This observation would indicate the selective use of local raw materials that were perhaps better adapted to their technological and functional needs.

The lithic assemblage in both levels shows a predominance of elements associated with small-medium flake production, with a large number of flakes and cores (Table 12), although we recognized a significate percentage of large flakes $(\mathrm{OC} 1=1.5 \%$ and $\mathrm{OC} 2=1.5 \%)$ and LCTs related items $(\mathrm{OC} 1=9.8 \%$ and $\mathrm{OC} 2=$ $7.8 \%)$. In addition, the extensive presence of unmodified pebbles (OC1 $=8.4 \%$ and OC2 $=4.4 \%$ ) and percussion elements is still relevant, mainly in the OC1 level $(\mathrm{OC} 1=2.9 \%$ and $\mathrm{OC} 2=0.5 \%)$. The flake tools have a low similar percentage in both assemblage (OC1 $=5.5 \%$ and $\mathrm{OC} 2=4.6 \%)$. The quartzite is the preferred raw material for medium (OC1 $=57.4 \%$ and OC2 $=55.8 \%$ ) and large flake (OC1 $=95.0 \%$ and OC2 $=95.3 \%)$ production in both levels, although the quartz has a relevant percentage in small flakes (OC1 = $65.6 \%$ and $\mathrm{OC} 2=65.0 \%)$. For flakes tools $(\mathrm{OC} 1=53.0 \%$ and $\mathrm{OC} 2=77.8 \%)$ and mainly LCTs the quartzite is almost exclusively used.

\subsubsection{Percussion material, unmodified and tested pebbles}


The number of percussion pieces, unmodified and tested pebbles has a representative percentage in both the OC1 and OC2 assemblages (Table 12). There is also a large number of hammerstones and tested pebbles in the OC1 assemblage. Unmodified pebbles are common $(\mathrm{OC} 1=107$ and $\mathrm{OC} 2=81)$ and, as cited above, these elements appear to have been brought to the site from the immediate surroundings. We identify a range of percussion materials in both assemblages, mainly hammerstones $(\mathrm{OC} 1=33$ and $\mathrm{OC} 2=9)$ and some anvils $(\mathrm{OC} 1=3$ and $\mathrm{OC} 2=1)$ or artefacts with both damage type $(\mathrm{OC} 1=2)$. These have a spherical morphology $(\mathrm{OC} 1=45.4 \%)$ and the percussion marks are clearly evident. The hammerstone size (weight) and distribution is similar to the unmodified pebbles (Table S1; $U=-1.436 p=0.151 ; D=0.07=p=0.991$ ). This dimensional homogeneity may suggest similar selection criteria, as some unmodified pebbles could have been used in percussion activities, but these did not generate macroscopic marks.

The tested pebbles are frequent in both assemblages $(\mathrm{OC} 1=30$ and $\mathrm{OC} 2=15)$, and are mainly derived from quartzite $(O C 1=18$ and $O C 2=9)$. These artefacts display a limited number of scars (1 or 2$)$ and the size distribution (for the more numeric representative OC1 assemblage) is different to both the unmodified pebbles $(U=-3.458 p=<0.05 ; D=0.27=p=<0.05)$ and hammerstones $(U=-2.624 p=<0.05 ; D=0.29$ $=p=<0.05$ ) (Table. S1). This could indicate some different selection criteria between tested pebbles and unmodified pebbles or hammerstones.

\subsubsection{Flakes and cores}

The frequency of small whole flakes $(\mathrm{OC} 1=89$ and $\mathrm{OC} 2=109)$ is more similar than fractured flakes $(\mathrm{OC} 1=$ 87 and OC2 $=135)$, while the proportion of medium and large whole flakes $(\mathrm{OC} 1=238$ and OC2 $=329)$ is higher than fractured flakes $(\mathrm{OC} 1=176$ and $\mathrm{OC} 2=227)$. The quartzite is the predominant raw in both assemblages, except for the small flakes where we observe an high percentage of quartz (Table 12). Usually, flakes have extensive cortical remains, although the most numerous are the ordinary flakes (OC1 $=54.0 \%$ and OC2 $=55.4 \%$ ) (Table. S2). The high frequency of cortical and cortical backed flakes indicates that many cores were initialised in the site. Other types of flakes (kombewa, flakes with debitage back or discoid flakes) are rare (Table. S2). Butts are usually cortical (OC1 $=41.1 \%$ and $\mathrm{OC} 2=43.3 \%)$, although if we consider as a whole the non-cortical butts (dihedral, facetted, plain, linear and punctiform) these have a similar percentage $(\mathrm{OC} 1=44.9 \%$ and $\mathrm{OC} 2=36.4 \%)$. It is pertinent to distinguish the occurrence of flakes with opposed platform that are correlated to bipolar knapping exploitation $(\mathrm{OC} 1=5.1 \%$ and $\mathrm{OC} 2=9.8 \%)$. Medium whole flakes have the same average size in both layers $(U=-1.489 p=0.137 ; D=0.085=p=0.203$; Table. S3).

The number of cores is very large in both levels $(\mathrm{OC} 1=113$ and $\mathrm{OC} 2=154)$, and these are mainly on quartzite $(\mathrm{OC} 1=59.2 \%$ and $\mathrm{OC} 2=61.6 \%)$. A large percentage of these core displays freehand percussion $(\mathrm{OC} 1=72.6 \%$ and $\mathrm{OC} 2=72.1 \%)$ and the remainder display a bipolar knapping on anvil $(\mathrm{OC} 1=10.6 \%$ and OC2 $=14.3 \%$ ). The recognised reduction scheme is usually elementary, with the monopolar type being very abundant $(\mathrm{OC} 1=53.2 \%$ and $\mathrm{OC} 2=49.2 \%)($ Table. S4; Fig. 9. 1-7). Other important schemes are bipolar on anvil knapping $(\mathrm{OC} 1=12.8 \%$ and $\mathrm{OC} 2=16.7 \%)$, peripheral $(\mathrm{OC} 1=13.8 \%$ and $\mathrm{OC} 2=10.6 \%)$ and discoidal 
$(\mathrm{OC} 1=5.3 \%$ and $\mathrm{OC} 2=10.6 \%)$ types (Table. S4; Fig. 9. 8-13). Other reduction patterns (disorganized, kombewa, multipolar or orthogonal) have a limited presence (<5\%) (Table. S4; Fig. 9. 14). There are no cores with Levallois exploitation features. The size of these cores is similar for both levels $(U=1.667 p=0.09 ; D=$ $0.113=p=0.377$; Table. S5), although we observe an extensive difference between freehand and bipolar on anvil cores $(U=-7.004 p=<0.05 ; D=0.647=p=<0.05$; Table. S5).

\subsubsection{Flake and pebbles tools}

Within this group we observed flake tools $(\mathrm{OC} 1=71$ and $\mathrm{OC} 2=85)$, refitting sub-products $(\mathrm{OC} 1=37$ and $\mathrm{OC} 2=51)$ and pebble tools $(\mathrm{OC} 1=14$ and $\mathrm{OC} 2=9)$. The flake tools transformation index is less in both levels $(\mathrm{OC} 1=5.1$ and $\mathrm{OC} 2=4.4)$ and the most habitual tool types are the denticulate/notch $(\mathrm{OC} 1=41.8 \%$ and OC2 $=42.4 \%)$ and scrapers $(\mathrm{OC} 1=24.1 \%$ and $\mathrm{OC} 2=30.5 \%)$; other tool types have a limit percentage Scrapers are of elementary types (single or transverse scrapers), although some complex examples (double or convergent scrapers) can also be found (Fig. 10.1-13). Denticulates and notches are of the simple type, although there are some examples of pointed double denticulates (Fig. 10. 10). Quartzite is the most used raw material $(\mathrm{OC} 1=73.2 \%$ and $\mathrm{OC} 2=85.6 \%)$ and the main common blanks are whole flakes $(\mathrm{OC} 1=78.4 \%$ and OC2 $=88.9 \%)$. Cortical flakes $(\mathrm{OC} 1=39.2 \%$ and OC2 $=38.1 \%)$ and ordinary flakes $(\mathrm{OC} 1=30.3 \%$ and OC2 $=41.5 \%)$ are the preferred blanks, while other flake types have residual percentages. The retouch features are identical in both levels, with short extension, simple or semi-abrupt inclination and direct position. The average size of tools is substantially higher than the average size of untransformed flakes $(U=-9.340 p$ $=<0.05 ; D=0.405=p=<0.05 ;$ Table. S3) .

\subsubsection{Large cutting tools (LCT) and subproducts}

The recovered LCTs are handaxes $(O C 1=33$ and $O C 2=21)$, cleavers $(O C 1=14$ and $O C 2=10)$, trihedral pick $(\mathrm{OC} 1=5$ and $\mathrm{OC} 2=3)$ and large flake tool $(\mathrm{OC} 1=24$ and $\mathrm{OC} 2=40)$, besides some points or base fragments $(\mathrm{OC} 1=10$ and $\mathrm{OC} 2=13)($ Table 12). All LCTs are made on quartzite, with the exception of one large flake tool in level $\mathrm{OC} 1$ and one partial handaxe on quartz from level OC2. The large flake tool has a similar feature that we describe to common flake tools, with large denticulates and scrapers on cortical flakes and retouch with short extension. The handaxes have amygdaloid, micoquian or lanceolate morphologies and great frontal and bilateral symmetry (Fig. 11). They are made on flakes ( $\mathrm{OC} 1=39.3 \%$ and $\mathrm{OC} 2=42.8 \%$ ), pebbles $(\mathrm{OC} 1=27.2 \%$ and $\mathrm{OC} 2=14.3 \%)$ and in some cases the extensive configuration disables the blank type determination. The tools usually have cortex on basal areas, but show regular edges that are finished with soft-hammer. Cleavers are less abundant than handaxes and they are usually of Tixier type $O$ (Fig. 12.1), although we observed other specific types, such as cleavers on kombewa flake (Fig. 12.2). Similar to the handaxes, cleavers have a regular shaping and have been finished with soft-hammer. Trihedral picks are not very abundant, although some typical examples can be found (Fig. 12. 3). The size of the different types of LCT shows some tools with about $130-140 \mathrm{~mm}$ in length and 500-600 $\mathrm{g}$ in weight (Table. S6). 
In both levels we have recognised final reshaping flakes of handaxes/cleavers (OC1 = 40 and OC2 $=57$ ). Butts and percussion bulbs suggest that a part of these flakes were extracted with soft-hammer, a situation that is similar to the LCTs. The significant presence of these flakes and the absence of large cores to take out large flake-blank (Table. 12), would indicate the introduction of configured LCTs that were later reshaped on-site.

\section{Discussion}

4.1. Geomorphologic position and chronology of the site

The published (reliable) radiometric age for the lower staircase of the Miño basin (with associated Acheulean implements), indicate that terrace level T3 is likely coeval with either MIS 6 or 7, as it stratigraphically postdates the T4 (+30-39 m) terrace formation dated to MIS 8-7 by Mendez-Quintas et al. (2018). Terrace T3 also stratigraphically pre-dates the formation of terrace T2 (+13-17 m) (without associated Acheulean sites), which has been dated to at least MIS 5 or late MIS 6 by Viveen et al. (2012). An MIS 6 rather than MIS 7 age would seem more plausible for Arbo owing to the absence of argiluviation processes that typically characterise interglacial sedimentary deposits and that are commonly observed in some of the T4 (+30-39 $\mathrm{m})$ river terrace sequences in the Miño basin (Méndez-Quintas et al., 2018b).

The ESR and pIR-IR ages, from levels OC2 and OC3, point to a laterally diachronous sedimentary history for the Arbo sequence. The pIR-IR age (118 $\pm 9 \mathrm{ka}$ ) obtained for level OC2 in the South sector provides an estimate for the timing of the debris flow sedimentation and localised reworking of the lithic assemblage from on older level or lag deposit (level OC1 or another unknown level) (see discussion in next section). This enables us to place a minimum age estimate of at least MIS 5 on the original lithic assemblage accumulation at Arbo. The ESR and pIR-IR ages for level OC3 indicate a much more recent sedimentary process at the site. These ages (around 20-60 ka) indicate that the deposition occurred around the start of MIS 2 through to the Last Glacial Maximum, most likely between the $\mathrm{H} 1$ and $\mathrm{H} 4$ Heinrich events (Naughton et al., 2009).

The collective chronological evidence available for the Arbo site (sedimentological properties of the Arbo infill sequence, and the new numerical chronologies presented here) enable us to constrain the original Acheulean occupation to sometime prior to MIS 5, most likely during MIS 6 and no earlier than MIS7. The original infill sequence was then partly eroded and continued to accumulate sediment (level OC3) during the late Upper Pleistocene.

\subsection{Main archaeological features of the Arbo assemblage}

The taphonomic integrity of the $\mathrm{OC} 1$ and $\mathrm{OC} 2$ lithics is a critical line of evidence in support of the macroscale stratigraphic reliability of the site, particularly as the sedimentary environment associated with the lithicbearing infill layers is potentially compatible with considerable erosional energies and high carrying capacities. Importantly, the majority of artefacts do not display surface abrasion or other types of mechanical 
alteration. The technological composition of both the OC1 and OC2 assemblages is also coherent, with large percentages of flakes and other knapping products. While the taphonomic and stratigraphic evidence (i.e., presence of gravity flows with poorly sorted clasts, evidence of abrasion in $13-17 \%$ of artefacts, artefact size selection) affirm that the two assemblages likely experienced some minor and localised sedimentary disturbances, mainly in level OC2, these disturbances were seemingly not sufficient enough to modify the surfaces of the artefacts or the technological composition of the assemblage. These observations are consistent with short displacement distances within the immediate vicinity of the site and confirm that some of the artefacts are in an autochthonous position (mainly OC1 level), while others display variable degrees of spatial displacement. Further taphonomic research is needed to fully ascertain the degree of lithic alteration and localised remobilisation in different sectors of the excavation area. Given the presence of locally displaced artefacts in at least layer OC2, we have cautiously interpreted the pIR-IR results obtained on layer OC2 as representing a minimum age estimate for the combined OC1-2 lithic assemblage.

The lithic industry recovered from both levels OC1 and OC2 display similar technological and technoeconomic features indicative of shared or repeated behavioural trends. The lithic assemblages can be classed as Acheulean industries characterised by the use of large flake blanks (LFA sensu Sharon, 2007). The selected raw materials are quartzite and quartz, recovered from the Miño river bedload, and the majority of lithic resources were introduced to the site from surroundings areas. Quartzite is common in all chaîne operatoire phases, while quartz has a complementary role, linked to flakes production. The flake tools and LCTs are made on quartzite blanks and the use of quartz is reduced. The extensive utilisation of quartzite is a common occurrence in southwestern European Acheulean sites (Santonja and Villa, 2006; Cologne and Mourre, 2009). Whenever there is a large range of raw materials available and flint is found among them, quartzite is the preferred rock for shaping LCTs, while flint is selected to obtain flakes or flake tools (Santonja and Villa, 2006; Rubio-Jara et al., 2016). The use of coarse raw materials, such as quartzite, basalt or sandstone is recurrent in the Acheulean record of Africa, Near East and India (Sharon, 2007), but these signal an important difference when compared to the raw materials used in northern Europe (Santonja and Villa, 2006; Tuffreau et al., 2008; Sharon, 2011; Moncel et al., 2015).

The density of lithic remains at Arbo (43.1 pieces $\mathrm{m}^{2}$ in level OC1 and 212.6 pieces $\mathrm{m}^{2}$ in level OC2) are among the highest observed in open-air Acheulean sites from the Iberian Peninsula (Fig. 13). In evaluating the significance of this observation it is important to consider the sedimentary, taphonomic and functional conditions of comparative sites across lberia, since these factors appear to introduce important differences in lithic densities. In low or medium energy environments, such as the Lower and Middle member at Ambrona, Torralba or Valdocarros, the observed densities do not exceed 10 pieces per m², (Rubio-Jara et al., 2016; Santonja et al., 2017). In contrast, sites for which artefact densities exceed 50 pieces per $\mathrm{m}^{2}$ are typically found in higher energy accumulative contexts, such as La Maya I (Santonja and Perez Gonzalez, 1984) or Pinedo (Querol and Santonja, 1979), or they are found within loam sediments, such as Charco Hondo I, which exceeds 200 pieces per $\mathrm{m}^{2}$ (Bárez et al., 2016). The high density of lithic remains found over a reduced excavated surface at Arbo $\left(38 \mathrm{~m}^{2}\right)$, where $442.9 \mathrm{~kg}$ of artefacts was recovered, would suggest repeated use 
of the site by hominins over a time period that is difficult to evaluate; although we cannot exclude some contribution to the total lithic accumulation arising from sedimentary processes.

The high percentages of total and partial cortical flakes, waste, hammerstones and allochthonous unmodified pebbles in the Arbo assemblages seem to indicate that the small-medium flakes chaine operatoires is completely represented at the site. This interpretation seems valid for the majority of the debitage, but not for the LCTs. It seems that the latter were introduced to the site as knapped objects and then re-shaped at the site, as indicated by the significant number of recovered handaxe resharpening flake in the two levels, as well as the high degree of morphology reduction. Additionally, we have not observed a significant correlation between the size of scars on the cores and the size of the flakes-blanks used for shaping the LCTs, indicating that the large flakes were introduced to the site. This circumstance is not exceptional in Acheulean contexts and has been reported to occur at other sites (Pope, 2002; Goren-Inbar and Sharon 2006; Santonja and Villa, 2006; Sharon, 2007; Goren-Inbar et al., 2018).

The reduction models applied to flake production are very elementary at Arbo. The most common cores display monopolar and peripheral patterns, whereas cores with discoid patterns are less abundant. The Levallois strategies are completely absent. The high percentage of bipolar cores, mostly on quartz, is a noteworthy feature of the assemblage. This knapping technique is known in other Middle Pleistocene Europeans sites (Mourre, 1996; Mourre, 2004; Jarry, 2010; Gallotti and Peretto, 2015) and their homologous African sites (de la Torre, 2004; Díez-Martín et al., 2011). The core exploitation patterns in the European Acheulean are also the most elemental system (Turq, 2000; Santonja and Villa, 2006; Mourre and Cologne, 2010). Only the discoid type has a noticeable presence, while the Levallois pattern is very limited in Acheulean contexts and is usually considered indicative of the development of the early ancient Middle Palaeolithic (EAMP) techno-complex (White et al., 2011; Moncel et al., 2015; Hérisson et al., 2016; Santonja et al., 2016; Villa et al., 2016a; Carmignani et al., 2017; Soriano and Villa, 2017).

The LCT group is dominated by handaxes and cleavers (with minor percentages of trihedral picks or large flakes tools) and it has a large numerical presence (150 examples) for a reduced excavated surface of 38 $\mathrm{m}^{2}$. Another 130 LCTs were recovered in the neighbourhood of the excavated area (Méndez Quintas et al., 2018c). The high density of LCTs at Arbo is not an isolated occurrence and similar trends have been observed elsewhere in the Miño basin, such as at the Porto Maior site (Méndez-Quintas et al., 2018b). The LCTs found in both levels $\mathrm{OC} 1$ and $\mathrm{OC} 2$ show very symmetric and repetitive morphologies. In particular, the handaxes are the lanceolate, micoquian or amygdaloid type, and the cleavers are type $O$, but both morpho-types are usually intensively regularised with soft-hammer.

\subsection{Placing the Arbo Acheulean assemblage in a regional and continental context}

Numerous LFA Acheulean sites are known from the northwest Iberian Peninsula, as well as from other western basins, although only a few are characterised by assemblages that contain extensive LCT accumulations and repetitive LCT morphologies (Cunha Ribeiro et al., 2017; Méndez-Quintas et al., 2018a). In the Miño River basin, several other sites contain LCT accumulations that display an advanced aspect, the 
most similar being the site of As Gándaras de Budiño (Méndez-Quintas, 2007, 2008; Méndez-Quintas et al., 2018a), associated with the T3 (+21-29 m) fluvial terrace. Both sites have a similar raw material management, with a preferential use of allochthonous quartzites for retouched tools -flake tools or LCTs- and local quartz for flake production. Also the reduction core pattern observed at both sites are elementary, but with a significant presence of discoidal schemes. The flake tools present include large numbers of denticulates, notches or scrapers, but with a low degree of standardization. The LCTs, mainly handaxes and cleavers, have a high degree of formal and technical standardization at both sites, with several showing the use of softhammer on the final stage of the configuration.

Additionally, the recently reported site of Porto Maior, which has been dated to MIS 8-7, records a similar Acheulean assemblage that contains abundant LCTs (Méndez-Quintas et al., 2018b). At level PM3 of Porto Maior, the number of lithic implements recovered has been limited and this prevents an adecuate comparison with other sites. However, level PM4 produced a large number of artefacts and some observations can be made when compared to Arbo. Firstly, the assemblage from PM4 displays a techno-typological difference in that only a small amount of debitage elements (flakes, cores or waste) were recovered, with most implements being shaped tools, mainly LCTs. Secondly, the handaxes and cleavers of level PM4 at Porto Maior are different in size (length or weight) and in reduction intensity when compared to those from Arbo. This important difference between both sites may reflect differences in behaviour and site functionality, where the PM4 lithic assemblage is the result of a specialized activity and short-term occupation, while in Arbo the occupation pattern was recurrent and the functionality was diversified.

Other Iberian sites display similar technological features, including the Complex Terrace of Butarque in the Manzanares basin (Madrid), Porzuna and El Sotillo (Ciudad Real), Burganes (Zamora) and El Basalito (Salamanca), and Vale Forno 3 "Milharós" (Portugal) (Raposo, 1996; Santonja and Pérez González, 2004; Santonja and Villa, 2006; Arroyo and de la Torre, 2013; Rubio-Jara et al., 2016). The chronological frameworks for these sites are very heterogeneous in coverage and quality. In some cases, the sites are either undated or have ambiguous chronologies that purportedly predate MIS 6 or 7 (Bárez et al., 2016; Rubio-Jara et al., 2016; Santonja et al., 2016; Cunha et al., 2017). In this context, the site of Arbo appears to be one of the younger dated Acheulean sites on the Iberian Peninsula. Outside of the Iberian Peninsula there are several Acheulean assemblages with standardised morphological LCTs spanning a wide timeframe (from MIS 13 to 7) within what is considered to be the European Acheulean (Roberts and Parfitt, 1999; Turq, 2000; Rosendahl, 2006; Barsky and de Lumley, 2010; Turq et al., 2010; Cologne et al., 2013; Valensi et al., 2013; Moncel et al., 2015). In the past, the presence of handaxes with more "advances" features was understood as a sign of an internal technological and chronological evolution of the Acheulean, but at present we know that it has its explanation in other factors, such as site functionality, reduction intensity or human behaviour (Hodgson, 2015; McNabb and Cole, 2015; Shipton and Clarkson, 2015; Lycett et al., 2016; Finkel and Barkai, 2018; Wynn and Gowlett, 2018). In assessing the chronological framework of the terminal Acheulean technocomplex in southwest Europe it is important to make a distinction between Iberian LFA Acheulean sites (without Levallois reduction sequences and repetitive morphology flake tools) and other similarly aged sites that exhibit some handaxes (more specifically handaxe support of tools sensu Böeda et 
al., 1990), but that are connected to the EAMP. The latter group includes sites such as Cueva del Ángel (Barroso Ruíz et al., 2011; Falguères et al., 2018), Cuesta de la Bajada (Santonja et al., 2014), the Middle Stratigraphic Complex of Ambrona (Santonja et al., 2016), Solana del Zamborino (Alvarez-Posada et al., 2017) or Gran Dolina TD10 (Ollé et al., 2013; Ollé et al., 2016), with an age range comprising MIS 9 to 7. The temporal overlap between Acheulean sites and EAMP sites is not exclusive to the Iberian Peninsula and is seen elsewhere in Europe at sites such as Schöningen, Torre in Pietra, Payre, Orgnac 3, La Micoque, Combe Grenal and Grotte Vaufrey, where the EAMP industry emerges during MIS 9 (Turq et al., 2010; Brenet et al., 2013; Faivre et al., 2013; Jaubert et al., 2013; Hérisson et al., 2016; Moncel and Schreve, 2016; Villa et al., 2016a; Lauer and Weiss, 2018; Mathias, 2018).

The present study at Arbo reinforces the temporal overlap between the Acheulean and EAMP technocomplexes of southwest Europe, adding further support to the non-linear evolutionary hypothesis outlined by Santonja et al. (2016). This hypothesis explains the coexistence of two distinctly different technological traditions in Europe during the Middle Pleistocene as a consequence of the superimposition of established European populations utilising core-flake industries by external human groups associated with an Acheulean technology. It therefore challenges the traditional notion of a gradual or linear transformation from the Acheulean to the Middle Palaeolithic, with the development of intermediate phases (Monnier, 2006; Hopkinson, 2007; Chazan, 2009; Moncel et al., 2011; Baena et al., 2017). Apart from the coexistence pattern between the two techno-complexes, which are becoming increasingly apparent as new chronological datasets such as Arbo emerge, we also note the absence of any kind of evolutionary pattern in the Acheulean technology of southwestern Europe. The existence of assemblages characterised by LCTs of repetitive morphologies is not associated with a specific chronological range, even though its development occurred prior to MIS 6 (Turq et al., 2010; Hernandez et al., 2012; Faivre et al., 2013; Jaubert et al., 2013; Demuro et al., 2014; Ollé et al., 2016; Santonja et al., 2016; Villa et al., 2016b; Cunha et al., 2017; Soriano and Villa, 2017).

\section{Conclusions}

This study presents a new and regionally significant Acheulean site from the Western margin of the Iberian Peninsula. The chronological framework established in the present study indicates that the Acheulean assemblage pre-dates MIS 5, and most likely corresponds to MIS 6 or MIS 7 at the earliest. The chronology obtained for this site and at other sites from the Atlantic Iberian fluvial basins supports the hypothesis that the Acheulean and Mousterian techno-complexes coexisted in south-west Europe during MIS 9 through to MIS 6. The site contains a particularly high density of stone tools, which exceeds 200 items per $\mathrm{m}^{2}$, and is one of the more extensive open-air Acheulean accumulations in the Iberian Peninsula.

The lithic technology at Arbo is characterised by local use of raw materials, elemental core reduction patterns and the total absence of Levallois knapping. The raw materials were introduced to the site from the surrounding areas, and managed integrally on-site. However, the LCTs were already shaped when brought to the site, and were then used, re-shaped and occasionally discarded on-site. We observe an economical 
use of raw materials, with extensive quartzite use and complementary sourcing of quartz for flake production. The flake tools are scarcely developed, mainly produced on quartzite, and do not present standardised or repetitive types, but the LCTs display standardised and regular appearances, and have been finalised with soft-hammer percussion. The site location, in an elevated position, and the particularities of the management and supply of raw materials suggest a complex prevision and anticipation behaviour.

The research developed by our team over recent years in the Miño River basin has revealed an important Acheulean and hominin presence across multiple localities during the second half of the Middle Pleistocene. These findings highlight the key role that the region is likely to play in future research into the Lower Palaeolithic of south-western Europe.

\section{Acknowledgements}

E. Méndez-Quintas is supported by Post-Doc Xunta de Galicia Grant. M. Demuro and L. Arnold were supported by ARC Discovery Early Career Researcher Award DE160100743 and ARC Future Fellowship project FT130100195, respectively. Aspects of the ESR dating study were partly funded by the Australian Research Council Future Fellowship Grant FT150100215. The three season of excavation was supported by Concello de Arbo. M. Santonja, A. Pérez-González and E. Méndez-Quintas funded by Spanish Ministry of Science, Innovation and Universities (HAR2017-82463-C4-2-P). All authors collaborate with the project Miño/Minho, Os primeiros habitants do Baixo Minho. Estudo das ocupações pleistocénicas da região. M. Duval is grateful to V. Guilarte for her invaluable contribution in the different steps of the analytical procure, and in particular with the ESR measurements. All authors are grateful to Ángel Vázquez Blanco and M. Ledo Bernárdez for their facilities in the research works.

\section{References}

Aguirre, E., 1964. Las Gándaras de Budiño Porriño (Pontevedra). Excavaciones Arqueologicas en España 31, 28.

Aguirre, E., Butzer, K.W., 1967. Problematical Pleistocene artifact assemblage from Northwestern Spain. Science 157, 430-431.

Aitken, M.J., 1985. Thermoluminescence Dating. Academic Press, London.

Aitken, M.J., 1998. An Introduction to Optical Dating: The Dating of Quaternary Sediments by the Use of Photonstimulated Luminescence. Oxford University Press.

Alvarez-Posada, C., Pares, J.M., Sala, R., Viseras, C., Pla-Pueyo, S., 2017. New magnetostratigraphic evidence for the age of Acheulean tools at the archaeo-palaeontological site "Solana del Zamborino" (Guadix - Baza Basin, S Spain). Sci. Rep. 7, 13495. 10.1038/s41598-017-14024-5

Álvarez Blázquez, X.M., Bouza Brey, F., 1949. Industrias Paleolíticas de la comarca de Tuy. Cuadernos de Estudios Gallegos XVI, 5-42. 
Arnold, L.J., Demuro, M., Pares, J.M., Arsuaga, J.L., Aranburu, A., Bermudez de Castro, J.M., Carbonell, E., 2014. Luminescence dating and palaeomagnetic age constraint on hominins from Sima de los Huesos, Atapuerca, Spain. J. Hum. Evol. 67, 85-107. 10.1016/j.jhevol.2013.12.001

Arnold, L.J., Demuro, M., Parés, J.M., Pérez-González, A., Arsuaga, J.L., Bermúdez de Castro, J.M., Carbonell, E., 2015. Evaluating the suitability of extended-range luminescence dating techniques over early and Middle Pleistocene timescales: Published datasets and case studies from Atapuerca, Spain. Quat. Int. 389, 167-190. 10.1016/j.quaint.2014.08.010

Arroyo, A., de la Torre, I., 2013. Acheulean Large Flake Technology in Campo de Calatrava (Ciudad Real, Spain). Archaeology, Ethnology and Anthropology of Eurasia 41, 2-10. 10.1016/j.aeae.2014.07.002

Arsuaga, J.L., Martinez, I., Arnold, L.J., Aranburu, A., Gracia-Tellez, A., Sharp, W.D., Quam, R.M., Falgueres, C., Pantoja-Perez, A., Bischoff, J., Poza-Rey, E., Pares, J.M., Carretero, J.M., Demuro, M., Lorenzo, C., Sala, N., MartinonTorres, M., Garcia, N., Alcazar de Velasco, A., Cuenca-Bescos, G., Gomez-Olivencia, A., Moreno, D., Pablos, A., Shen, C.C., Rodriguez, L., Ortega, A.I., Garcia, R., Bonmati, A., Bermudez de Castro, J.M., Carbonell, E., 2014. Neandertal roots: Cranial and chronological evidence from Sima de los Huesos. Science 344, 1358-1363. 10.1126/science.1253958

Asfaw, B., Beyene, Y., Suwa, G., Walter, R.C., White, T.D., WoldeGabriel, G., Yemane, T., 1992. The earliest Acheulean from Konso-Gardula. Nature 360, 732-735.

Auclair, M., Lamothe, M., Huot, S., 2003. Measurement of anomalous fading for feldspar IRSL using SAR. Radiation Measurements 37, 487-492.

Baena, J., Moncel, M.-H., Cuartero, F., Chacón Navarro, M.G., Rubio, D., 2017. Late Middle Pleistocene genesis of Neanderthal technology in Western Europe: The case of Payre site (south-east France). Quat. Int. 436, 212-238. 10.1016/j.quaint.2014.08.031

Baena Preysler, J., Torres Navas, C., Sharon, G., 2018. Life history of a large flake biface. Quat. Sci. Rev. 190, 123136. 10.1016/j.quascirev.2018.04.015

Bar-Yosef, O., Belfer-Cohen, A., 2001. From Africa to Eurasia-early dispersals. Quarternary International 75, 19-28.

Bárez, S., Baena, J., Pérez-González, A., Torres, C., Rus, I., Vega de Miguel, J., 2016. Acheulian flint quarries in the Madrid Tertiary basin, central Iberian Peninsula: First data obtained from geoarchaeological studies. Quat. Int. 411, 329348. 10.1016/j.quaint.2016.01.041

Barroso Ruíz, C., Botella Ortega, D., Caparrós, M., Moigne, A.M., Celiberti, V., Testu, A., Barsky, D., Notter, O., Riquelme Cantal, J.A., Rodríguez, M.P., Carretero León, M.I., Monge Gómez, G., Khatib, S., Saos, T., Gregoire, S., Bailón, S., García Solano, J.A., Cabral Mesa, A.L., Djerrab, A., George Hedley, I., Abdessadok, S., Batalla Llasat, G., Astier, N., Bertin, L., Boulbes, N., Cauche, D., Filoux, A., Hanquet, C., Milizia, C., Moutoussamy, J., Rossoni, E., Verdú Bermejo, L., de Lumley, H., 2011. The Cueva del Angel (Lucena, Spain): An Acheulean hunters habitat in the South of the Iberian Peninsula. Quat. Int. 243, 105-126. 10.1016/j.quaint.2011.02.021 
Barsky, D., de Lumley, H., 2010. Early European Mode 2 and the stone industry from the Caune de l'Arago's archeostratigraphical levels "P". Quat. Int. 223-224, 71-86. 10.1016/j.quaint.2009.12.005

Bermúdez de Castro, J.M., Martinón-Torres, M., 2013. A new model for the evolution of the human Pleistocene populations of Europe. Quat. Int. 295, 102-112. 10.1016/j.quaint.2012.02.036

Bermúdez de Castro, J.M., Martinón-Torres, M., Martínez de Pinillos, M., García-Campos, C., Modesto-Mata, M., Martín-Francés, L., Arsuaga, J.L., 2018. Metric and morphological comparison between the Arago (France) and Atapuerca-Sima de los Huesos (Spain) dental samples, and the origin of Neanderthals. Quat. Sci. Rev. 10.1016/j.quascirev.2018.04.003

Boëda, E., 1993. Le débitage discoïde et le débitage Levallois récurrent centripède. Bulletin de la Société Préhistorique Française, 392-404.

Böeda, E., Geneste, J.M., Meignen, L., 1990. Identification de chaînes opératoires lithiques du Paléolithique ancien et moyen. Paléo 2, 43-80.

Bordes, F., 1961. Typologie du Paléolithique ancien et moyen. Impriméries Delmas.

Bøtter-Jensen, L., Mejdahl, M., 1988. Assessment of beta dose-rate using a GM multicounter system. Nuclear Tracks and Radiation Measurements 14, 187-191.

Bourguignon, L., 1997. Le Moustérien de type Quina: nouvelle définition d'une entité technique. Universite de Paris XNanterre, p. 372.

Bouza Brey, F., Álvarez Blázquez, X.M., 1954. Industrias paleolíticas do Baixo Miño (concellos de A Guarda, O Rosal, Tomiño e Oia). Trabalhos de Antropologia e Etnologia XIV, 5-65.

Brenet, M., Bourguignon, L., Cologne, D., Folgado, M., Jarry, M., Leloulier, L.-A., Mourre, V., Turq, A., 2013. Les technocomplexes au début du Paléolithique moyen en Aquitaine septentrionale: complexité, complémentarité des productions de débitage et de façonnage et implications comportementales, in: Jaubert, J., Forument, N., Depaepe, P. (Eds.), Transitions, ruptures et continuité en Préhistoire. Volume 1. Société préhistorique française, pp. 81-101.

Brennan, B.J., 2003. Beta doses to spherical grains. Radiation Measurements 37, 299-303. 10.1016/S1350$4487(03) 00011-8$

Brennan, B.J., Lyons, R.G., Phillips, S.W., 1991. Attenuation of alpha particle track dose for spherical grains. Nuclear Tracks and Radiation Measurements 18, 249-253.

Butzer, K.W., 1967. Geomorphology and Stratigraphy of the Palaeolithic site of Budiño. Eiszeitalter und Gegenwart 18, 82-103. 
Buylaert, J.-P., Jain, M., Murray, A.S., Thomsen, K.J., Thiel, C., Sohbati, R., 2012. A robust feldspar luminescence dating method for Middle and Late Pleistocene sediments. Boreas 41, 431-451.

Buylaert, J.P., Murray, A.S., Thomsen, K.J., Jain, M., 2009. Testing the potential of an elevated temperature IRSL signal from K-feldspar. Radiation Measurements 44, 560-565.

Carbonell, E., Barsky, D., Sala, R., Celiberti, V., 2016. Structural continuity and technological change in Lower Pleistocene toolkits. Quat. Int. 393, 6-18. 10.1016/j.quaint.2015.04.008

Carmignani, L., Moncel, M.H., Fernandes, P., Wilson, L., 2017. Technological variability during the Early Middle Palaeolithic in Western Europe. Reduction systems and predetermined products at the Bau de l'Aubesier and Payre (South-East France). PLoS One 12, e0178550. 10.1371/journal.pone.0178550

Chazan, M., 2009. Assessing the Lower to Middle Paleolithic Transition, in: Camps, M., Chauhan, P. (Eds.), Sourcebook of Paleolithic Transitions: Methods, Theories, and Interpretations. Springer New York, New York, NY, pp. 237-243.

Clark, J.D., 1994. The Acheulean industrial complex in Africa and elsewhere, in: Corruccini, R., Ciochon, R. (Eds.), Integrative Paths to the Past. Prentice Hall, New Jersey, pp. 451-469.

Cologne, D., Jarry, M., Jaubert, J., Mourre, V., Turq, A., 2013. Quel Paléolithique ancien en Quercy? Paleo. supplément 4, 197-212.

Cologne, D., Mourre, V., 2009. Quartzite et quartzites: aspects petrographiques, economiques et technologiques des materiaux majoritaires du Paleolithique Ancien et Moyen du Sud-Ouest de la France, in: Grimaldi, S., Cura, S. (Eds.), Technological Analysis on Quartzite Exploitation. BAR International Series 1998, pp. 3-12.

Cunha, P.P., Martins, A.A., Buylaert, J.-P., Murray, A.S., Raposo, L., Mozzi, P., Stokes, M., 2017. New data on the chronology of the Vale do Forno sedimentary sequence (Lower Tejo River terrace staircase) and its relevance as a fluvial archive of the Middle Pleistocene in western Iberia. Quat. Sci. Rev. 166, 204-226. 10.1016/j.quascirev.2016.11.001

Cunha Ribeiro, J.-P., Monteiro-Rodrigues, S., Gomes, A., Méndez Quintas, E., Meireles, J., Pérez-González, A., Santonja, M., 2017. Ocupações Pleistocénicas na margem esquerda do Baixo Minho (Miño/Minho 2). Objetivos e primeiros resultados de um projeto transfronteiriço, in: VV.AA (Ed.), Arqueologia em Portugal / 2017-Estado da Questão. Associação dos Arqueólogos Portugueses, pp. 303-318.

de la Torre, I., 2004. Estrategias tecnológicas en el Pleistoceno inferior de África oriental (Olduvai y Peninj, norte de Tanzania), Departamento de Prehistoria. Universidad Complutense de Madrid, Madrid, p. 612.

Deino, A.L., Behrensmeyer, A.K., Brooks, A.S., Yellen, J.E., Sharp, W.D., Potts, R., 2018. Chronology of the Acheulean to Middle Stone Age transition in eastern Africa. Science. 
Demuro, M., Arnold, L., Parés, J.M., Sala, R., 2015. Extended-range luminescence chronologies suggest potentially complex bone accumulation histories at the Early-to-Middle Pleistocene palaeontological site of Huescar-1 (GuadixBaza basin, Spain). Quat. Int. 389, 191-212. 10.1016/j.quaint.2014.08.035

Demuro, M., Arnold, L.J., Parés, J.M., Pérez-González, A., Ortega, A.I., Arsuaga, J.L., Bermúdez de Castro, J.M., Carbonell, E., 2014. New Luminescence Ages for the Galería Complex Archaeological Site: Resolving Chronological Uncertainties on the Acheulean Record of the Sierra de Atapuerca, Northern Spain. PLOS ONE 9, e110169. 10.1371/journal.pone.0110169

Díez-Martín, F., Sánchez Yustos, P., Domínguez-Rodrigo, M., Prendergast, M., 2011. An experimental study of bipolar and freehand knapping of Naibor Soit quartz from Olduvai Gorge (Tanzania). Am. Antiq. 76, 690-708.

Diez-Martín, F., Sánchez Yustos, P., Uribelarrea, D., Baquedano, E., Mark, D.F., Mabulla, A., Fraile, C., Duque, J., Díaz, I., Pérez-González, A., Yravedra, J., Egeland, C.P., Organista, E., Domínguez-Rodrigo, M., 2015. The Origin of the Acheulean: The 1.7 Million-Year-Old Site of FLK West, Olduvai Gorge (Tanzania). Sci. Rep. 5, 17839. 10.1038/srep17839

Dinçer, B., 2016. The Lower Paleolithic in Turkey: Anatolia and Hominin Dispersals Out of Africa, in: Harvati, K., Roksandic, M. (Eds.), Paleoanthropology of the Balkans and Anatolia. Springer, pp. 213-228.

Duller, G.A., 2007. Assessing the error on equivalent dose estimates derived from single aliquot regenerative dose measurements. Ancient TL 25, 15-24.

Duval, M., Arnold, L.J., 2013. Field gamma dose-rate assessment in natural sedimentary contexts using $\mathrm{LaBr} 3(\mathrm{Ce})$ and $\mathrm{Nal}(\mathrm{TI})$ probes: A comparison between the "threshold" and "windows" techniques. Applied Radiation and Isotopes 74, 36-45. 10.1016/j.apradiso.2012.12.006

Duval, M., Arnold, L.J., Guilarte Moreno, V., Demuro, M., Santonja, M., Pérez-González, A., 2017. Electron spin resonance dating of optically bleached quartz grains from the Middle Palaeolithic site of Cuesta de la Bajada (Spain) using the multiple centres approach. Quaternary Geochronology 37, 82-96. 10.1016/j.quageo.2016.09.006

Duval, M., Guilarte Moreno, V., 2012. Assessing the influence of the cavity temperature on the ESR signal of the Aluminum center in quartz grains extracted from sediment. Ancient TL 30, 11-16.

Duval, M., Guilarte Moreno, V., 2015. ESR dosimetry of optically bleached quartz grains extracted from Plio-Quaternary sediment: Evaluating some key aspects of the ESR signals associated to the Ti-centers. Radiation Measurements 78 , 28-41. 10.1016/j.radmeas.2014.10.002

Duval, M., Guilarte Moreno, V., Campaña, I., Arnold, L., Miguens, L., Iglesias, J., González-Sierra, S., 2018. Quantifying hydrofluoric acid etching of quartz and feldspar coarse grains based on weight loss estimates: implication for ESR and luminescence dating studies. Ancient TL 36, 1-14. 
Duval, M., Voinchet, P., Arnold, L., Parés, J.M., Minnella, W., Guilarte Moreno, V., Demuro, M., Falgueres, C., Bahain, J., Despriee, J., Submitted. A multi-technique dating study sheds new light on the chronology of two Lower Palaeolithic sites of the Middle Loire Basin, France: Lunery-la Terre-des-Sablons and Brinay-la Noira. Quat. Int.

Faivre, J.P., Turq, A., Bourguignon, L., Cologne, D., Jarry, M., Jaubert, J., Bismuth, T., Demars, P.-Y., 2013. Le Paléolithique moyen du Quercy: comportements techno-économiques et variabilité des productions lithiques. Paleo, supplément 4, 231-270.

080

Falguères, C., Ghaleb, B., Tombret, O., Ben Arous, E., Richard, M., Moigne, A.M., Saos, T., Frouin, M., Caparros, M., Barroso-Ruiz, C., 2018. ESR/U-series dates on Equus teeth from the Middle Pleistocene Acheulean site of Cueva del Angel, Spain. Quaternary Geochronology. 10.1016/j.quageo.2018.02.003

Finkel, M., Barkai, R., 2018. The Acheulean Handaxe Technological Persistence: A Case of Preferred Cultural Conservatism? Proceedings of the Prehistoric Society, 1-19. 10.1017/ppr.2018.2

Forman, S.L., J., P., Lepper, K., 2000. Luminescence Geochronology, in: Sowers, J., Noller, J., Washington, L.W. (Eds.), Quaternary Geochronology: methods and applications. American Geophysical Union, pp. 157-176.

Galbraith, R.F., 2002. A note on the variance of a background-corrected OSL count. Ancient TL 20, 49-51.

Gallotti, R., 2016. The East African origin of the Western European Acheulean technology: Fact or paradigm? Quat. Int. 411, 9-24. 10.1016/j.quaint.2015.10.115

Gallotti, R., Peretto, C., 2015. The Lower/early Middle Pleistocene small débitage productions in Western Europe: New data from Isernia La Pineta t.3c (Upper Volturno Basin, Italy). Quat. Int. 357, 264-281. 10.1016/j.quaint.2014.06.055

Goren-Inbar, N., Alperson-Afil, N., Sharon, G., Herzlinger, G., 2018. The Acheulian Site of Gesher Benot Ya'aqov Vol IV: The Lithic Assemblages. Springer.

Goren-Inbar, N., Sharon, G., 2006. Invisible Handaxes and Visible Acheulian Biface Technology at Gesher Benot Ya'aqov, Israel, in: Goren-Inbar, N., Sharon, G. (Eds.), Axe Age: Acheulian Tool-making from Quarry to Discard, pp. 111-135.

Grün, R., 1994. A cautionary note: use of 'water content' and 'depth for cosmic ray dose rate' in AGE and DATA programs. Ancient TL 12, 50-51.

Guérin, G.M., N., Adamiec, G., 2011. Dose-rate conversion factors: update. Ancient TL 29, 5-8.

Hérisson, D., Brenet, M., Cliquet, D., Moncel, M.-H., Richter, J., Scott, B., Van Baelen, A., Di Modica, K., De Loecker, D., Ashton, N., Bourguignon, L., Delagnes, A., Faivre, J.-P., Folgado-Lopez, M., Locht, J.-L., Pope, M., Raynal, J.-P., Roebroeks, W., Santagata, C., Turq, A., Van Peer, P., 2016. The emergence of the Middle Palaeolithic in north-western Europe and its southern fringes. Quat. Int. 411, 233-283. 10.1016/j.quaint.2016.02.049 
Hernandez, M., Mercier, N., Bertran, P., Cologne, D., Leloulier, L.-A., 2012. Premiers éléments de datation des industries du Pléistocène moyen (Acheuléen - Paléolithique moyen ancien) de la région pyrénéo-garonnaise: une approche géochronologique pluri-méthodes (TL, OSL et TT-OSL) des sites de Duclos et Romentères. Paleo 23, 155170.

108

Hodgson, D., 2015. The symmetry of Acheulean handaxes and cognitive evolution. J. Archaeol. Sci.: Reports 2, 204208. 10.1016/j.jasrep.2015.02.002

Hopkinson, T., 2007. The transition from the Lower to the Middle Palaeolithic in Europe and the inmcorporation of difference. Antiquity 81, 294-307.

Huntley, D.J., Baril, M., 1997. The K content of the K-feldspars being measured in optical dating or in thermoluminescence dating. Ancient TI 15, 11-13.

Huntley, D.J., Hancock, R.G.V., 2001. The Rb contents of the K-feldspar grains being measured in optical dating. Ancient TL 19, 43-46.

Huntley, D.J., Lamothe, M., 2001. Ubiquity of anomalous fading in K-feldspars and the measurement and correction for it in optical dating. Canadian Journal of Earth Sciences 38, 1093-1106.

Inizan, M.-L., Reduron, M., Roche, H., Tixier, J., 1999. Technology and Terminology of Knapped Stone. Cercle de Recherches et d'Etudes Préhistoriques.

Jarry, M., 2010. Les groupes humains du Pléistocène moyen et supérieur en Midi toulousain: contextes, ressources et comportements entre Massif Central et Pyrénées. Université de Toulouse II - Le Mirail, p. 458.

Jaubert, J., Allard, M., Bahain, J., Bordes, J.G., Bourguignon, L., Brugal, J., Castel, J.-C., Chalard, P., Clottes, J., Couchoud, L., Ducasse, S., Faivre, J.P., Falguères, C., Fontugne, M., Guillermin, P., Jarry, M., Ladier, E., Langlais, M., Mourre, V., Oberlin, C., Quinif, Y., Renard, C., Turq, A., Valladas, H., 2013. Le Quercy pléistocène: région à peuplement continu depuis 0,3 Ma? Archéostratigraphies et datations radiométriques. Paleo, supplément 4, 67-106.

Kreutzer, S., Duval, M., Bartz, M., Bertran, P., Bosq, M., Eynaud, F., Verdin, F., Mercier, N., 2018. Deciphering longterm coastal dynamics using IR-RF and ESR dating: A case study from Médoc, south-West France. Quaternary Geochronology. 10.1016/j.quageo.2018.09.005

Lauer, T., Weiss, M., 2018. Timing of the Saalian- and Elsterian glacial cycles and the implications for Middle Pleistocene hominin presence in central Europe. Sci. Rep. 8, 5111. 10.1038/s41598-018-23541-w

Lepre, C.J., Roche, H., Kent, D.V., Harmand, S., Quinn, R.L., Brugal, J.-P., Texier, P.-J., Lenoble, A., Feibel, C.S., 2011. An earlier origin for the Acheulian. Nature 477, 82-85. 10.1038/nature10372 
Lycett, S.J., Schillinger, K., Eren, M.I., von Cramon-Taubadel, N., Mesoudi, A., 2016. Factors affecting Acheulean handaxe variation: Experimental insights, microevolutionary processes, and macroevolutionary outcomes. Quat. Int. 411, Part B, 386-401. 10.1016/j.quaint.2015.08.021

Mathias, C., 2018. Les phases anciennes du Paléolithique moyen dans le Sud-Est et le Sud-Ouest de la France: étude des systèmes techniques lithiques. Université de Perpignan.

McNabb, J., Cole, J., 2015. The mirror cracked: Symmetry and refinement in the Acheulean handaxe. J. Archaeol. Sci.: Reports 3, 100-111. 10.1016/j.jasrep.2015.06.004

Méndez-Quintas, E., 2007. El yacimiento achelense de As Gándaras de Budiño. La industria en facies fluviales. Complutum 18, 27-45.

Méndez-Quintas, E., 2008. La industria lítica de las facies coluviales del yacimiento achelense de As Gándaras de Budiño. EI Locus V en las excavaciones de Vidal Encinas. Zephyrus LXIII, 41-61.

Méndez-Quintas, E., Santonja, M., Pérez-González, A., Arnold, L., Cunha Ribeiro, J.-P., Demuro, M., Díaz-Rodríguez, M., Duval, M., Gomes, A., Meireles, J., Monteiro-Rodrigues, S., Serodio Domínguez, A., 2018a. El yacimiento achelense de As Gándaras de Budiño: Síntesis y perspectivas después de 50 años de desencuentros. Estudos do Quaternario 19, 1-22. 10.30893/eq.v0i19.182

Méndez-Quintas, E., Santonja, M., Perez-Gonzalez, A., Duval, M., Demuro, M., Arnold, L.J., 2018b. First evidence of an extensive Acheulean large cutting tool accumulation in Europe from Porto Maior (Galicia, Spain). Sci. Rep. 8, 3082. 10.1038/s41598-018-21320-1

Méndez Quintas, E., Pérez-González, A., Ledo Bernárdez, M., Serodio Domínguez, A., 2018c. La industria lítica del yacimiento achelense de Arbo (Pontevedra). Variables del paleolítico antiguo de Galicia en el contexto peninsular. Zephyrus LXXXII, 3-34. 10.14201/zephyrus201882334

Miall, A.D., 1996. The Geology of Fluvial Deposits. Sedimentary Facies, Basin Analysis, and Petroleum Geology. Springer, Berlin.

Moncel, M.-H., Arzarello, M., Boëda, É., Bonilauri, S., Chevrier, B., Gaillard, C., Forestier, H., Yinghua, L., Sémah, F., Zeitoun, V., 2018. The assemblages with bifacial tools in Eurasia (first part). What is going on in the West? Data on western and southern Europe and the Levant. Comptes Rendus Palevol 17, 45-60. 10.1016/j.crpv.2015.09.009

Moncel, M.-H., Ashton, N., Lamotte, A., Tuffreau, A., Cliquet, D., Despriée, J., 2015. The Early Acheulian of northwestern Europe. J. Anthropol. Archaeol. 40, 302-331. 10.1016/j.jaa.2015.09.005

Moncel, M.-H., Despriée, J., Voinchet, P., Tissoux, H., Moreno, D., Bahain, J.-J., Courcimault, G., Falguères, C., 2013. Early Evidence of Acheulean Settlement in Northwestern Europe - La Noira Site, a 700000 Year-Old Occupation in the Center of France. PLOS ONE 8, e75529. 10.1371/journal.pone.0075529 
Moncel, M.-H., Moigne, A.-M., Sam, Y., Combier, J., 2011. The Emergence of Neanderthal Technical Behavior: New

Moncel, M.-h., Schreve, D., 2016. The Acheulean in Europe: Origins, evolution and dispersal. Quat. Int. 411, 1-8. 10.1016/j.quaint.2016.08.039

Monnier, G.F., 2006. The Lower/Middle Paleolithic Periodization in Western Europe: An Evaluation. Current Anthropology 47, 709-744.

Mounier, A., Caparros, M., 2015. The phylogenetic status of Homo heidelbergensis - a cladistic study of Middle Pleistocene hominins. Bmsap 27, 110-134. 10.1007/s13219-015-0127-4

Mounier, A., Marchal, F., Condemi, S., 2009. Is Homo heidelbergensis a distinct species? New insight on the Mauer mandible. J. Hum. Evol. 56, 219-246. 10.1016/j.jhevol.2008.12.006

Mourre, V., 1996. Le débitage sur enclume au Paléolithique inférieur et moyen.Techniques, méthodes et schémas conceptuels, Département d'Ethnologie, Sociologie comparative et Préhistoire. Université de Paris X - Nanterre, Paris, p. 55.

Mourre, V., 2004. Le débitage sur enclume au Paléolithique moyen dans le Sud-Ouest de la France, in: Van Peer, P., Bonjean, D., Semal, P. (Eds.), Session 5: Paléolithique moyen. XIVème Congrès de l'UISPP. BAR S1239, Liège, 2-8 sept. 2001, pp. 29-38.

Mourre, V., Cologne, D., 2010. La question du débitage de grands éclats à l'acheuléen. Paleo 2009-2010, 35-48.

Naughton, F., Sánchez Goñi, M.F., Kageyama, M., Bard, E., Duprat, J., Cortijo, E., Desprat, S., Malaizé, B., Joly, C., Rostek, F., Turon, J.L., 2009. Wet to dry climatic trend in north-western Iberia within Heinrich events. Earth and Planetary Science Letters 284, 329-342. 10.1016/j.epsl.2009.05.001

Nicoud, E., 2013. What Does the Acheulean Consist of? The Example of Western Europe (MIS 16-9). Mitteilungen der Gesellschaft für Urgeschichte 22, 41-60.

Ollé, A., Mosquera, M., Rodríguez-Álvarez, X.P., García-Medrano, P., Barsky, D., de Lombera-Hermida, A., Carbonell, E., 2016. The Acheulean from Atapuerca: Three steps forward, one step back. Quat. Int. 411, 316-328. 10.1016/j.quaint.2016.01.042

Ollé, A., Mosquera, M., Rodríguez, X.P., de Lombera-Hermida, A., García-Antón, M.D., García-Medrano, P., Peña, L., Menéndez, L., Navazo, M., Terradillos, M., Bargalló, A., Márquez, B., Sala, R., Carbonell, E., 2013. The Early and Middle Pleistocene technological record from Sierra de Atapuerca (Burgos, Spain). Quat. Int. 295, 138-167. 10.1016/j.quaint.2011.11.009 
Pereira, A., Nomade, S., Voinchet, P., Bahain, J.J., Falguères, C., Garon, H., Lefèvre, D., Raynal, J.P., Scao, V., Piperno, M., 2015. The earliest securely dated hominin fossil in Italy and evidence of Acheulian occupation during glacial MIS 16 at Notarchirico (Venosa, Basilicata, Italy). Journal of Quaternary Science 30, 639-650. 10.1002/jqs.2809

Pope, M., 2002. The significance of biface-rich assemblages: An examination of behavioural controls on lithic assemblage formation in the Lower Palaeolithic., Department of Archaeology. University of Southampton, Southampton, p. 349.

Prescott, J.R., Hutton, J.T., 1988. Cosmic ray and gamma ray dosimetry for TL and ESR. Nuclear Tracks. Radiation Measurements 14, 223-227.

Prescott, J.R., Hutton, J.T., 1994. Cosmic ray contributions to dose rates for luminescence and ESR dating: Large depths and long-term time variations. Radiation Measurements 23, 497-500.

Querol, M.A., Santonja, M., 1979. El yacimiento achelense de Pinedo (Toledo). Excavaciones Arqueológicas en España 103.

Raposo, L., 1996. Quartzite bifaces and cleaver in the final acheulian assembalge of Milharós (Alpiarça, Portugal), in: Moloney, N., Raposo, L., Santonja, M. (Eds.), Non-Flint Stone Tools and the Palaeolithic Occupation of the Iberian Peninsula, pp. 151-165.

Raposo, L., Carreira, J.R., Salvador, M., 1985. A estação acheulense de Milharõs, Val de Forno, Alpiarça, I Reunião do Quaternário Ibérico, Lisboa 1985. Grupo de Trabalho Português para o Estudo do Quaternário e Grupo Español de Trabajo del Quaternario, pp. 41-60.

Readhead, M.L., 1987. Thermoluminescence dose rate and dating equations for the case of disequilibrium in the decay series. Nuclear Tracks and Radiation Measurements 13, 197-207.

Richter, J., 2015. The acheulean in Central Europe: Did it exist or not?, in: VV.AA (Ed.), Terra Amata Nice, AlpesMaritimes, France Tome IV: Les industries acheuleennes. CNRS, pp. 761-770.

Rightmire, G.P., 2008. Homo in the middle pleistocene: Hypodigms, variation, and species recognition. Evolutionary Anthropology 17, 8-21. 10.1002/evan.20160

Roberts, H.M., 2012. Testing Post-IR IRSL protocols for minimising fading in feldspars, using Alaskan loess with independent chronological control. Radiation Measurements 47, 716-724. 10.1016/j.radmeas.2012.03.022

Roberts, M.B., Parfitt, S.A., 1999. Boxgrove: a Middle Pleistocene hominid site at Eartham Quarry, Boxgrove, West Sussex. English Heritage, London.

Rocca, R., Abruzzese, C., Aureli, D., 2016. European Acheuleans: Critical perspectives from the East. Quat. Int. 411, 402-411. 10.1016/j.quaint.2016.01.025 
Rubio-Jara, S., Panera, J., Rodríguez-de-Tembleque, J., Santonja, M., Pérez-González, A., 2016. Large flake Acheulean in the middle of Tagus basin (Spain): Middle stretch of the river Tagus valley and lower stretches of the rivers Jarama and Manzanares valleys. Quat. Int. 411, 349-366. 10.1016/j.quaint.2015.12.023

Sánchez-Cervera, B., Santonja Gómez, M., Pérez-González, A., Domínguez-Rodrigo, M., Sánchez-Romero, L., 2015. La industria lítica del yacimiento achelense de Torralba (Soria, España). Colecciones marqués de Cerralbo y Howell. Trabajos de Prehistoria 72, 41-63. 10.3989/tp.2015.12143

Santonja, M., Pérez-González, A., 2010. Mid-Pleistocene Acheulean industrial complex in the Iberian Peninsula. Quat. Int. 223-224, 154-161. j.quaint.2010.02.010

Santonja, M., Pérez-González, A., Dominguez- Rodrigo, M., Panera Gallego, J., Rubio Jara, S., Sesé, C., Soto Rodriguez, E., Arnold, L., Duval, M., Demuro, M., Ortiz Menéndez, J.E., Torres, T., Mercier, N., Barba, R., Yravedra, J., 2014. The Middle Paleolithic site of Cuesta de la Bajada (Teruel, Spain): a perspective on the Acheulean and Middle Paleolithic technocomplexes in Europe. J. Archaeol. Sci. 49, 556-571. 10.1016/j.jas.2014.06.003

Santonja, M., Pérez-González, A., Panera, J., Rubio-Jara, S., Méndez-Quintas, E., 2016. The coexistence of Acheulean and Ancient Middle Palaeolithic techno-complexes in the Middle Pleistocene of the Iberian Peninsula. Quat. Int. 411, 367-377. 10.1016/j.quaint.2015.04.056

Santonja, M., Perez Gonzalez, A., 1984. Las industrias paleolíticas de la Maya I en su ámbito regional. Excavaciones Arqueológicas en España 135.

Santonja, M., Pérez González, A., 2004. Geoarqueología del yacimiento achelense de El Basalito (Castraz de Yeltes, Salamanca). Discusión acerca de su naturaleza y significado. Zona Arqueológica 4, 472-483.

Santonja, M., Rubio Jara, S., Panera, J., Sánchez-Romero, L., Tarriño, A., Pérez-González, A., 2017. Ambrona revisited: The Acheulean lithic industry of the Lower Stratigraphic Complex. Quat. Int. 480, 95-117. 10.1016/j.quaint.2017.01.021

Santonja, M., Villa, P., 2006. The Acheulean in Southwestern Europe, in: Goren-Inbar, N., Sharon, G. (Eds.), Axe Age. Acheulian Tool-making from Quarry to Discard. Equinox Publishers, pp. 429-478.

Schumm, S.A., 1977. The fluvial system. Wiley Interscience, New York.

Scott, B., Ashton, N., 2011. The Early Middle Palaeolithic: The European Context, in: Nick Ashton, S.G.L., Chris, S. (Eds.), Developments in Quaternary Sciences. Elsevier, pp. 91-112.

Sharon, G., 2007. Acheulian Large Flake Industries: Technology, Chronology, and Significance. BAR International Series 1701. 
Sharon, G., 2011. Flakes Crossing the Straits? Entame Flakes and Northern Africa-lberia contact during the Acheulean. Afr. Archaeol. Rev., 1-16. 10.1007/s10437-011-9087-3

Sharon, G., Barsky, D., 2016. The emergence of the Acheulian in Europe - A look from the east. Quat. Int. 411, 25-33. 10.1016/j.quaint.2015.11.108

Shipton, C., Clarkson, C., 2015. Flake scar density and handaxe reduction intensity. J. Archaeol. Sci.: Reports. 10.1016/j.jasrep.2015.01.013

Soriano, S., Villa, P., 2017. Early Levallois and the beginning of the Middle Paleolithic in central Italy. PLoS One 12, e0186082. 10.1371/journal.pone.0186082

Stringer, C., 2012. The status of Homo heidelbergensis (Schoetensack 1908). Evolutionary Anthropology 21, 101-107. 10.1002/evan.21311

Taşkıran, H., 2018. The distribution of Acheulean culture and its possible routes in Turkey. Comptes Rendus Palevol 17, 99-106. 10.1016/j.crpv.2016.12.005

Thiel, C., Buylaert, J.-P., Murray, A., Terhorst, B., Hofer, I., Tsukamoto, S., Frechen, M., 2011. Luminescence dating of the Stratzing loess profile (Austria) - Testing the potential of an elevated temperature post-IR IRSL protocol. Quat. Int. 234, 23-31. 10.1016/j.quaint.2010.05.018

Thomsen, K.J., Murray, A.S., Jain, M., Bøtter-Jensen, L., 2008. Laboratory fading rates of various luminescence signals from feldspar-rich sediment extracts. Radiation Measurements 43, 1474-1486.

Tixier, J., 1956. Le hachereau dans l'Acheuléen nord-africain. Notes typologiques, XVe session du Congrès préhistorique de France, Poitiers-Angoulême, pp. 914-923.

Tixier, J., Turq, A., 1999. Kombewa et alii. Paléo 11, 135-143.

Toyoda, S., Falgueres, C., 2003. The method to represent the ESR signal intensity of the aluminium hole center in quartz for the purpose of dating. Advances in ESR Applications 20, 7-10.

Toyoda, S., Voinchet, P., Falguères, C., Dolo, J.M., Laurent, M., 2000. Bleaching of ESR signals by the sunlight: a laboratory experiment for establishing the ESR dating of sediments. Applied Radiation and Isotopes 52, 1357-1362.

Tuffreau, A., Lamotte, A., Goval, E., 2008. Les industries acheuléennes de la France septentrionale. L'Anthropologie 112, 104-139. 10.1016/j.anthro.2008.01.003

Turq, A., 2000. Le Paleolithique Inferieur et Moyen entre Dordogne et Lot. Paléo. Supplément 2, 456. 
Turq, A., Brenet, M., Colonge, D., Jarry, M., Lelouvier, L.-A., O'Farrell, M., Jaubert, J., 2010. The first human occupations in southwestern France: A revised summary twenty years after the Abbeville/Saint Riquier colloquium. Quat. Int. 223224, 383-398.

Valensi, P., Michel, V., El Guennouni, K., Liouville, M., 2013. New data on human behavior from a 160,000 year old Acheulean occupation level at Lazaret cave, south-east France: An archaeozoological approach. Quat. Int. 316, 123139. 10.1016/j.quaint.2013.10.034

Vallverdu, J., Saladie, P., Rosas, A., Huguet, R., Caceres, I., Mosquera, M., Garcia-Tabernero, A., Estalrrich, A., Lozano-Fernandez, I., Pineda-Alcala, A., Carrancho, A., Villalain, J.J., Bourles, D., Braucher, R., Lebatard, A., Vilalta, J., Esteban-Nadal, M., Bennasar, M.L., Bastir, M., Lopez-Polin, L., Olle, A., Verges, J.M., Ros-Montoya, S., MartinezNavarro, B., Garcia, A., Martinell, J., Exposito, I., Burjachs, F., Agusti, J., Carbonell, E., 2014. Age and date for early arrival of the Acheulian in Europe (Barranc de la Boella, la Canonja, Spain). PLoS One 9, e103634. 10.1371/journal.pone.0103634

Vasiliniuc, Ş., Vandenberghe, D.A.G., Timar-Gabor, A., Panaiotu, C., Cosma, C., van den Haute, P., 2012. Testing the potential of elevated temperature post-IR IRSL signals for dating Romanian loess. Quaternary Geochronology 10, 7580. 10.1016/j.quageo.2012.02.014

Vialet, A., Modesto-Mata, M., Martinon-Torres, M., Martinez de Pinillos, M., Bermudez de Castro, J.M., 2018. A reassessment of the Montmaurin-La Niche mandible (Haute Garonne, France) in the context of European Pleistocene human evolution. PLoS One 13, e0189714. 10.1371/journal.pone.0189714

Viana, A., 1930. Estações Paleolíticas do Alto Minho. Portucale III, 5-51.

Villa, P., Soriano, S., Grün, R., Marra, F., Nomade, S., Pereira, A., Boschian, G., Pollarolo, L., Fang, F., Bahain, J.-J., 2016a. The Acheulian and Early Middle Paleolithic in Latium (Italy): Stability and Innovation. PLoS ONE 11, e0160516. 10.1371/journal.pone.0160516

Villa, V., Pereira, A., Chaussé, C., Nomade, S., Giaccio, B., Limondin-Lozouet, N., Fusco, F., Regattieri, E., Degeai, J.P., Robert, V., Kuzucuoglu, C., Boschian, G., Agostini, S., Aureli, D., Pagli, M., Bahain, J.J., Nicoud, E., 2016b. A MIS 15-MIS 12 record of environmental changes and Lower Palaeolithic occupation from Valle Giumentina, central Italy. Quat. Sci. Rev. 151, 160-184. 10.1016/j.quascirev.2016.09.006

Viveen, W., Braucher, R., Bourlès, D., Schoorl, J.M., Veldkamp, A., van Balen, R.T., Wallinga, J., Fernandez-Mosquera, D., Vidal-Romani, J.R., Sanjurjo-Sanchez, J., 2012. A 0.65Ma chronology and incision rate assessment of the NW Iberian Miño River terraces based on 10Be and luminescence dating. Global and Planetary Change 94-95, 82-100. 10.1016/j.gloplacha.2012.07.001

Voinchet, P., Moreno, D., Bahain, J.-J., Tissoux, H., Tombret, O., Falguères, C., Moncel, M.-H., Schreve, D., Candy, I., Antoine, P., Ashton, N., Beamish, M., Cliquet, D., Despriée, J., Lewis, S., Limondin-Lozouet, N., Locht, J.-L., Parfitt, S., Pope, M., 2015. New chronological data (ESR and ESR/U-series) for the earliest Acheulian sites of north-western Europe. Journal of Quaternary Science 30, 610-622. 10.1002/jqs.2814 
315 Wang, X.L., Wintle, A.G., 2013. Investigating the contribution of recuperated TL to post-IR IRSL signals in a perthitic 316 feldspar. Radiation Measurements 49, 82-87.

317 White, M., Ashton, N., Scott, B., 2011. The Emergence, Diversity and Significance of Mode 3 (Prepared Core)

318 Technologies, in: Nick Ashton, S.G.L., Chris, S. (Eds.), Developments in Quaternary Sciences. Elsevier, pp. 53-65.

319 Wynn, T., Gowlett, J., 2018. The handaxe reconsidered. Evolutionary Anthropology 27, 21-29. 10.1002/evan.21552 


\section{Table and figure captions}

Table 1. Environmental dose rates obtained for the 90-125 $\mu \mathrm{m}$ K-feldspar grains at Arbo, Spain.

Table 2. Results obtained from high resolution gamma-ray spectrometry (HRGS) measurements of ${ }^{40} \mathrm{~K}$, and the ${ }^{238} \mathrm{U}$ and ${ }^{232} \mathrm{Th}$ decay chains of the three luminescence dating samples from Arbo (Spain). Values shown are the specific radionuclide activities (Bq kg-1) and daughter-to-parent ratios.

Table 3. Single-aliquot regenerative-dose (SAR) protocol used in this study to measure the pIR-IR225 and pIR-IR290 dose recovery test and De values for multi-grain aliquots of K-feldspars. A test dose of $50 \mathrm{~Gy}$ was used when measuring samples OC16-1 and OC16-2.

Table 4. Dose recovery test results for the pIR-IR 225 and pIR-IR 290 signals of samples OC16-2 and OC16-3 from Arbo.

Table 5. Residual equivalent dose values $\left(D_{e}\right)$ for the pIR-IR ${ }_{290}$ signal of samples exposed to prolonged sunlight.

Table 6. $D_{e}$ summary statistics, fading rates and final ages obtained for the Arbo luminescence dating samples. Data shown is for the pIR-IR 290 signal measured on 160-grain aliquots containing 90-125 $\mu \mathrm{m}$ K-feldspar grains.

Table 7. ESR data derived from the measurement of the Al centre. Repeatability of the ESR intensities was assessed through the variation of the mean ESR intensity obtained after each day of measurement $(n=3)$. Similarly, the repeatability of the $D E$ values corresponds to the variability of the $D E$ values calculated for each day of measurement $(n=3)$. The DE values derived from the SSE function are provided for comparison only in Fig. 7.

Table 8. ESR data derived from the measurement of the Ti-Li \& Ti-H centres. DE values were obtained by fitting a Ti-2 function (data weighting by $1 / \mathrm{s}^{2}$ ). In parenthesis, fitting results derived from the SSE function (see Fig. 7).

Table 9. Comparison of the radionuclide contents measured by ICP and HRGS. To facilitate comparison, concentrations obtained by ICP-MS measurements have been converted into activities values, except for K- 40 .

Table 10. Comparison of the gamma dose rate values derived from in situ and laboratory analyses. Laboratory values were obtained from the measured water content values, and by either assuming equilibrium (full series conversion factors form Guérin et al., 2011) or considering the observed disequilibrium in the U-238 decay chain (pre-Rn conversions factors).

Table 11. ESR dating results calculated for samples VI1201 \& VI1202. $\left({ }^{*}\right)$ : Results derived from the use of a SSE function.

Table 12. Main technological groups in the lithic assemblages of levels OC1 and OC2.

Table 13. Size ( $\mathrm{mm}$ ) and weight $(\mathrm{g})$ of unmodified pebbles, hammerstones and tested pebbles in levels OC1 and OC2.

Table 14. Size ( $\mathrm{mm}$ ) and weight $(\mathrm{g})$ of whole flakes and retouched flake tools in levels OC1 and OC2.

Fig. 1. Location and geomorphology of the Arbo site, which sits on bedrock terrace T7 (+65-77 $\mathrm{m})$ in the Miño river basin. Another nearby acheulean sites mentioned in the text 1: Porto Maior; 2: As Gándaras de Budiño.

Fig. 2. Stratigraphic profile, geometric level relationships and location of geochronology samples at the Arbo site, Miño river basin.

Fig. 3. Stratigraphic logs for the northern and southern sectors of the Arbo site. Facies description based on Miall (1996) and color recognition by Munsell Soil Color Chart.

Fig. 4. Plan-view excavation photographs for level OC1 (A-C) and OC2 (D-F), showing the extensive in situ lithic accumulations preserved at the Arbo site.

Fig. 5. (A) Standardised sensitivity-corrected dose-response curve and (B) pIR-IR 290 decay curves obtained for a 160grain aliquot containing K-feldspar grains of sample OC16-3 that passed the SAR quality assurance criteria. 
Fig. 6. Radial plots showing 160-grain aliquot De values obtained for the Arbo K-feldspar samples using the pIR-IR 290 protocol. The grey shaded band in each plot is centred on the weighted mean (CAM) $D_{e}$ estimate.

Fig. 7. ESR DRCs obtained from the measurements of the Al and Ti centres. ESR intensities correspond to average values and associated standard deviations derived from the repeated measurements.

Fig. 8. Spatial distribution (A) and artefact density (B) for the lithic industry and natural clasts found in levels OC1 and OC2.

Fig. 9. Examples of cores from level OC1 and OC2. 1-7: monopolar cores. 8-9: peripheral cores. 10-12: discoidal cores. 13: kombewa core. 14: bipolar on anvil core. Artefacts 7, 12 and 14 are made from quartz, the remainder of pieces are made from quartzite (drawing by E. Méndez-Quintas).

Fig. 10. Examples of flake tools from levels OC1 and OC2. 1-5,7: scrapers. 6, 8-9, 11,13: denticulate. 10: Tayac point. 12: retouch notch. Artefacts 1, 4-6 and 10 are made from quartz, the remainder of artefacts are made from quartzite (drawing by E. Méndez-Quintas).

Fig. 11. Well-shaped quartzite handaxes from levels OC1 and OC2. All pieces show final retouch with soft-hammer (drawing by E. Méndez-Quintas).

Fig. 12. Cleavers (1-2) and trihedral pick (3) on quartzite from levels OC1 and OC2 with partial retouch by soft-hammer (drawing by E. Méndez-Quintas).

Fig. 13. Comparison of stone tool densities at European Acheulean sites (data and references summarised from 


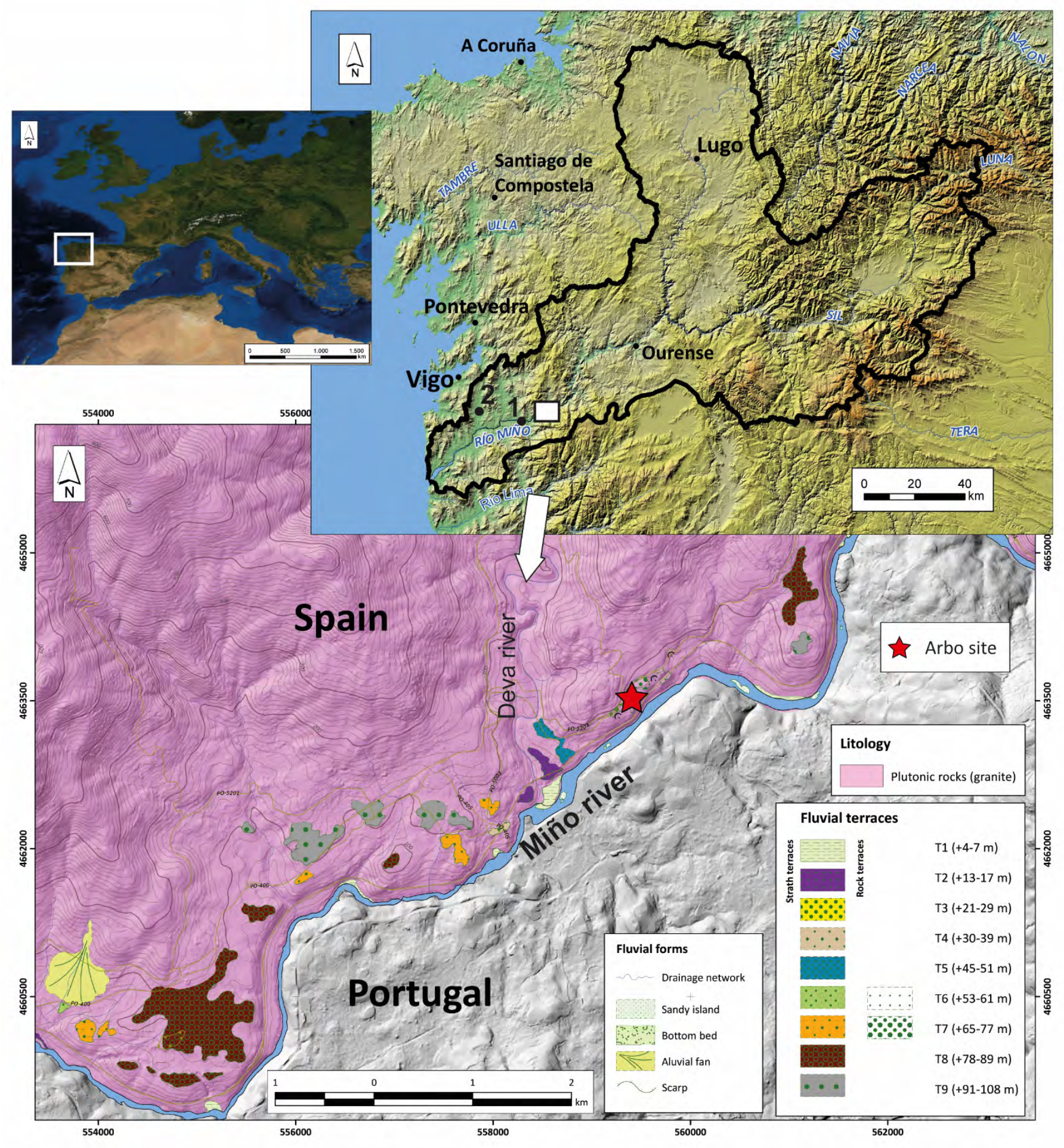

Fig. 1. 


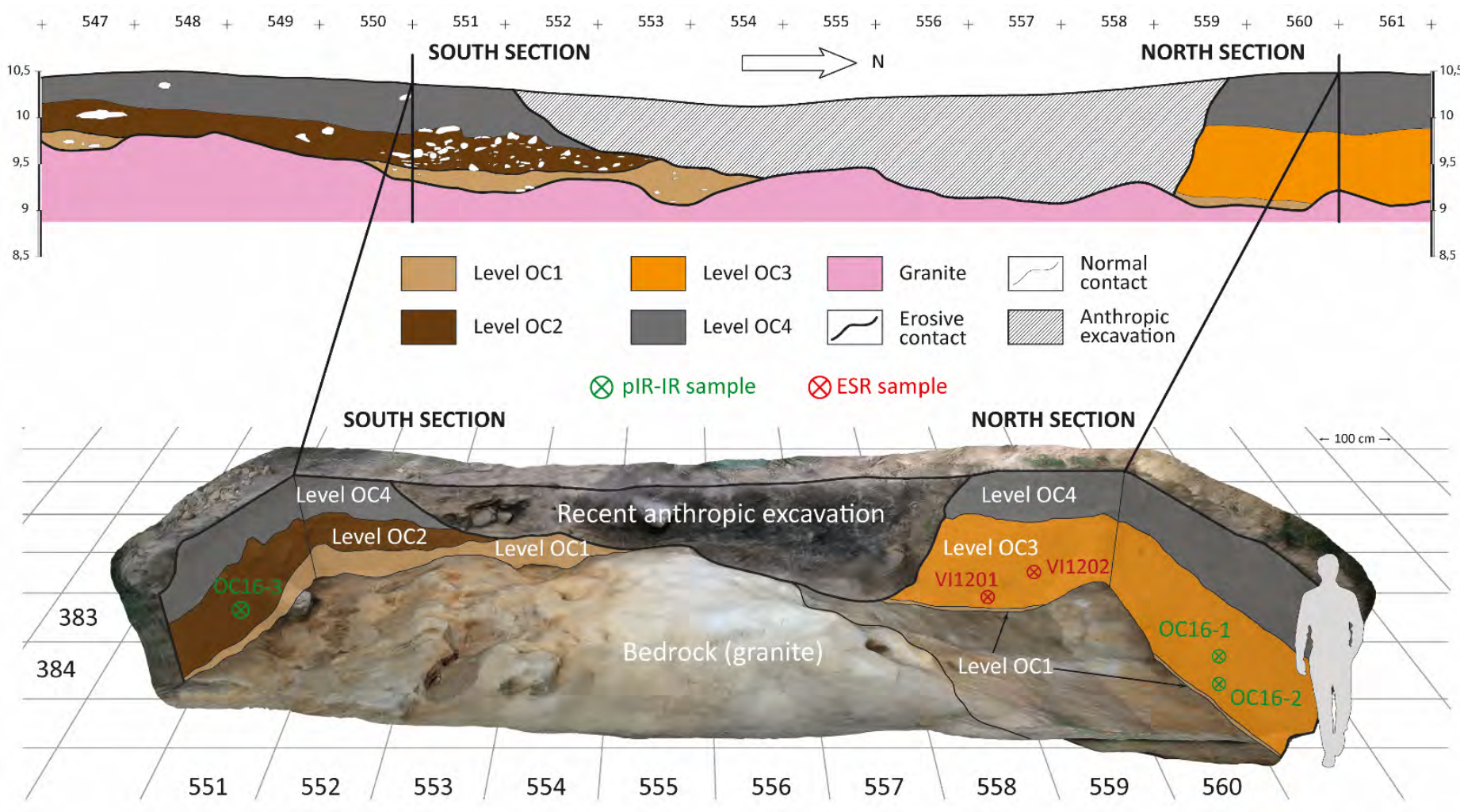

Fig. 2. 
LOG NORTH AREA
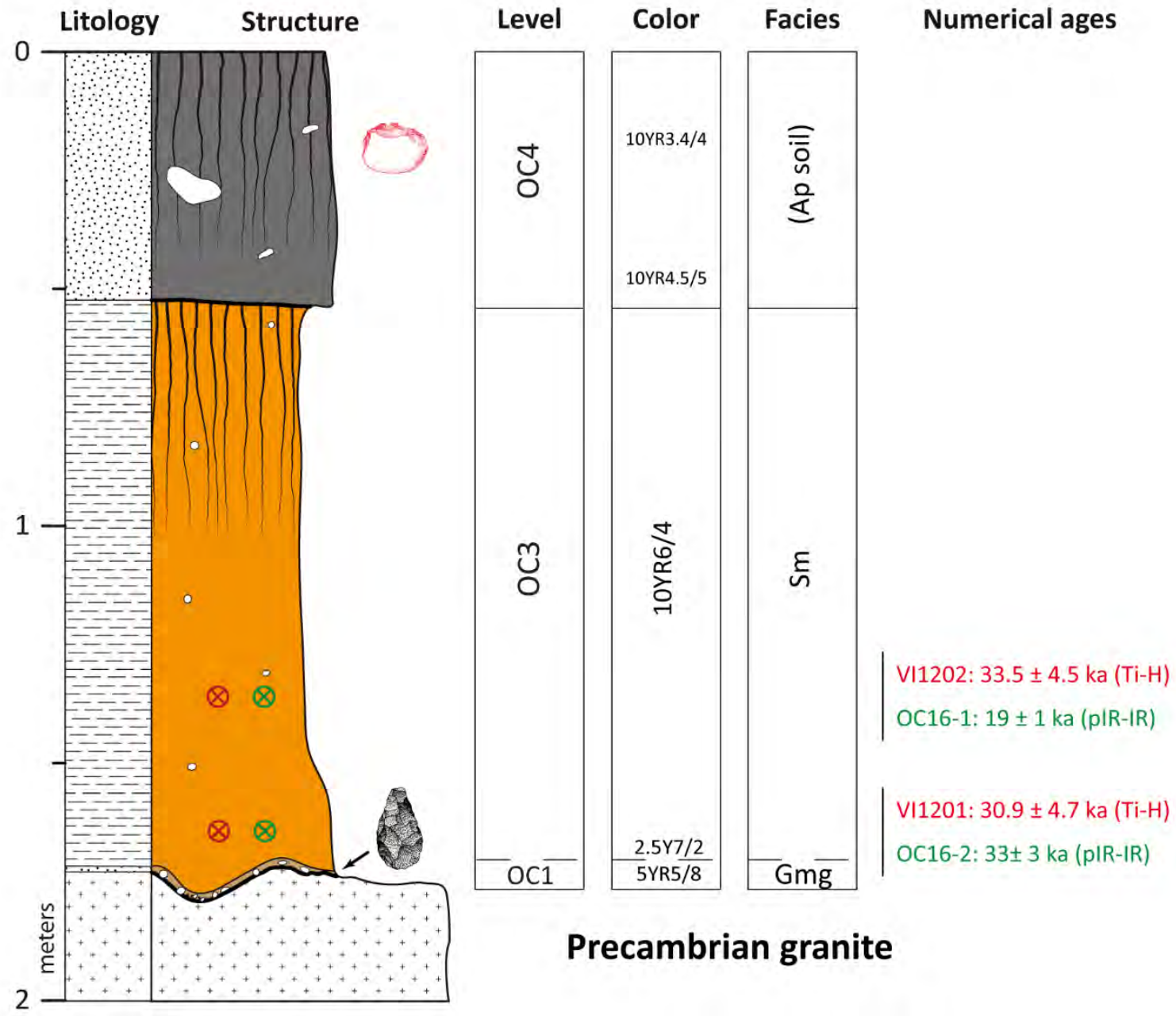

\section{Precambrian granite}

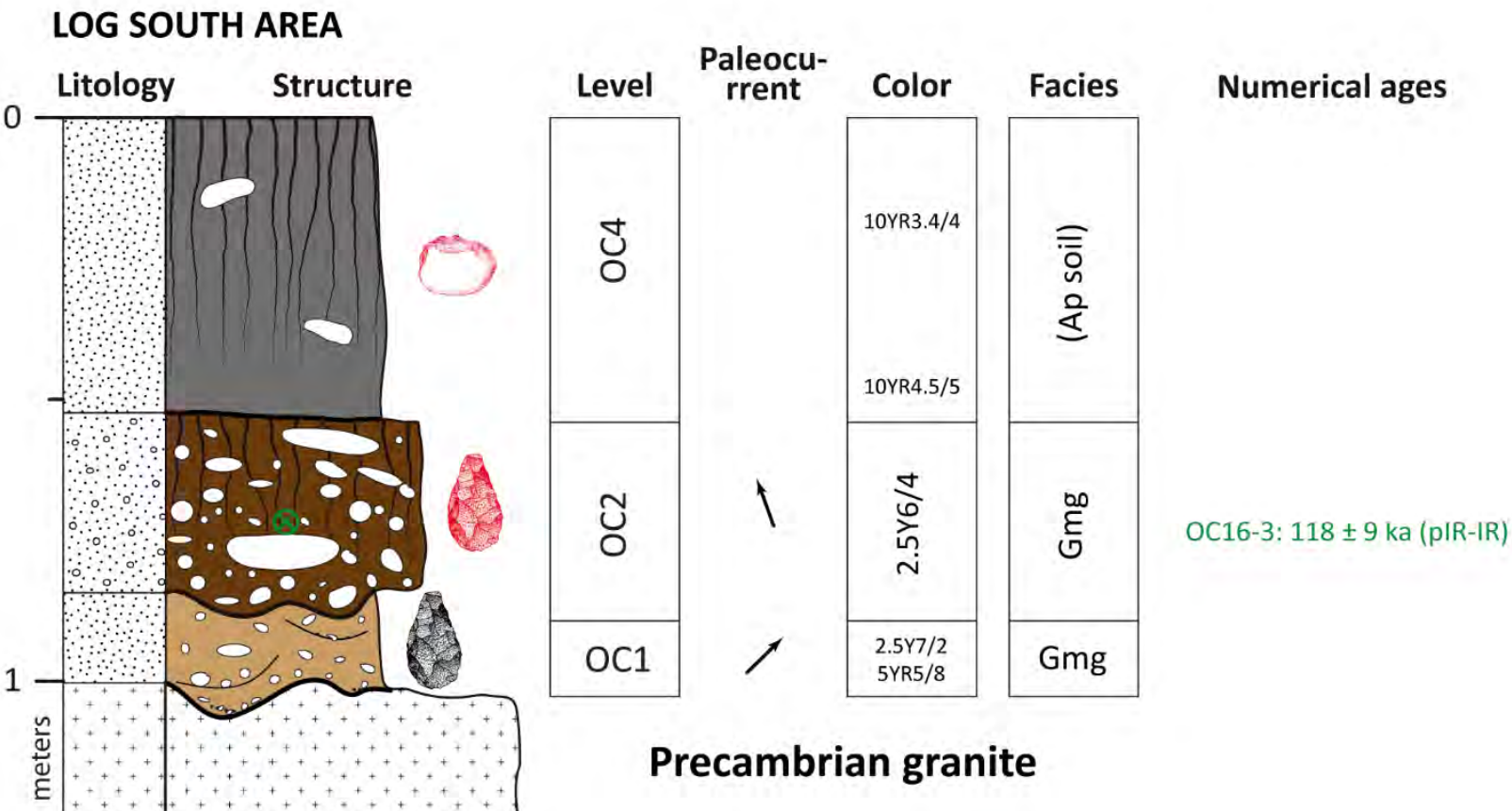

\begin{tabular}{|c|c|c|c|c|c|c|c|}
\hline$\ldots$ & Massive sands & $=$ & $\begin{array}{l}\text { Massive mud } \\
\text { fine sand }\end{array}$ & $\because \because 0$ & Clast & & $\begin{array}{l}\text { Acheulean industry } \\
\text { minor disturbance/major disturbance }\end{array}$ \\
\hline$\because \because$ & $\begin{array}{l}\text { Clast matrix- } \\
\text { supported }\end{array}$ & & Soil process & 3 & $\begin{array}{l}\text { Reworked } \\
\text { industry }\end{array}$ & $\otimes / 8$ & $\begin{array}{l}\text { ESR / luminescence } \\
\text { samples }\end{array}$ \\
\hline
\end{tabular}

Fig. 3. 

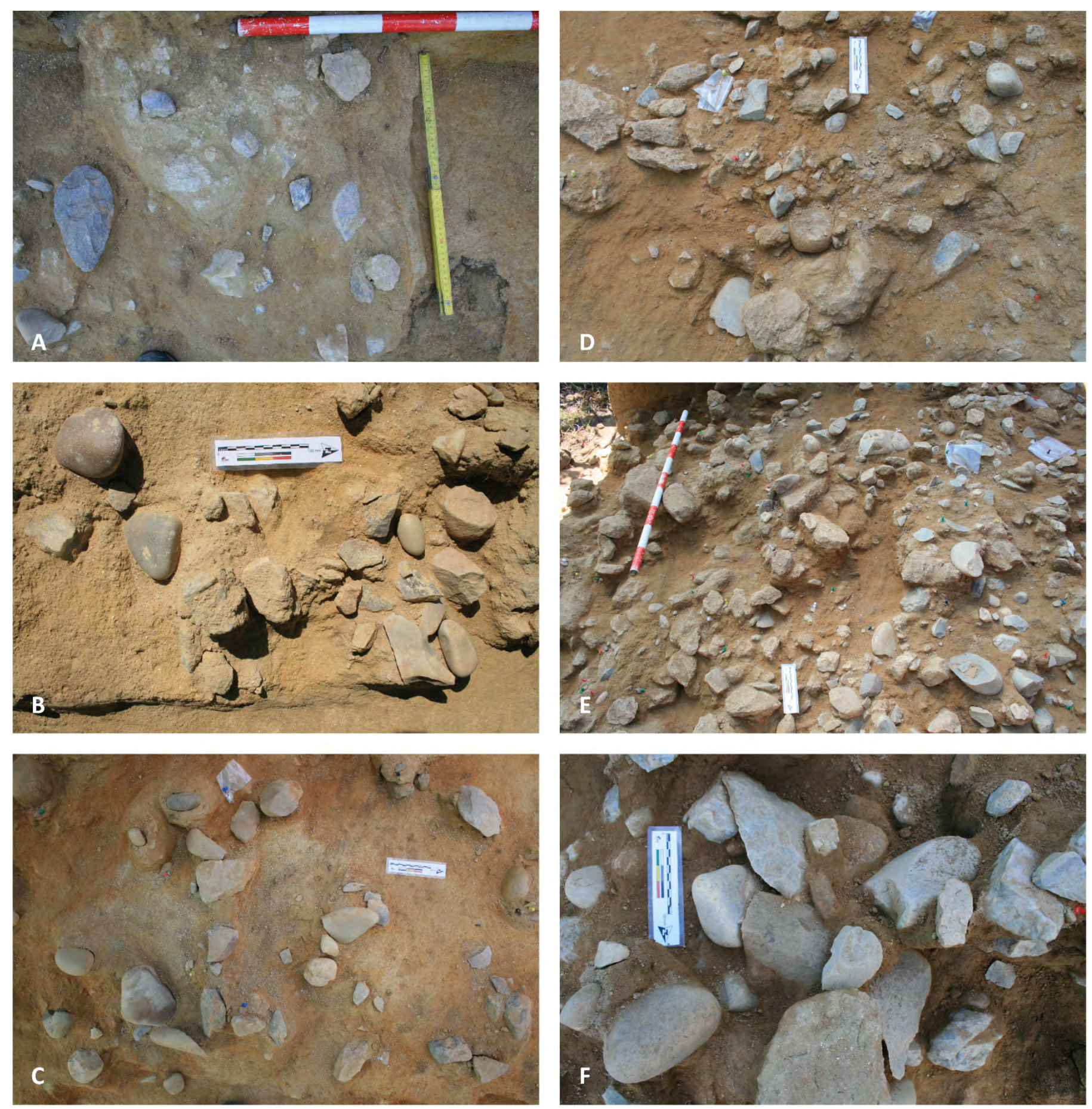

Fig. 4. 

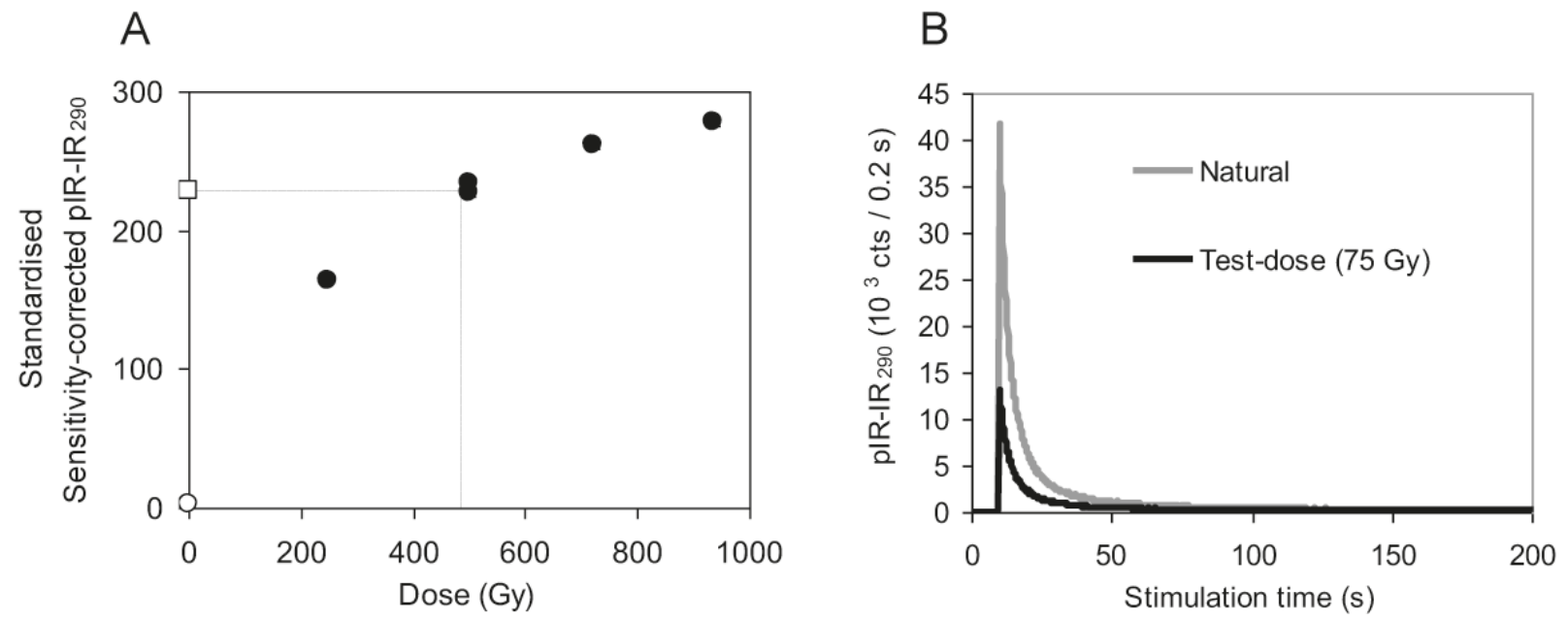

Fig. 5 . 

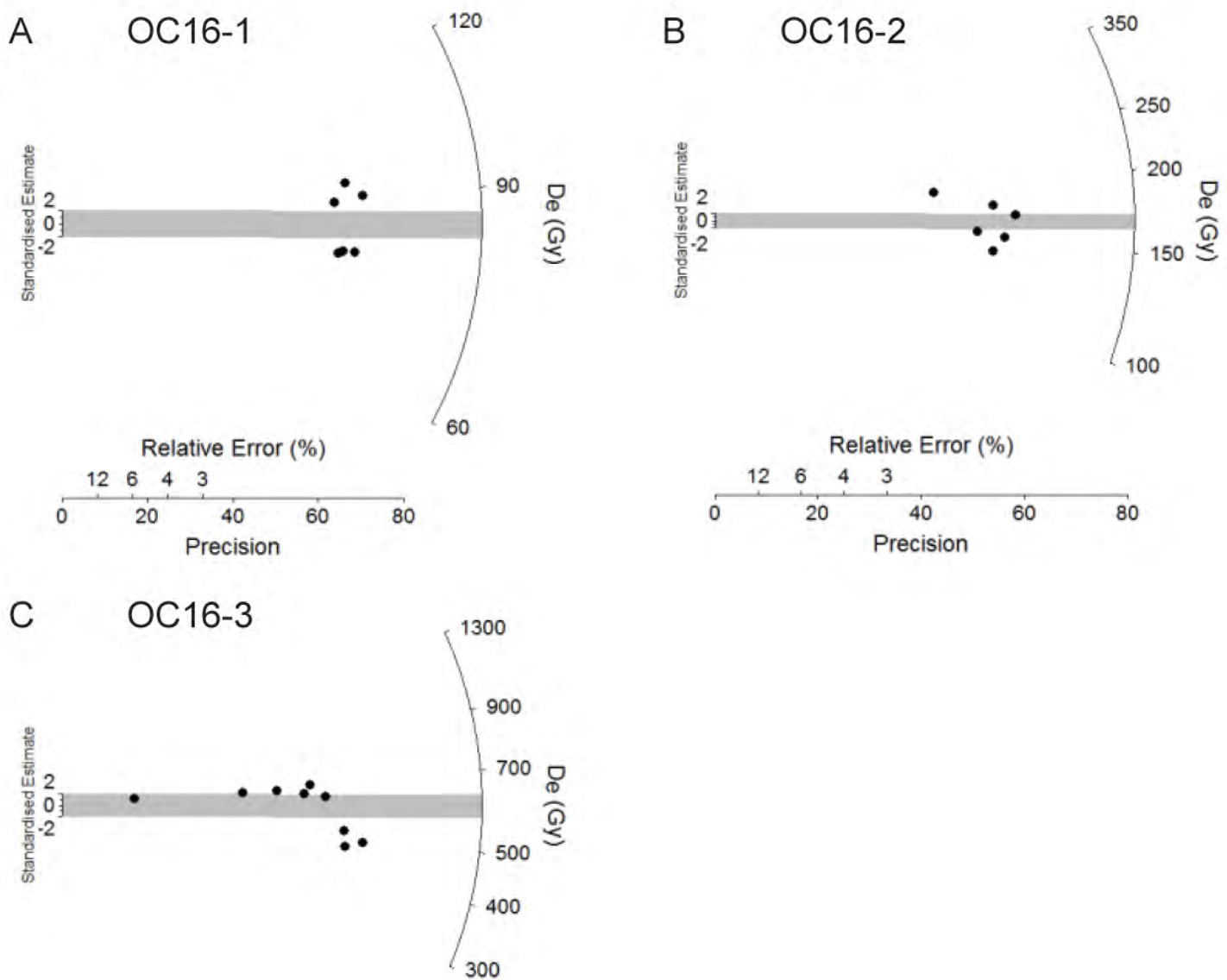

Relative Error (\%)

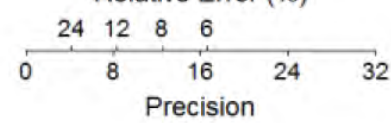

Fig. 6. 

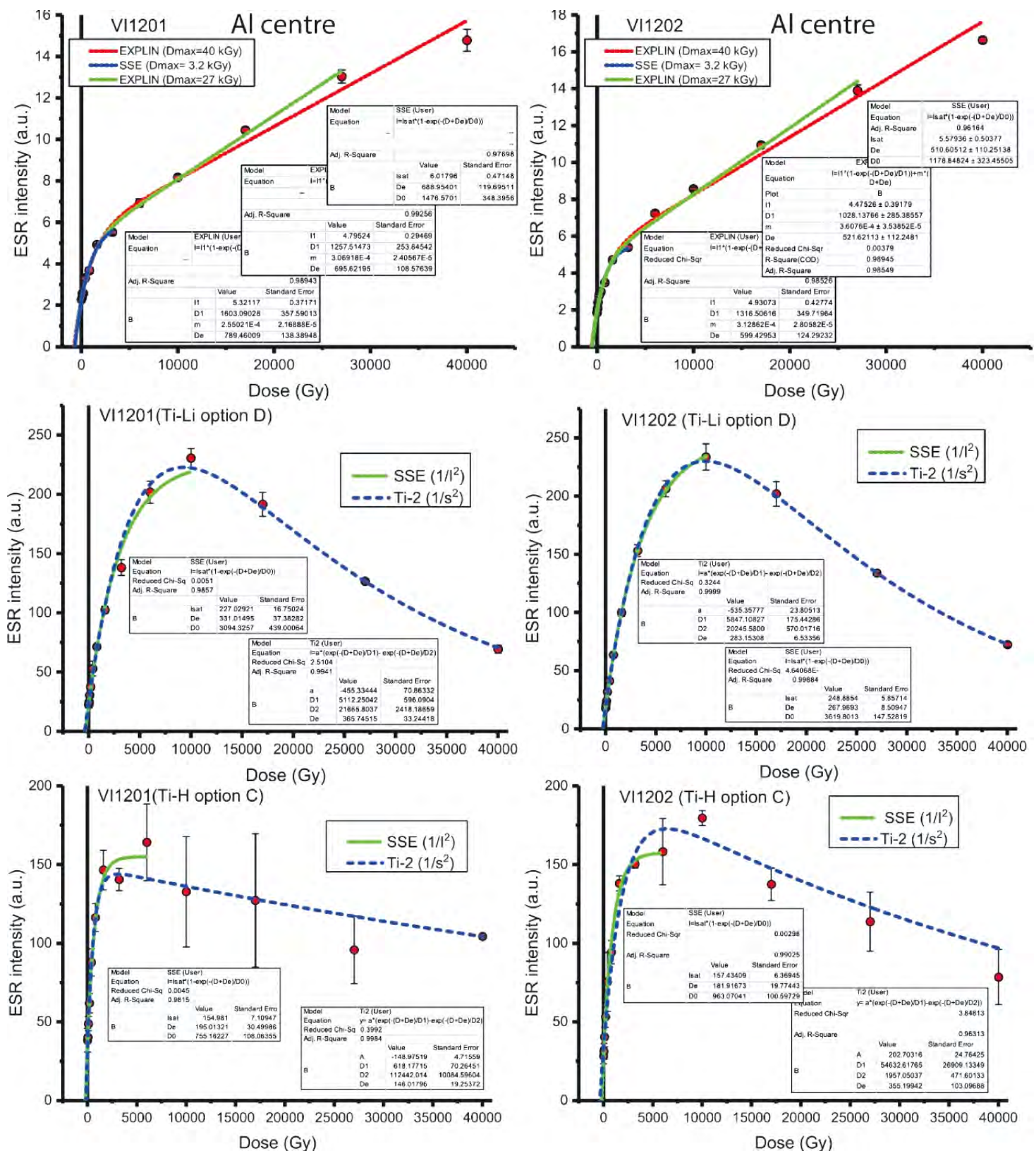

Fig. 7. 

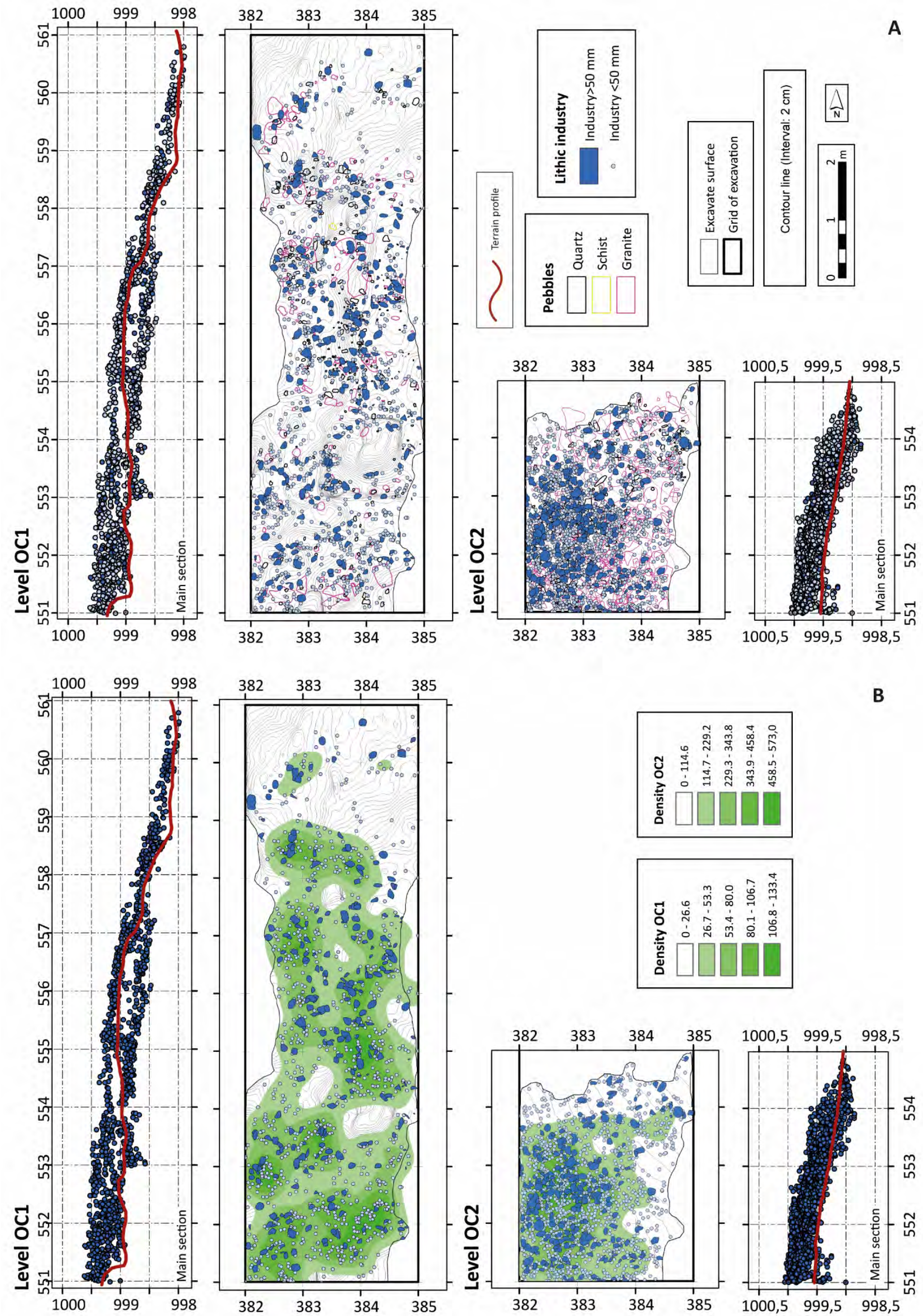

B
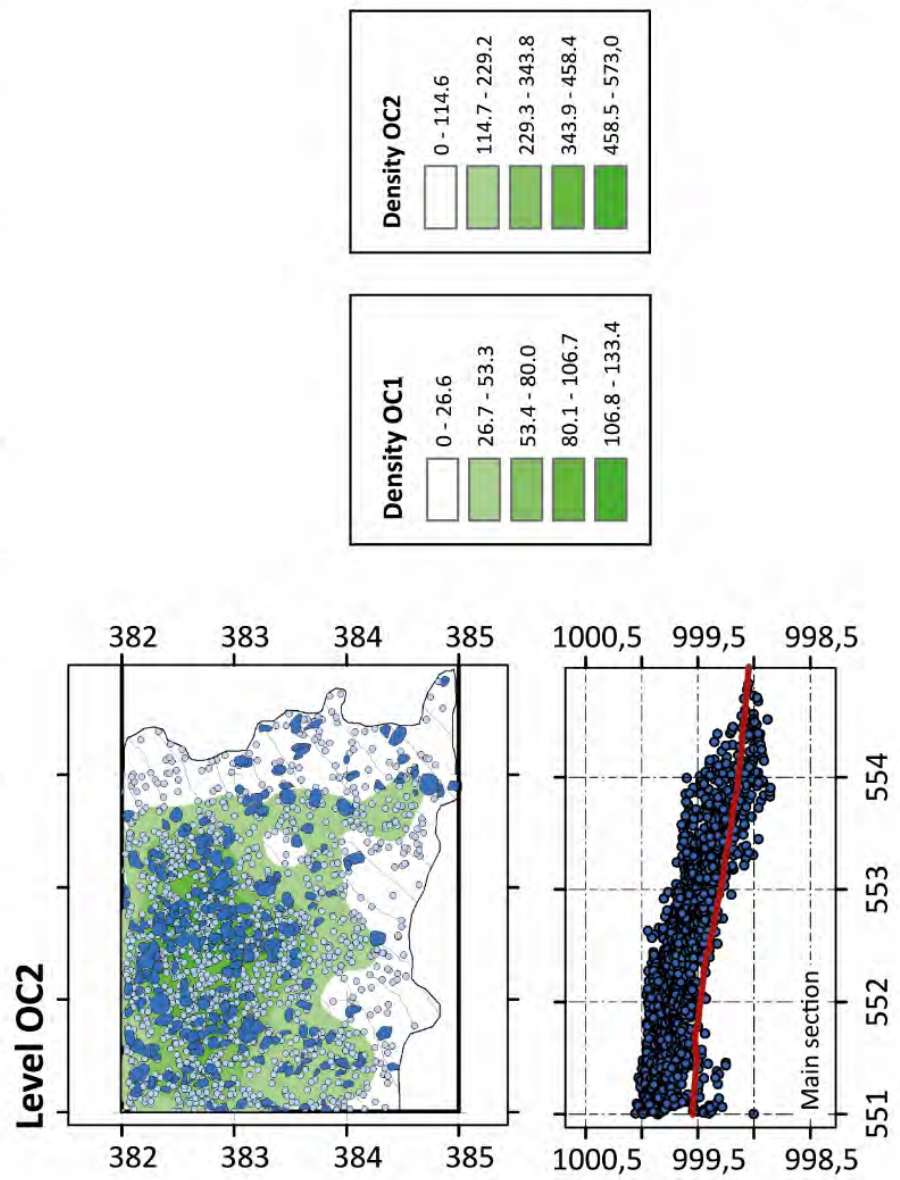

Fig. 8. 

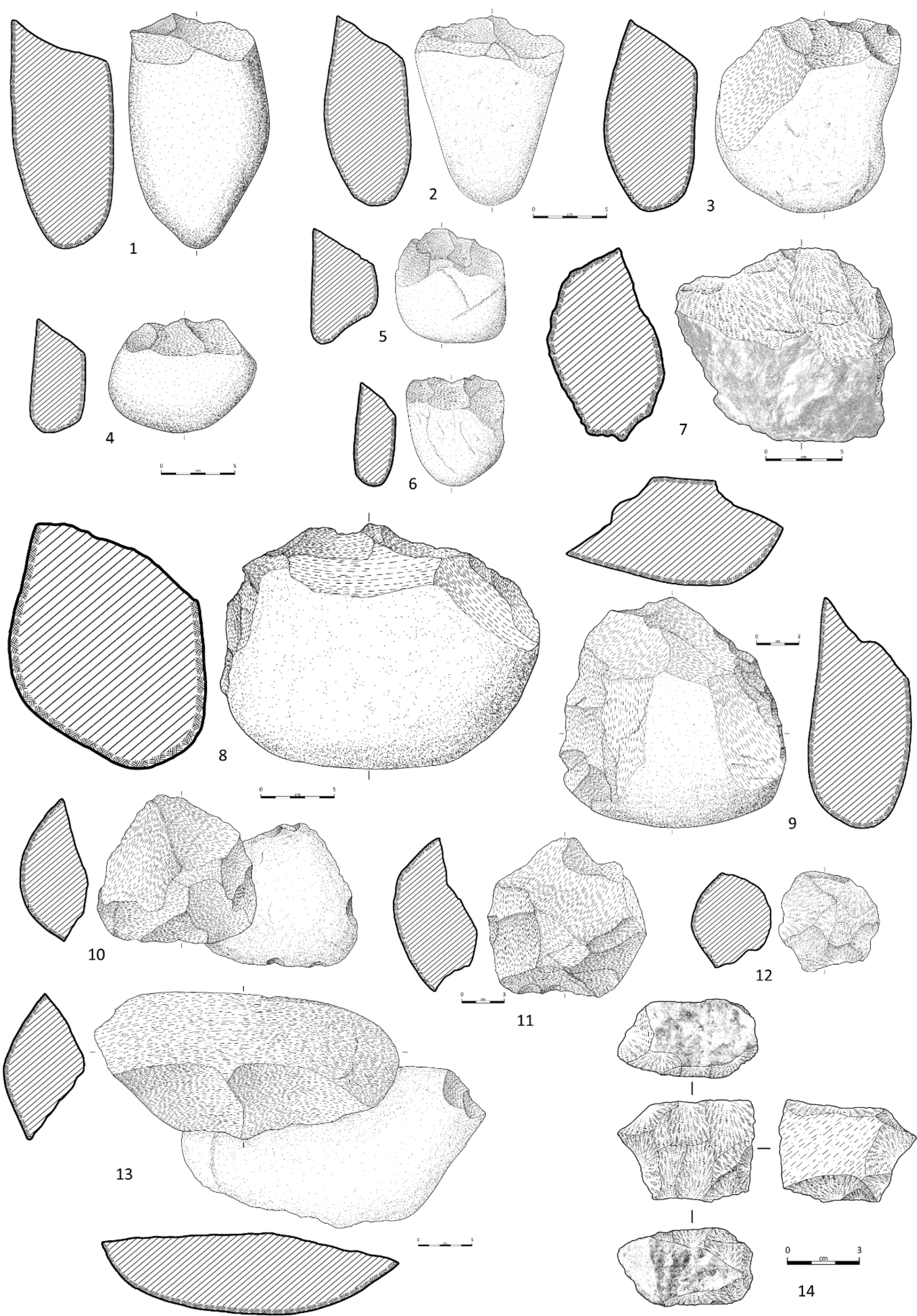

Fig. 9. 

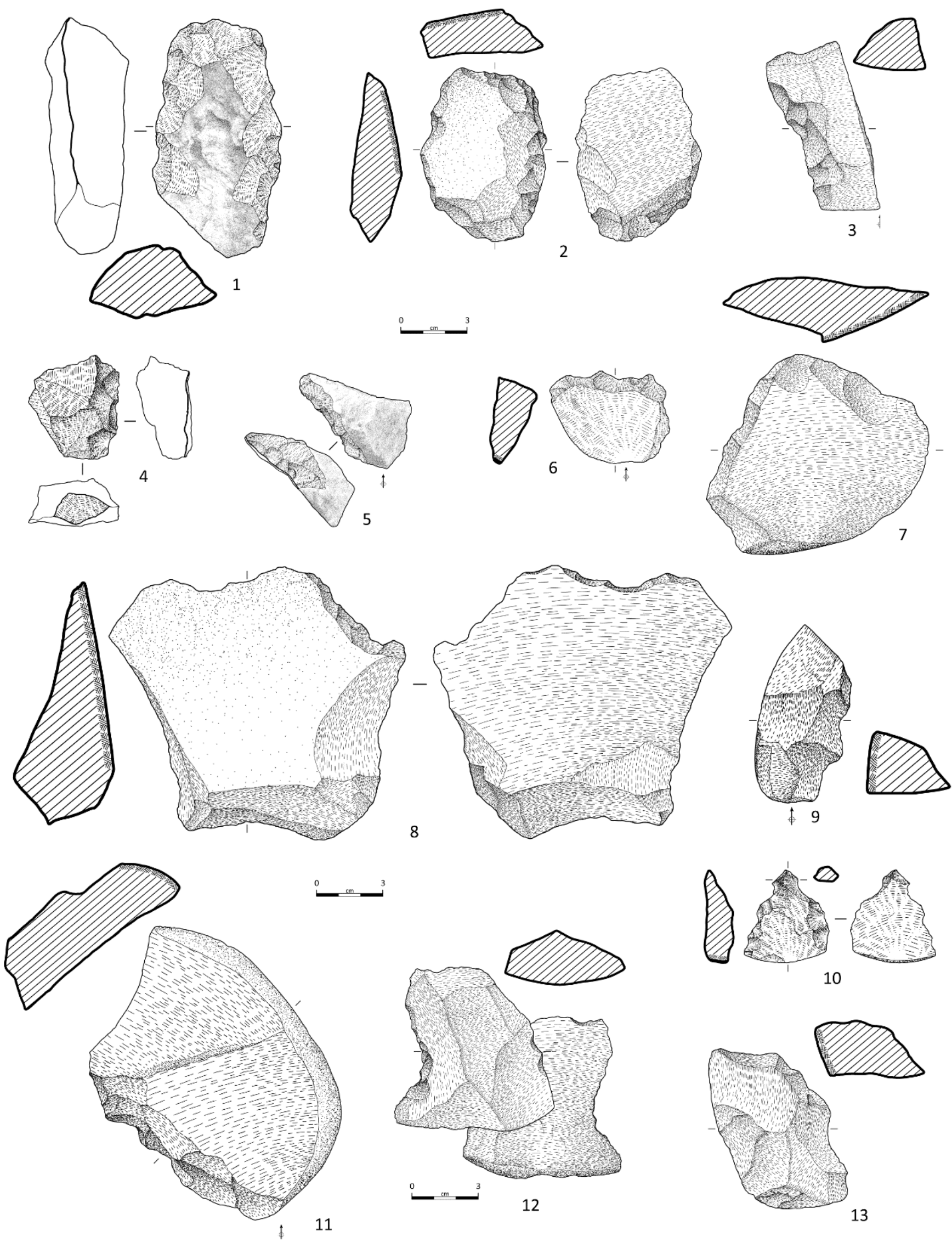

Fig. 10 . 

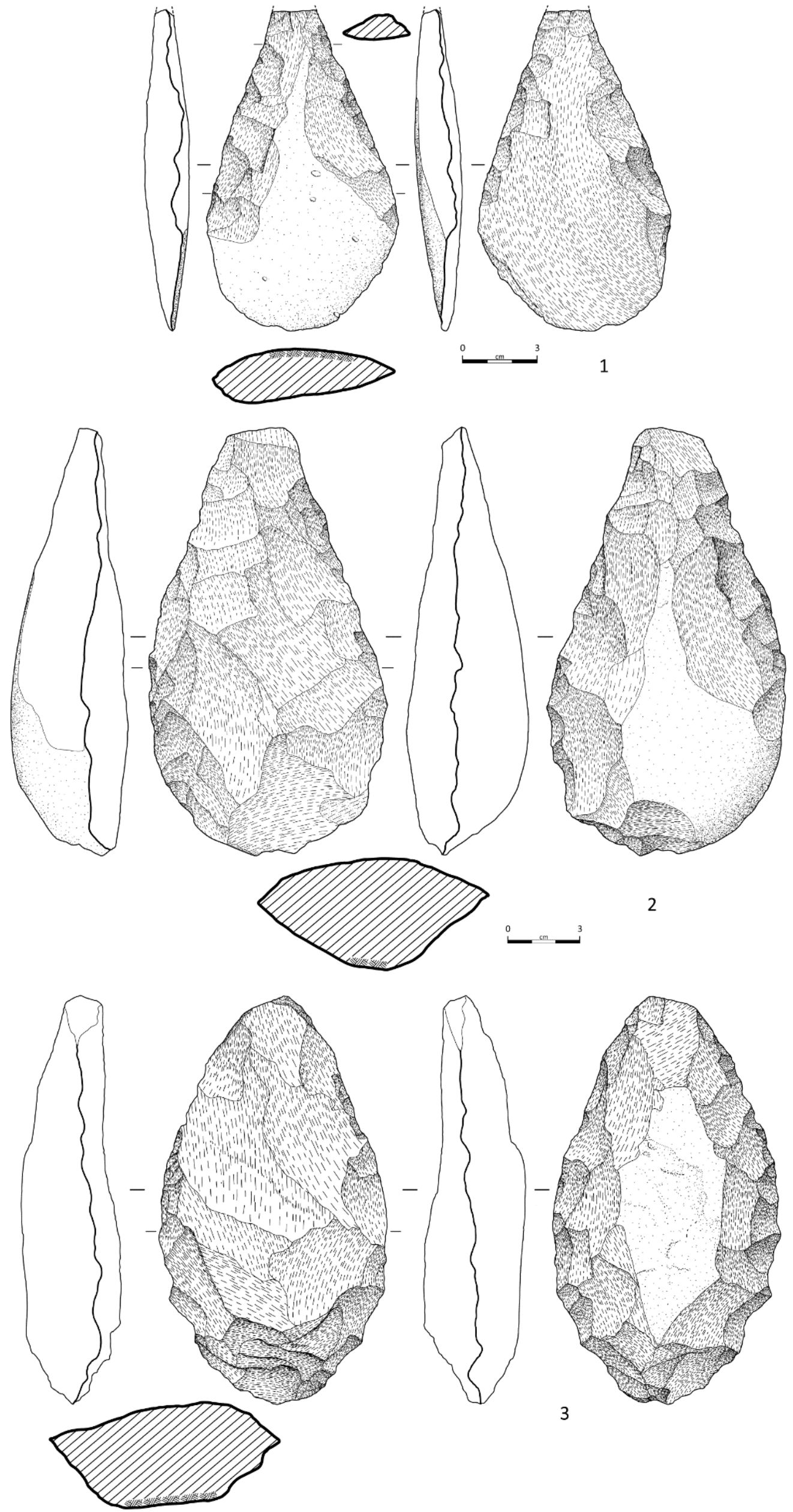

Fig. 11. 


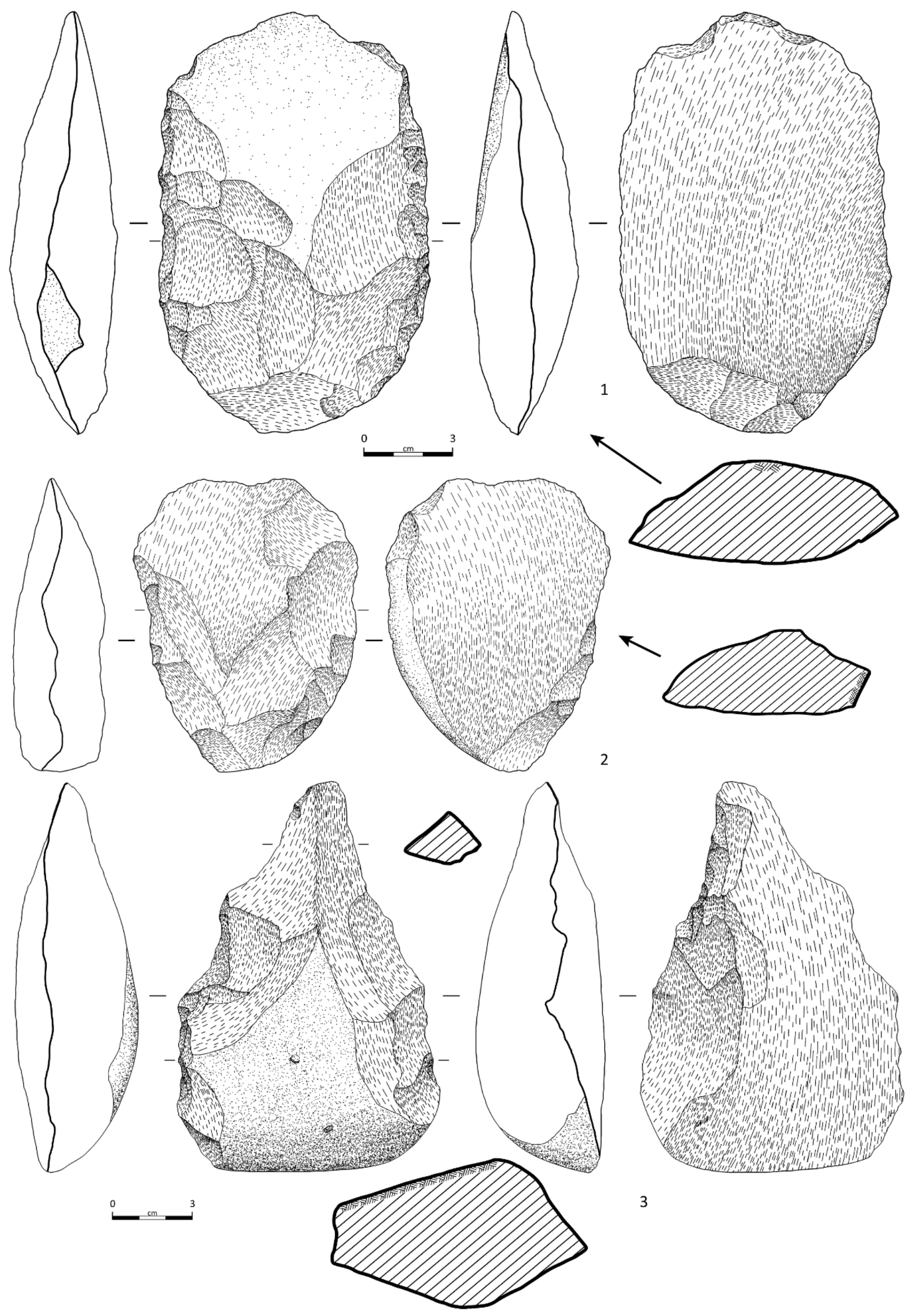

Fig. 12 . 


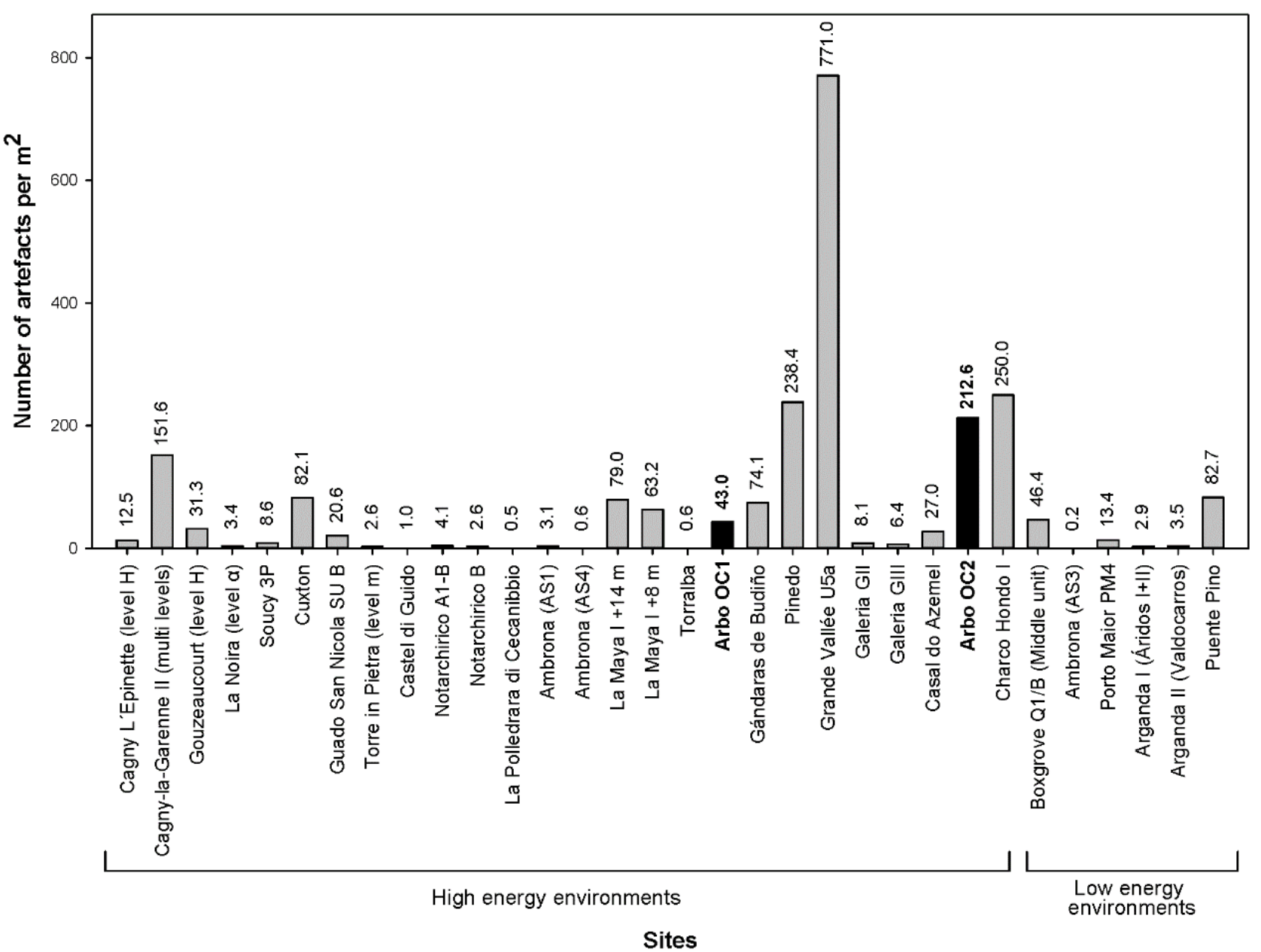

Fig. 13. 


\begin{tabular}{|c|c|c|c|c|c|c|c|c|c|c|}
\hline \multirow[b]{2}{*}{ Sample } & \multirow[b]{2}{*}{$\begin{array}{c}\text { Sample } \\
\text { depth } \\
\text { (m) }\end{array}$} & \multirow[b]{2}{*}{$\begin{array}{c}\text { Water } \\
\text { content a }\end{array}$} & \multirow[b]{2}{*}{ Mineral } & \multirow[b]{2}{*}{$\begin{array}{c}\text { Grain } \\
\text { fraction } \\
(\mu \mathrm{m})\end{array}$} & \multicolumn{5}{|c|}{ Environmental dose rate (Gy / ka) b } & \multirow[b]{2}{*}{ Total dose rate ${ }^{h}$} \\
\hline & & & & & $\begin{array}{c}\text { Gamma } \\
\text { dose rate }\end{array}$ & $\begin{array}{l}\text { Beta dose } \\
\text { rate } d\end{array}$ & $\begin{array}{c}\text { Cosmic } \\
\text { dose rate }\end{array}$ & $\begin{array}{c}\text { Internal } \\
\text { dose rate } \\
(U+T h)^{f}\end{array}$ & $\begin{array}{l}\text { Internal dose } \\
\text { rate }(K+R b)^{g}\end{array}$ & \\
\hline OC16-1 & 0.84 & 28.2 & K-feldspar & $90-125$ & $1.48 \pm 0.05$ & $2.39 \pm 0.12$ & $0.15 \pm 0.01$ & $0.06 \pm 0.03$ & $0.43 \pm 0.03$ & $4.50 \pm 0.27$ \\
\hline OC16-2 & 1.46 & 25.0 & K-feldspar & $90-125$ & $1.74 \pm 0.06$ & $2.72 \pm 0.13$ & $0.14 \pm 0.01$ & $0.06 \pm 0.03$ & $0.43 \pm 0.03$ & $5.09 \pm 0.29$ \\
\hline OC16-3 & 0.90 & 25.1 & K-feldspar & $90-125$ & $1.71 \pm 0.06$ & $2.80 \pm 0.15$ & $0.15 \pm 0.02$ & $0.06 \pm 0.03$ & $0.43 \pm 0.03$ & $5.15 \pm 0.29$ \\
\hline
\end{tabular}

1 a Water content, expressed as \% of dry mass of sample and assigned a relative uncertainty of $\pm 20 \%$. Long-term water contents are $60 \%$ of saturated values.

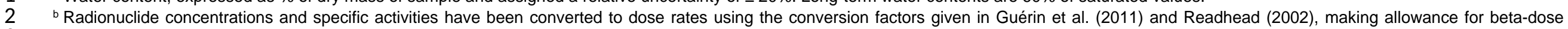
attenuation (Mejdahl, 1979; Brennan, 2003).

attenuation (Mejdahl, 1979; Brennan, 2003).

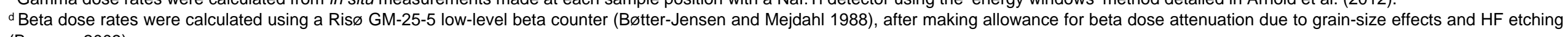
(Brennan 2003).

e Cosmic-ray dose rates were calculated according to Prescott and Hutton (1994) and assigned a relative uncertainty of $\pm 10 \%$.

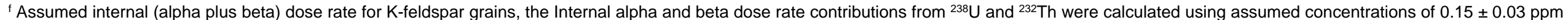

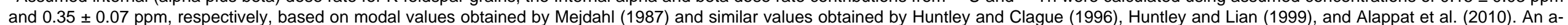

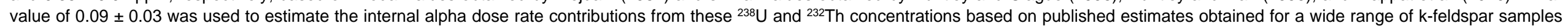
(e.g. Rees-Jones, 1995; Lang and Wagner, 1997; Banerjee et al., 2001; Lang et al., 2003; Berger et al., 2008; Feathers et al., 2012).

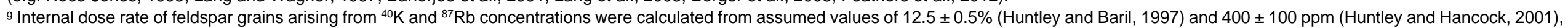
respectively.

${ }^{\mathrm{h}}$ Mean \pm total uncertainty ( $68 \%$ confidence interval), calculated as the quadratic sum of the random and systematic uncertainties.

Table 1. 
Sample Radionuclide specific activities (Bq/kg) a, b

Daughter: parent isotopic ratio

$238 \mathrm{U}$

${ }^{226} \mathrm{Ra}$

${ }^{210} \mathrm{~Pb}$

${ }^{228} \mathrm{Ra}$

${ }^{228} \mathrm{Th}$

${ }^{40} \mathrm{~K}$

${ }^{226} \mathrm{Ra}:{ }^{238} \mathrm{U}$

${ }^{210} \mathrm{~Pb}:{ }^{226} \mathrm{Ra}$

${ }^{228} \mathrm{Th}:{ }^{228} \mathrm{Ra}$

OC16-

$102.1 \pm 13.2$

$85.2 \pm 6.0$

$81.9 \pm 9.4$

$61.2 \pm 5.8$

$60.4 \pm 4.6$

$937 \pm 32$

$0.84 \pm 0.12$

$0.96 \pm 0.13$

$0.99 \pm 0.12$

OC16-2

$104.3 \pm 13.1$

$94.3 \pm 6.4$

$87.8 \pm 10.0$

$37.1 \pm 3.9$

$47.1 \pm 3.7$

$1004 \pm 35$

$0.90 \pm 0.13$

$0.93 \pm 0.12$

$1.27 \pm 0.17$

OC16-3

$120.4 \pm 15.5$

$108.7 \pm 7.4$

$103.3 \pm 11.8$

$68.7 \pm 6.3$

$66.1 \pm 5.1$

$1066 \pm 36$

$0.90 \pm 0.13$

$0.95 \pm 0.13$

$0.96 \pm 0.12$

a Measurements made on dried and powdered sediment sub-samples of $\sim 130 \mathrm{~g}$. The specific activities of ${ }^{238} \mathrm{U}$ (determined from ${ }^{235} \mathrm{U}$ emissions

after correcting for ${ }^{226} \mathrm{Ra}$ interference, and ${ }^{234} \mathrm{Th}$ emissions after correcting for ${ }^{228} \mathrm{Ra}$ interference), ${ }^{226} \mathrm{Ra}$ (derived from ${ }^{214} \mathrm{~Pb}$ and ${ }^{214} \mathrm{Bi}$ emissions),

${ }^{210} \mathrm{~Pb},{ }^{228} \mathrm{Ra}$ (derived from ${ }^{228} \mathrm{Ac}$ emissions), ${ }^{228} \mathrm{Th}$ (derived from ${ }^{212} \mathrm{~Pb},{ }^{212} \mathrm{Bi}$ and ${ }^{208} \mathrm{TI}$ emissions) and ${ }^{40} \mathrm{~K}$ were measured for each sediment

sample, and used to derive the daughter-to-parent isotope ratios for ${ }^{226} \mathrm{Ra}:{ }^{238} \mathrm{U},{ }^{210} \mathrm{~Pb}:{ }^{226} \mathrm{Ra}$ and ${ }^{228} \mathrm{Th}:{ }^{228} \mathrm{Ra}$ shown in columns $8-10$.

b Mean \pm total uncertainty ( $68 \%$ confidence interval), calculated as the quadratic sum of the random and systematic uncertainties.

Table 2. 


\begin{tabular}{|c|c|c|}
\hline Step & SAR pIR-IR 225 & SAR pIR-IR 290 \\
\hline 1 & Dose (natural or laboratory) & Dose (natural or laboratory) \\
\hline 2 & Preheat $1\left(250^{\circ} \mathrm{C}\right.$ for $\left.60 \mathrm{~s}\right)$ & Preheat $1\left(320^{\circ} \mathrm{C}\right.$ for $\left.60 \mathrm{~s}\right)$ \\
\hline 3 & IR stimulation ( $50^{\circ} \mathrm{C}$ for $\left.200 \mathrm{~s}\right)$ & IR stimulation ( $50^{\circ} \mathrm{C}$ for $200 \mathrm{~s}$ ) \\
\hline 4 & pIR-IR stimulation (225으 for $200 \mathrm{~s})$ & pIR-IR stimulation (290 for $200 \mathrm{~s})$ \\
\hline 5 & Test dose (50 Gy) & Test dose (50 Gy) \\
\hline 6 & Preheat $2\left(250^{\circ} \mathrm{C}\right.$ for $\left.60 \mathrm{~s}\right)$ & Preheat $2\left(320^{\circ} \mathrm{C}\right.$ for $\left.60 \mathrm{~s}\right)$ \\
\hline 7 & IR stimulation $\left(50^{\circ} \mathrm{C}\right.$ for $\left.200 \mathrm{~s}\right)$ & IR stimulation ( $50^{\circ} \mathrm{C}$ for $200 \mathrm{~s}$ ) \\
\hline 8 & pIR-IR stimulation $\left(225^{\circ} \mathrm{C}\right.$ for $\left.200 \mathrm{~s}\right)$ & pIR-IR stimulation $\left(290^{\circ} \mathrm{C}\right.$ for $\left.200 \mathrm{~s}\right)$ \\
\hline 9 & High temperature IR wash (at $290^{\circ} \mathrm{C}$ for $100 \mathrm{~s}$ ) & High temperature IR wash (at $325^{\circ} \mathrm{C}$ for $100 \mathrm{~s}$ ) \\
\hline 10 & $\begin{array}{l}\text { Repeat measurement cycle for } \\
\text { different sized regenerative doses }\end{array}$ & $\begin{array}{l}\text { Repeat measurement cycle for } \\
\text { different sized regenerative doses }\end{array}$ \\
\hline
\end{tabular}

Table 3. 


\begin{tabular}{|c|c|c|c|c|c|c|c|c|c|c|c|c|c|c|}
\hline \multirow[b]{2}{*}{ Sample } & \multirow[b]{2}{*}{$\begin{array}{l}\text { Mineral/ } \\
\text { Signal }\end{array}$} & \multirow[b]{2}{*}{$\begin{array}{l}\text { Grains } \\
\text { per disc }\end{array}$} & \multirow[b]{2}{*}{$\begin{array}{l}\text { Grain } \\
\text { size } \\
(\mu \mathrm{m})\end{array}$} & \multirow[b]{2}{*}{$\begin{array}{l}\text { Given } \\
\text { dose } \\
\text { (Gy) }\end{array}$} & \multirow[b]{2}{*}{ Bleaching } & \multicolumn{4}{|c|}{ Residual (non-dosed) assessment } & \multicolumn{5}{|c|}{ Dose recovery test } \\
\hline & & & & & & $\begin{array}{l}\text { accepted/ } \\
\text { measured }\end{array}$ & $\begin{array}{l}\text { Recyclin } \\
\text { g ratio }\end{array}$ & $\begin{array}{c}\text { Weighted } \\
\text { mean } D_{e} \\
(G y)\end{array}$ & $\begin{array}{c}\text { Over- } \\
\text { dispersio } \\
\text { n (\%) }\end{array}$ & $\begin{array}{l}\text { accepted/ } \\
\text { measured }\end{array}$ & $\begin{array}{l}\text { Recycling } \\
\text { ratio }\end{array}$ & $\begin{array}{c}\text { Weighted } \\
\text { mean } D_{e} \\
(G y)\end{array}$ & $\begin{array}{c}\text { Over- } \\
\text { dispersion } \\
(\%)\end{array}$ & $\begin{array}{c}\text { Net } \\
\text { measured/ } \\
\text { given dose } \\
\text { ratio }\end{array}$ \\
\hline OC16-2 & $\begin{array}{l}\text { K-feldspar / } \\
\text { pIR-IR }\end{array}$ & $\sim 160$ & $90-125$ & $300 \pm 6$ & $\begin{array}{c}8 \text { hours in } \\
\text { daylight }\end{array}$ & $2 / 2$ & $\begin{array}{l}1.00 \pm \\
0.01\end{array}$ & $5 \pm 1$ & $13 \pm 7$ & $3 / 3$ & $\begin{array}{c}0.99 \pm \\
0.01\end{array}$ & $272 \pm 3$ & $0 \pm 0$ & $0.89 \pm 0.02$ \\
\hline OC16-2 & $\begin{array}{l}\text { K-feldspar / } \\
\text { pIR-IR }\end{array}$ & $\sim 160$ & $90-125$ & $300 \pm 6$ & $\begin{array}{c}8 \text { hours in } \\
\text { daylight }\end{array}$ & $2 / 2$ & $\begin{array}{l}0.96 \pm \\
0.02\end{array}$ & $16 \pm 1$ & $0 \pm 0$ & $3 / 3$ & $\begin{array}{c}0.98 \pm \\
0.01\end{array}$ & $327 \pm 5$ & $0 \pm 0$ & $1.04 \pm 0.03$ \\
\hline OC16-3 & $\begin{array}{l}\text { K-feldspar / } \\
\text { pIR-IR }\end{array}$ & $\sim 160$ & $90-125$ & $500 \pm 10$ & $\begin{array}{c}8 \text { hours in } \\
\text { daylight }\end{array}$ & $2 / 2$ & $\begin{array}{l}1.02 \pm \\
0.01\end{array}$ & $15 \pm 1$ & $2 \pm 2$ & $3 / 3$ & $\begin{array}{c}0.99 \pm \\
0.01\end{array}$ & $481 \pm 8$ & $0 \pm 0$ & $0.94 \pm 0.03$ \\
\hline OC16-3 & $\begin{array}{l}\text { K-feldspar / } \\
\text { pIR-IR }\end{array}$ & $\sim 160$ & $90-125$ & $500 \pm 10$ & $\begin{array}{c}8 \text { hours in } \\
\text { daylight }\end{array}$ & $2 / 2$ & $\begin{array}{l}1.01 \pm \\
0.01\end{array}$ & $29 \pm 1$ & $0 \pm 0$ & $3 / 3$ & $\begin{array}{c}1.00 \pm \\
0.01\end{array}$ & $539 \pm 12$ & $3 \pm 3$ & $1.02 \pm 0.03$ \\
\hline
\end{tabular}




\begin{tabular}{|c|c|c|c|c|c|c|c|c|}
\hline \multirow[t]{2}{*}{ Sample } & \multirow[t]{2}{*}{ Mineral/Signal } & \multirow[t]{2}{*}{$\begin{array}{l}\text { Grains per } \\
\text { disc }\end{array}$} & \multirow{2}{*}{$\begin{array}{c}\text { Grain } \\
\text { size } \\
(\mu \mathrm{m})\end{array}$} & \multirow[t]{2}{*}{ Bleaching } & \multicolumn{4}{|c|}{ Residual assessment } \\
\hline & & & & & $\begin{array}{l}\text { accepted/ } \\
\text { measured }\end{array}$ & $\begin{array}{l}\text { Recycling } \\
\text { ratio }\end{array}$ & W-mean $D_{e}(G y)$ & $\begin{array}{c}\text { Overdispersion } \\
(\%)\end{array}$ \\
\hline OC16-1 & $\begin{array}{l}\text { K-feldspar / } \\
\text { pIR-IR } 290\end{array}$ & $\sim 160$ & $\begin{array}{l}90- \\
125\end{array}$ & $\begin{array}{l}15 \text { days in } \\
\text { daylight }\end{array}$ & $3 / 3$ & $1.01 \pm 0.01$ & $6.00 \pm 0.28$ & $6 \pm 3$ \\
\hline OC16-2 & $\begin{array}{l}\text { K-feldspar / } \\
\text { plR-IR } 290\end{array}$ & $\sim 160$ & $\begin{array}{l}90- \\
125\end{array}$ & $\begin{array}{l}15 \text { days in } \\
\text { daylight }\end{array}$ & $3 / 3$ & $1.00 \pm 0.01$ & $9.27 \pm 0.29$ & $4 \pm 2$ \\
\hline OC16-3 & $\begin{array}{l}\text { K-feldspar / } \\
\text { pIR-IR } 290\end{array}$ & $\sim 160$ & $\begin{array}{l}90- \\
125\end{array}$ & $\begin{array}{l}15 \text { days in } \\
\text { daylight }\end{array}$ & $3 / 3$ & $0.99 \pm 0.01$ & $7.26 \pm 0.36$ & $6 \pm 3$ \\
\hline
\end{tabular}

Table 5 


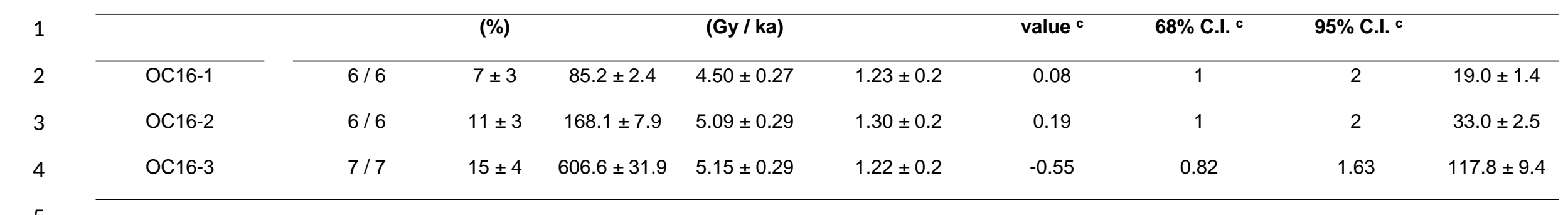

$6 \quad$ a CAM $=$ central age model of Galbraith et al. (1999)

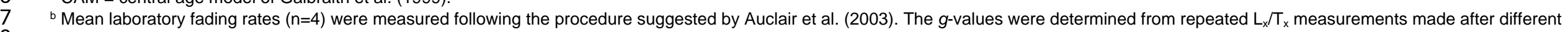
storage times (ranging from $0.17 \mathrm{~h}$ to $30 \mathrm{~h}$ ) using Eq. 4 of Huntley and Lamothe (2001), and have been normalised to a measurement delay time of two days to enable direct comparisons with published values.

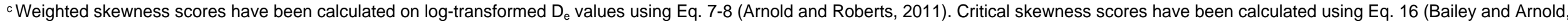

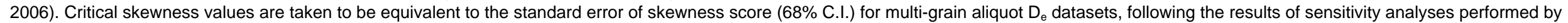

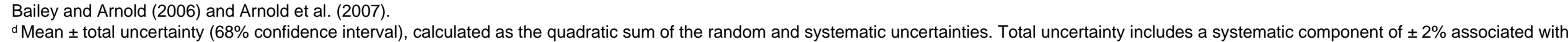
${ }^{d}$ Mean \pm total uncertainty $(68 \%$ co
laboratory beta-source calibration. 


\begin{tabular}{|c|c|c|c|c|c|c|c|}
\hline & \multicolumn{4}{|c|}{$D_{\max }=40 \mathrm{kGy}$} & \multicolumn{2}{|c|}{$\mathrm{D}_{\max }=27 \mathrm{kGy}$} \\
\hline Sample & $\begin{array}{c}\text { Bleaching } \\
\text { Coefficient } \\
(\%)\end{array}$ & $\begin{array}{c}\text { Repeatability } \\
\text { of the ESR } \\
\text { intensities } \\
(\%)\end{array}$ & $\begin{array}{c}\text { Repeatability } \\
\text { of the } D_{E} \\
\text { estimates } \\
(\%)\end{array}$ & $\begin{array}{c}\text { Adjusted } \\
\mathrm{r}^{2}\end{array}$ & $\begin{array}{c}\mathrm{D}_{\mathrm{E}} \\
\text { value } \\
(\mathrm{Gy})\end{array}$ & $\begin{array}{c}\text { Adjusted } \\
\mathrm{r}^{2}\end{array}$ & $\begin{array}{c}\mathrm{D}_{\mathrm{E}} \text { value } \\
(\mathrm{Gy})\end{array}$ \\
\hline VI1201 & $37.4 \pm 1.1$ & 2.6 & 14.3 & 0.989 & $\begin{array}{c}790 \pm \\
138\end{array}$ & 0.993 & $696 \pm 109$ \\
\hline VI1202 & $33.8 \pm 1.1$ & 0.7 & 10.6 & 0.985 & $\begin{array}{c}599 \pm \\
124\end{array}$ & 0.986 & $522 \pm 112$ \\
\hline
\end{tabular}

1

Table 7. 


\begin{tabular}{|c|c|c|c|c|c|c|c|c|}
\hline \multicolumn{4}{|c|}{ Ti-Li centre (option D) } & \multicolumn{5}{c|}{ Ti-H centre (option C) } \\
\hline Sample & $\begin{array}{c}\text { Repeatability } \\
\text { ESR intensities } \\
(\%)\end{array}$ & $\begin{array}{c}D_{E} \\
\text { repeatability } \\
(\%)\end{array}$ & Adj. $r^{2}$ & $\begin{array}{c}D_{E} \\
(G y)\end{array}$ & $\begin{array}{c}\text { Repeatability } \\
\text { ESR intensities } \\
(\%)\end{array}$ & $\begin{array}{c}D_{E} \\
\text { repeatability } \\
(\%)\end{array}$ & Adj. $r^{2}$ & $\begin{array}{c}D_{E} \\
(G y)\end{array}$ \\
\hline VI1201 & 2.6 & 2.8 & 0.994 & $\begin{array}{c}366 \\
\pm 33\end{array}$ & 11.3 & 19.6 & 0.0 .998 & $146 \pm 19$ \\
\hline VI1202 & 2.5 & 11.4 & 0.999 & $\begin{array}{c}283 \\
\pm 7\end{array}$ & 6.1 & 11.1 & $\begin{array}{c}0.963 \\
(0.990)\end{array}$ & $\begin{array}{c}355 \pm 103 \\
(182 \pm 20)\end{array}$ \\
\hline
\end{tabular}

1

2

Table 8.

3 


\begin{tabular}{|l|r|r|r|c|c|c|c|}
\hline \multirow{2}{*}{ Sample } & \multicolumn{4}{|l|}{ ICP-MS measurements } & \multicolumn{4}{l|}{ High Resolution Gamma Spectrometry } \\
\cline { 2 - 8 } & U-238 (Bq/kg) & Th-232 (Bq/kg) & K-40 (\%) & U-238 (Bq/kg) & Rn-222 (Bq/kg) & Th-232 (Bq/kg) & $\mathrm{K}-40(\%)$ \\
\hline VI1201 & $98.5 \pm 3.6$ & $45.8 \pm 1.9$ & $3.2 \pm 0.1$ & $94.7 \pm 8.4$ & $76.7 \pm 4.9$ & $46.3 \pm 2.7$ & $3.2 \pm 0.1$ \\
\hline VI1202 & $130.9 \pm 2.2$ & $51.3 \pm 2.1$ & $3.4 \pm 0.1$ & $112.9 \pm 12.3$ & $83.8 \pm 5.3$ & $54.3 \pm 2.7$ & $3.3 \pm 0.1$ \\
\hline
\end{tabular}

1

2

Table 9.

3

4 


\begin{tabular}{|l|c|c|c|c|}
\hline & In situ measurement & \multicolumn{3}{|l|}{ Laboratory analyses } \\
\hline Sample & Threshold $(\mu \mathrm{G} / \mathrm{a})$ & $\begin{array}{l}\text { ICP-MS [full-series] } \\
(\mu \mathrm{Gy} / \mathrm{a})\end{array}$ & $\begin{array}{l}\text { HRGS [full-series] } \\
(\mu \mathrm{Gy} / \mathrm{a})\end{array}$ & $\begin{array}{l}\text { HRGS [pre-Rn] } \\
(\mu \mathrm{Gy} / \mathrm{a})\end{array}$ \\
\hline VI1201 & $1840 \pm 109$ & $1994 \pm 123$ & $1984 \pm 221$ & $1847 \pm 216$ \\
\hline VI1202 & $1886 \pm 112$ & $2309 \pm 122$ & $2197 \pm 272$ & $1980 \pm 247$ \\
\hline
\end{tabular}

1

Table 10.

3

4 


\begin{tabular}{lcccc}
\hline Sample & \multicolumn{2}{c}{ VI1201 } & \multicolumn{2}{c}{ VI1202 } \\
\hline Scenario & Equilibrium & Disequilibrium & Equilibrium & Disequilibrium \\
\hline Depth $(\mathrm{m})$ & $1.5 \pm 0.5$ & $1.5 \pm 0.5$ & $1.3 \pm 0.5$ & $1.3 \pm 0.5$ \\
Measured water content $(\%)$ & 7.7 & 7.7 & 9.2 & 9.2 \\
Time average water content $(\%)$ & $20 \pm 5$ & $20 \pm 5$ & $20 \pm 5$ & $20 \pm 5$ \\
\hline Internal dose rate $(\mu \mathrm{G} / \mathrm{a})$ & $50 \pm 30$ & $50 \pm 30$ & $50 \pm 30$ & $50 \pm 30$ \\
Alpha dose rate $(\mu \mathrm{Gy} / \mathrm{a})$ & $90 \pm 74$ & $83 \pm 68$ & $110 \pm 93$ & $96 \pm 80$ \\
Beta dose rate $(\mu \mathrm{Gy} / \mathrm{a})$ & $2746 \pm 225$ & $2673 \pm 222$ & $3123 \pm 248$ & $2864 \pm 237$ \\
Gamma dose rate $(\mu \mathrm{Gy} / \mathrm{a})$ & $1679 \pm 128$ & $1337 \pm 122$ & $1984 \pm 146$ & $1422 \pm 130$ \\
Cosmic dose rate $(\mu \mathrm{Gy} / \mathrm{a})$ & $166 \pm 16$ & $165 \pm 16$ & $171 \pm 17$ & $171 \pm 17$ \\
Total dose rate $(\mu \mathrm{Gy} / \mathrm{a})$ & $4731 \pm 365$ & $4309 \pm 334$ & $5438 \pm 412$ & $4604 \pm 359$ \\
\hline $\mathrm{D}_{\mathrm{E}}(\mathrm{Gy})$ Al centre & $696 \pm 109$ & $696 \pm 109$ & $522 \pm 112$ & $522 \pm 112$ \\
$\mathrm{D}_{\mathrm{E}}(\mathrm{Gy})$ Ti-Li centre & $366 \pm 33$ & $366 \pm 33$ & $283 \pm 7$ & $283 \pm 7$ \\
$\mathrm{D}_{\mathrm{E}}(\mathrm{Gy})$ Ti-H centre & $146 \pm 19$ & $146 \pm 19$ & $355 \pm 103$ & $355 \pm 103$ \\
& & & $182 \pm 20^{*}$ & $182 \pm 20^{*}$ \\
\hline Age (ka) Al centre & $\mathbf{1 4 7 . 1} \pm \mathbf{2 5 . 7}$ & $\mathbf{1 6 1 . 5 \pm \mathbf { 2 8 . 2 }}$ & $\mathbf{9 6 . 0} \pm \mathbf{2 1 . 8}$ & $\mathbf{1 1 3 . 4} \pm \mathbf{2 5 . 9}$ \\
Age (ka) Ti-Li centre & $\mathbf{7 7 . 4} \pm \mathbf{9 . 2}$ & $\mathbf{8 4 . 9 \pm \mathbf { 1 0 . 1 }}$ & $\mathbf{5 2 . 0} \pm \mathbf{4 . 1}$ & $\mathbf{6 1 . 5} \pm \mathbf{5 . 0}$ \\
Age (ka) Ti-H centre & $\mathbf{3 0 . 9} \pm \mathbf{4 . 7}$ & $\mathbf{3 3 . 9} \pm \mathbf{5 . 1}$ & $\mathbf{6 5 . 3} \pm \mathbf{1 9 . 6}$ & $\mathbf{7 7 . 1} \pm \mathbf{2 3 . 2}$ \\
& & & $\mathbf{3 3 . 5} \pm \mathbf{4 . 5}$ & $\mathbf{3 9 . 5} \pm \mathbf{5 . 3}$ \\
\hline
\end{tabular}

Table 11. 


\begin{tabular}{|c|c|c|c|c|c|c|c|c|}
\hline \multicolumn{9}{|c|}{ Level OC1 } \\
\hline & \multicolumn{2}{|c|}{ Quartzite } & \multicolumn{2}{|c|}{ Quartz } & \multicolumn{2}{|c|}{ Others } & \multicolumn{2}{|c|}{ Total } \\
\hline & $n$ & $\%$ & $\mathrm{n}$ & $\%$ & $\mathrm{n}$ & $\%$ & $\mathrm{n}$ & $\%$ \\
\hline Allochthonous pebble & 71 & 9.0 & 27 & 5.7 & 10 & 29.4 & 108 & 8.4 \\
\hline Tested pebble & 18 & 2.3 & 11 & 2.3 & 1 & 2.9 & 30 & 2.3 \\
\hline Hammerstones/anvils & 28 & 3.6 & 4 & 0.8 & 6 & 17.6 & 38 & 2.9 \\
\hline Small size $(<30 \mathrm{~mm})$ flake & 53 & 6.8 & 103 & 21.8 & 1 & 2.9 & 157 & 12.2 \\
\hline Medium size (30-100 mm) flake & 226 & 28.8 & 164 & 34.7 & 4 & 11.8 & 394 & 30.5 \\
\hline Large size $(>100 \mathrm{~mm})$ flake & 19 & 2.4 & 1 & 0.2 & 0 & 0.0 & 20 & 1.5 \\
\hline Flakes fragment & 30 & 3.8 & 13 & 2.7 & 0 & 0.0 & 43 & 3.3 \\
\hline Waste & 56 & 7.1 & 73 & 15.4 & 9 & 26.5 & 138 & 10.7 \\
\hline Small-medium size core & 70 & 8.9 & 43 & 9.1 & 3 & 8.8 & 116 & 9.0 \\
\hline Large size core & 0 & 0.0 & 0 & 0.0 & 0 & 0.0 & 0 & 0.0 \\
\hline Flake tool & 35 & 4.5 & 31 & 6.6 & 0 & 0.0 & 66 & 5.1 \\
\hline Pebble tool & 14 & 1.8 & 0 & 0.0 & 0 & 0.0 & 14 & 1.1 \\
\hline Flake tool fragment & 5 & 0.6 & 0 & 0.0 & 0 & 0.0 & 5 & 0.4 \\
\hline Flake from resharpening tool & 35 & 4.5 & 2 & 0.4 & 0 & 0.0 & 37 & 2.9 \\
\hline LCT: handaxe & 33 & 4.2 & 0 & 0.0 & 0 & 0.0 & 33 & 2.6 \\
\hline LCT: cleaver on flake & 14 & 1.8 & 0 & 0.0 & 0 & 0.0 & 14 & 1.1 \\
\hline LCT: trihedral pick & 5 & 0.6 & 0 & 0.0 & 0 & 0.0 & 5 & 0.4 \\
\hline LCT: large flake tool (>100 mm) & 23 & 2.9 & 1 & 0.2 & 0 & 0.0 & 24 & 1.9 \\
\hline LCT: fragment & 10 & 1.3 & 0 & 0.0 & 0 & 0.0 & 10 & 0.8 \\
\hline LCT: flakes from LCT reduction & 40 & 5.1 & 0 & 0.0 & 0 & 0.0 & 40 & 3.1 \\
\hline TOTAL & 785 & & 473 & & 34 & & 1292 & \\
\hline \multicolumn{9}{|c|}{ Level OC2 } \\
\hline & \multicolumn{2}{|c|}{ Quartzite } & \multicolumn{2}{|c|}{ Quartz } & \multicolumn{2}{|c|}{ Others } & \multicolumn{2}{|c|}{ Total } \\
\hline & $\mathrm{n}$ & $\%$ & $\mathrm{n}$ & $\%$ & $\mathrm{n}$ & $\%$ & $\mathrm{n}$ & $\%$ \\
\hline Allochthonous pebble & 45 & 4.5 & 31 & 3.8 & 6 & 14.3 & 82 & 4.4 \\
\hline Tested pebble & 9 & 0.9 & 5 & 0.6 & 1 & 2.4 & 15 & 0.8 \\
\hline Hammerstones/anvils & 8 & 0.8 & 2 & 0.2 & 0 & 0.0 & 10 & 0.5 \\
\hline Small size $(<30 \mathrm{~mm})$ flake & 75 & 7.6 & 141 & 17.2 & 1 & 2.4 & 217 & 11.7 \\
\hline Medium size $(30-100 \mathrm{~mm})$ flake & 296 & 29.9 & 220 & 26.9 & 14 & 33.3 & 530 & 28.6 \\
\hline Large size $(>100 \mathrm{~mm}$ ) flake & 24 & 2.4 & 1 & 0.1 & 1 & 2.4 & 26 & 1.4 \\
\hline Flakes fragment & 58 & 5.9 & 12 & 1.5 & 1 & 2.4 & 71 & 3.8 \\
\hline Waste & 112 & 11.3 & 332 & 40.6 & 12 & 28.6 & 456 & 24.6 \\
\hline Small-medium size core & 95 & 9.6 & 55 & 6.7 & 4 & 9.5 & 154 & 8.3 \\
\hline Large size core & 0 & 0.0 & 0 & 0.0 & 0 & 0.0 & 0 & 0.0 \\
\hline Flake tool & 63 & 6.4 & 17 & 2.1 & 1 & 2.4 & 81 & 4.4 \\
\hline Pebble tool & 9 & 0.9 & 0 & 0.0 & 0 & 0.0 & 9 & 0.5 \\
\hline Flake tool fragment & 4 & 0.4 & 0 & 0.0 & 0 & 0.0 & 4 & 0.2 \\
\hline Flake from resharpening tool & 50 & 5.1 & 1 & 0.1 & 0 & 0.0 & 51 & 2.8 \\
\hline LCT: handaxe & 20 & 2.0 & 1 & 0.1 & 0 & 0.0 & 21 & 1.1 \\
\hline LCT: cleaver on flake & 10 & 1.0 & 0 & 0.0 & 0 & 0.0 & 10 & 0.5 \\
\hline LCT: trihedral pick & 3 & 0.3 & 0 & 0.0 & 0 & 0.0 & 3 & 0.2 \\
\hline LCT: large flake tool (>100 mm) & 39 & 3.9 & 0 & 0.0 & 1 & 2.4 & 40 & 2.2 \\
\hline LCT: fragment & 13 & 1.3 & 0 & 0.0 & 0 & 0.0 & 13 & 0.7 \\
\hline LCT: flakes from LCT reduction & 57 & 5.8 & 0 & 0.0 & 0 & 0.0 & 57 & 3.1 \\
\hline TOTAL & 990 & & 818 & & 42 & & 1850 & \\
\hline
\end{tabular}

Table 12. 
Supplementary Material-Méndez-Quintas et al. Insights into the late stages of the Acheulean technocomplex of Western Iberia from the Arbo site (Galicia, Spain)

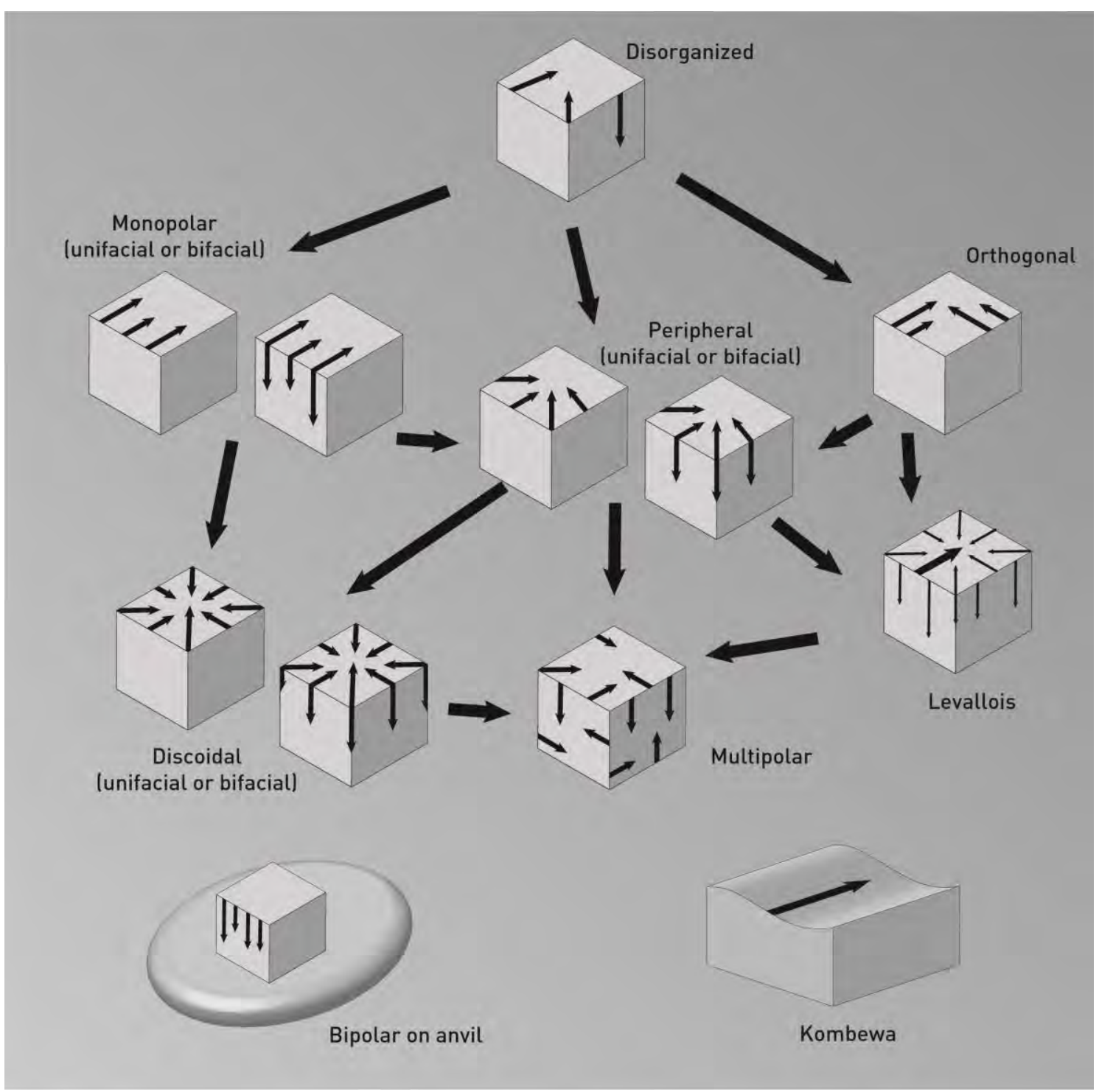

Figure S1. Core reduction pattern observed in the lithic assemblages at Arbo site 


\begin{tabular}{|c|c|c|c|c|c|c|}
\hline & & & $n$ & Ranges & Average & St. deviation \\
\hline \multirow{12}{*}{ 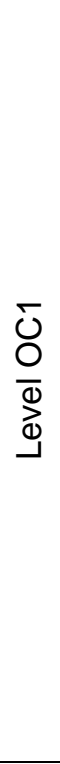 } & \multirow{4}{*}{ 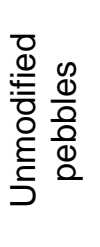 } & Length & 107 & $44-197$ & 86.5 & 29.1 \\
\hline & & Width & 107 & $27-130$ & 63.4 & 21.5 \\
\hline & & Thickness & 107 & $13-92$ & 40.7 & 17.2 \\
\hline & & Weight & 107 & 23-2269 & 392.6 & 395.8 \\
\hline & \multirow{4}{*}{ 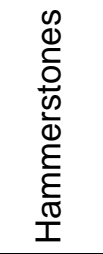 } & Length & 32 & $42-137$ & 81.7 & 21.3 \\
\hline & & Width & 32 & $39-114$ & 68.9 & 17.8 \\
\hline & & Thickness & 32 & $19-88$ & 45.7 & 14.9 \\
\hline & & Weight & 32 & 80-1527 & 420.9 & 324.6 \\
\hline & \multirow{4}{*}{ 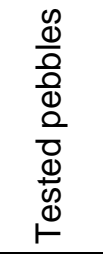 } & Length & 30 & $57-199$ & 106.9 & 35.1 \\
\hline & & Width & 30 & $52-174$ & 84.9 & 23.1 \\
\hline & & Thickness & 30 & $24-150$ & 58.1 & 25.3 \\
\hline & & Weight & 30 & $129-5328$ & 846.2 & 969.8 \\
\hline \multirow{12}{*}{$\begin{array}{l}\text { Õ } \\
\frac{0}{0} \\
\stackrel{D}{0}\end{array}$} & \multirow{4}{*}{ 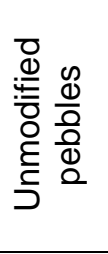 } & Length & 81 & $42-174$ & 88.0 & 23.8 \\
\hline & & Width & 81 & $31-152$ & 67.8 & 20.9 \\
\hline & & Thickness & 81 & $16-111$ & 44.0 & 16.3 \\
\hline & & Weight & 81 & $38-3057$ & 427.7 & 423.1 \\
\hline & \multirow{4}{*}{ 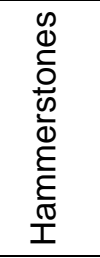 } & Length & 9 & $62-112$ & 81.9 & 20.1 \\
\hline & & Width & 9 & $40-105$ & 65.0 & 23.2 \\
\hline & & Thickness & 9 & $18-90$ & 41.1 & 24.1 \\
\hline & & Weight & 9 & $79-1422$ & 415.4 & 471.9 \\
\hline & \multirow{4}{*}{ 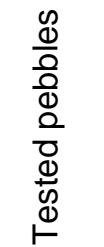 } & Length & 15 & $35-228$ & 101.0 & 47.5 \\
\hline & & Width & 15 & $29-135$ & 79.4 & 29.6 \\
\hline & & Thickness & 15 & $26-102$ & 50.8 & 20.7 \\
\hline & & Weight & 15 & $46-4951$ & 798.3 & 1234.1 \\
\hline
\end{tabular}

Table S1. Size and weight values for unmodified pebbles, hammerstone and tested pebble in the main assemblage of Arbo site. 


\begin{tabular}{|c|c|c|c|c|c|c|c|c|c|}
\hline & & \multicolumn{2}{|c|}{ Quartzite } & \multicolumn{2}{|c|}{ Quartz } & \multicolumn{2}{|c|}{ Others } & \multicolumn{2}{|c|}{ Total } \\
\hline & & $n$ & $\%$ & $n$ & $\%$ & $n$ & $\%$ & $n$ & $\%$ \\
\hline \multirow{12}{*}{$\begin{array}{l}\overline{0} \\
\overline{0} \\
\bar{d}\end{array}$} & Highly cortical flakes (>75\%) & $38(8)$ & 15.5 & 23 & 13.9 & 2 & 50.0 & 63 & 15.2 \\
\hline & Cortical flakes (50-75\%) & $18(2)$ & 7.3 & 8 & 4.8 & 1 & 25.0 & 27 & 6.5 \\
\hline & Decortical flakes (<25\%) & $113(2)$ & 46.1 & 108 & 65.5 & 1 & 25.0 & 222 & 53.6 \\
\hline & Partially cortical flakes (25-50\%) & $17(3)$ & 6.9 & 11 & 6.7 & 0 & 0.0 & 28 & 6.8 \\
\hline & Kombewa flakes & 6 & 2.4 & 0 & 0.0 & 0 & 0.0 & 6 & 1.4 \\
\hline & Flakes with debitage back & 2 & 0.8 & 1 & 0.6 & 0 & 0.0 & 3 & 0.7 \\
\hline & Flakes with cortical back & $46(4)$ & 18.8 & $13(1)$ & 7.9 & 0 & 0.0 & 59 & 14.3 \\
\hline & Levallois flake & 0 & 0.0 & 0 & 0.0 & 0 & 0.0 & 0 & 0.0 \\
\hline & Levallois point & 0 & 0.0 & 0 & 0.0 & 0 & 0.0 & 0 & 0.0 \\
\hline & Discoidal flake & 3 & 1.2 & 0 & 0.0 & 0 & 0.0 & 3 & 0.7 \\
\hline & Pseudo-Levallois point & 2 & 0.8 & 1 & 0.6 & 0 & 0.0 & 3 & 0.7 \\
\hline & TOTAL & 245 & & 165 & & 4 & & 414 & \\
\hline \multirow{12}{*}{ 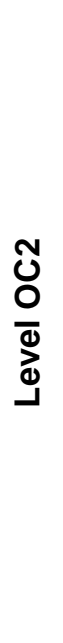 } & Highly cortical flakes (>75\%) & $44(8)$ & 13.8 & 31 & 14.0 & $2(1)$ & 13.3 & 77 & 13.8 \\
\hline & Cortical flakes (50-75\%) & $17(4)$ & 5.3 & 9 & 4.1 & 2 & 13.3 & 28 & 5.0 \\
\hline & Decortical flakes (<25\%) & $164(6)$ & 51.3 & 137 & 62.0 & 8 & 53.3 & 309 & 55.6 \\
\hline & Partially cortical flakes (25-50\%) & 10 & 3.1 & 18 & 8.1 & 0 & 0.0 & 28 & 5.0 \\
\hline & Kombewa flakes & 9 & 2.8 & 0 & 0.0 & 0 & 0.0 & 9 & 1.6 \\
\hline & Flakes with debitage back & 6 & 1.9 & 3 & 1.4 & 0 & 0.0 & 9 & 1.6 \\
\hline & Flakes with cortical back & $63(6)$ & 19.7 & $23(1)$ & 10.4 & 3 & 20.0 & 89 & 16.0 \\
\hline & Levallois flake & 0 & 0.0 & 0 & 0.0 & 0 & 0.0 & 0 & 0.0 \\
\hline & Levallois point & 1 & 0.3 & 0 & 0.0 & 0 & 0.0 & 1 & 0.2 \\
\hline & Discoidal flake & 4 & 1.3 & 0 & 0.0 & 0 & 0.0 & 4 & 0.7 \\
\hline & Pseudo-Levallois point & 2 & 0.6 & 0 & 0.0 & 0 & 0.0 & 2 & 0.4 \\
\hline & TOTAL & 320 & & 221 & & 15 & & 556 & \\
\hline
\end{tabular}

Table S2. Main flakes types (in parentheses number of large flakes, $>100 \mathrm{~mm}$ ) in the main assemblage of Arbo site. 


\begin{tabular}{|c|c|c|c|c|c|c|}
\hline & & & $\mathrm{n}$ & Ranges & Average & St. deviation \\
\hline \multirow{8}{*}{$\begin{array}{l}\overline{0} \\
\bar{O} \\
\overline{0} \\
\end{array}$} & \multirow{4}{*}{ 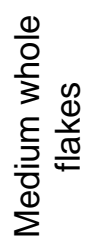 } & Length & 238 & $15-178$ & 46.0 & 29.1 \\
\hline & & Width & 238 & $10-159$ & 48.7 & 21.5 \\
\hline & & Thickness & 238 & $2-1335$ & 16.6 & 17.2 \\
\hline & & Weight & 238 & $23-2269$ & 62.6 & 395.8 \\
\hline & \multirow{4}{*}{ 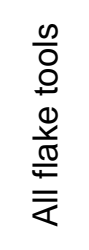 } & Length & 79 & $22-169$ & 68.8 & 28.9 \\
\hline & & Width & 79 & $21-181$ & 70.3 & 34.5 \\
\hline & & Thickness & 79 & $8-50$ & 25.1 & 10.2 \\
\hline & & Weight & 79 & $5-856$ & 178.5 & 205.8 \\
\hline \multirow{8}{*}{ 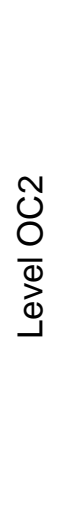 } & \multirow{4}{*}{ 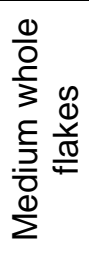 } & Length & 329 & $15-159$ & 47.7 & 19.3 \\
\hline & & Width & 329 & $15-176$ & 47.3 & 22.7 \\
\hline & & Thickness & 329 & $4-53$ & 16.8 & 7.9 \\
\hline & & Weight & 329 & $6-924$ & 57.0 & 102.2 \\
\hline & \multirow{4}{*}{ 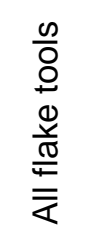 } & Length & 120 & $17-153$ & 72.4 & 26.7 \\
\hline & & Width & 120 & $15-185$ & 66.1 & 34.1 \\
\hline & & Thickness & 120 & $8-78$ & 24.8 & 11.4 \\
\hline & & Weight & 120 & $10-1366$ & 167.7 & 199.0 \\
\hline
\end{tabular}

Table S3. Size and weight values for medium size whole flaks and flake tools in the Arbo site. 


\begin{tabular}{|c|c|c|c|c|c|c|c|c|c|}
\hline & & \multicolumn{2}{|c|}{ Quartzite } & \multicolumn{2}{|c|}{ Quartz } & \multicolumn{2}{|c|}{ Others } & \multicolumn{2}{|c|}{ Total } \\
\hline & & $n$ & $\%$ & $n$ & $\%$ & $n$ & $\%$ & $n$ & $\%$ \\
\hline \multirow{9}{*}{$\frac{\overline{0}}{\overline{0}}$} & Disorganized & 5 & 8.9 & 0 & 0.0 & 0 & 0.0 & 5 & 5.3 \\
\hline & Monopolar & 36 & 64.3 & 13 & 35.1 & 1 & 100.0 & 50 & 53.2 \\
\hline & Peripheral & 7 & 12.5 & 6 & 16.2 & 0 & 0.0 & 13 & 13.8 \\
\hline & Discoidal & 3 & 5.4 & 2 & 5.4 & 0 & 0.0 & 5 & 5.3 \\
\hline & Multipolar & 0 & 0.0 & 2 & 5.4 & 0 & 0.0 & 2 & 2.1 \\
\hline & Orthogonal & 3 & 5.4 & 1 & 2.7 & 0 & 0.0 & 4 & 4.3 \\
\hline & Kombewa & 2 & 3.6 & 1 & 2.7 & 0 & 0.0 & 3 & 3.2 \\
\hline & Bipolar on anvil & 0 & 0.0 & 12 & 32.4 & 0 & 0.0 & 12 & 12.8 \\
\hline & TOTAL & 56 & & 37 & & 1 & & 94 & \\
\hline \multirow{9}{*}{$\frac{\text { త్ }}{\text { ฮั }}$} & Disorganized & 5 & 6.1 & 1 & 2.1 & 1 & 33.3 & 7 & 5.3 \\
\hline & Monopolar & 49 & 59.8 & 14 & 29.8 & 2 & 66.7 & 65 & 49.2 \\
\hline & Peripheral & 10 & 12.2 & 4 & 8.5 & 0 & 0.0 & 14 & 10.6 \\
\hline & Discoidal & 9 & 11.0 & 5 & 10.6 & 0 & 0.0 & 14 & 10.6 \\
\hline & Multipolar & 0 & 0.0 & 1 & 2.1 & 0 & 0.0 & 1 & 0.8 \\
\hline & Orthogonal & 1 & 1.2 & 2 & 4.3 & 0 & 0.0 & 3 & 2.3 \\
\hline & Kombewa & 6 & 7.3 & 0 & 0.0 & 0 & 0.0 & 6 & 4.5 \\
\hline & Bipolar on anvil & 2 & 2.4 & 20 & 42.6 & 0 & 0.0 & 22 & 16.7 \\
\hline & TOTAL & 82 & & 47 & & 3 & & 132 & \\
\hline
\end{tabular}

Table S4. Type of core reduction pattern buy raw material and level at Arbo site. 


\begin{tabular}{|c|c|c|c|c|c|c|}
\hline & & & $n$ & Ranges & Average & St. deviation \\
\hline \multirow{8}{*}{ 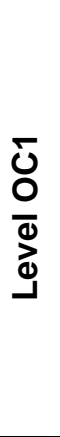 } & \multirow{4}{*}{ 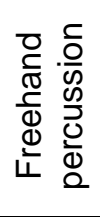 } & Length & 82 & $42-205$ & 95.8 & 29.7 \\
\hline & & Width & 82 & 41-240 & 84.1 & 31.3 \\
\hline & & Thickness & 82 & $21-120$ & 53.4 & 19.3 \\
\hline & & Weight & 82 & $52-3953$ & 657.5 & 706.8 \\
\hline & \multirow{4}{*}{ 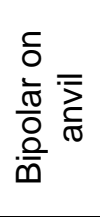 } & Length & 12 & 33-95 & 52.4 & 17.7 \\
\hline & & Width & 12 & $34-58$ & 43.3 & 8.6 \\
\hline & & Thickness & 12 & $25-43$ & 33.1 & 5.7 \\
\hline & & Weight & 12 & $38-205$ & 96.5 & 51.8 \\
\hline \multirow{8}{*}{$\frac{\text { ঠิ }}{\frac{0}{0}}$} & \multirow{4}{*}{ 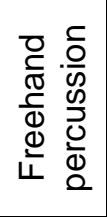 } & Length & 110 & 36-190 & 89.5 & 32.9 \\
\hline & & Width & 110 & $26-173$ & 81.0 & 27.9 \\
\hline & & Thickness & 110 & $13-100$ & 47.3 & 15.7 \\
\hline & & Weight & 110 & $46-4231$ & 530.9 & 565.7 \\
\hline & \multirow{4}{*}{ 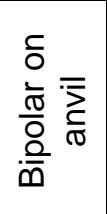 } & Length & 21 & $15-96$ & 53.3 & 20.4 \\
\hline & & Width & 21 & $15-69$ & 44.4 & 15.7 \\
\hline & & Thickness & 21 & $9-67$ & 33.3 & 13.9 \\
\hline & & Weight & 21 & $2-483$ & 128.0 & 125.4 \\
\hline
\end{tabular}

Table S5. Size and weight values for main groups of whole cores at Arbo site. 


\begin{tabular}{|c|c|c|c|c|c|c|}
\hline & & & $\mathrm{n}$ & Ranges & Average & St. deviation \\
\hline \multirow{16}{*}{ 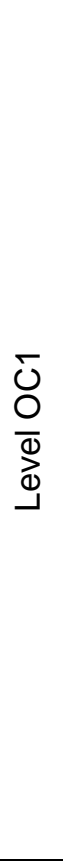 } & \multirow{4}{*}{$\begin{array}{l}0 \\
\mathbb{0} \\
\mathbb{x} \\
\mathbb{\pi} \\
\mathbb{0} \\
\mathbb{1} \\
1\end{array}$} & Length & 29 & $89-215$ & 142.6 & 35.1 \\
\hline & & Width & 29 & 65-126 & 89.1 & 16.1 \\
\hline & & Thickness & 29 & $25-68$ & 45.5 & 11.1 \\
\hline & & Weight & 29 & 215-1330 & 660.1 & 363.2 \\
\hline & \multirow{4}{*}{ 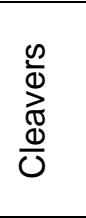 } & Length & 14 & $80-188$ & 130.4 & 27.6 \\
\hline & & Width & 14 & $55-137$ & 93.4 & 20.0 \\
\hline & & Thickness & 14 & $23-49$ & 38.2 & 7.5 \\
\hline & & Weight & 14 & 114-1068 & 524.9 & 254.5 \\
\hline & \multirow{4}{*}{ 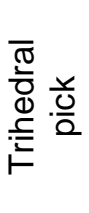 } & Length & 5 & $108-184$ & 140.2 & 31.6 \\
\hline & & Width & 5 & $67-119$ & 91.0 & 19.0 \\
\hline & & Thickness & 5 & $27-50$ & 42.8 & 9.1 \\
\hline & & Weight & 5 & $254-943$ & 595.8 & 268.5 \\
\hline & \multirow{4}{*}{ 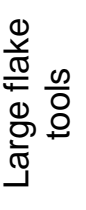 } & Length & 24 & $65-169$ & 115.8 & 65.5 \\
\hline & & Width & 24 & $65-181$ & 107.9 & 30.6 \\
\hline & & Thickness & 24 & $16-50$ & 37.3 & 8.2 \\
\hline & & Weight & 24 & $142-856$ & 443.8 & 194.6 \\
\hline \multirow{12}{*}{ 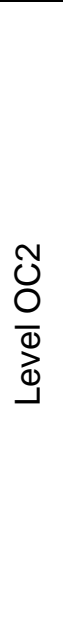 } & \multirow{4}{*}{ 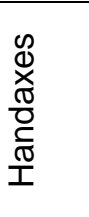 } & Length & 14 & 78-203 & 142.7 & 36.1 \\
\hline & & Width & 14 & $72-124$ & 94.6 & 15.1 \\
\hline & & Thickness & 14 & $19-58$ & 43.4 & 11.2 \\
\hline & & Weight & 14 & 281-1086 & 595.2 & 278.0 \\
\hline & \multirow{4}{*}{$\begin{array}{l}\stackrel{\infty}{\Phi} \\
\stackrel{\infty}{\Phi} \\
\frac{\infty}{U}\end{array}$} & Length & 10 & $81-174$ & 147.6 & 26.5 \\
\hline & & Width & 10 & $65-125$ & 97.5 & 15.6 \\
\hline & & Thickness & 10 & $24-66$ & 42.3 & 11.7 \\
\hline & & Weight & 10 & $134-1068$ & 702.4 & 242.1 \\
\hline & \multirow{4}{*}{ 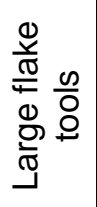 } & Length & 40 & $70-153$ & 98.7 & 19.8 \\
\hline & & Width & 40 & $40-185$ & 99.0 & 34.9 \\
\hline & & Thickness & 40 & $15-78$ & 33.3 & 12.5 \\
\hline & & Weight & 40 & 67-1366 & 443.8 & 194.6 \\
\hline
\end{tabular}

Table S6. Size and weight values for main LCT types (only whole specimen) at Arbo site 